\title{
Isotope and fatty acid trends along continental shelf depth gradients: Inshore versus offshore hydrological influences on benthic trophic functioning
}

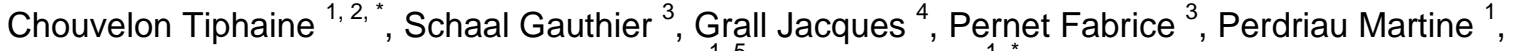 \\ A-Pernet E.J. ${ }^{1,5}$, Le Bris Hervé ${ }^{1, *}$
}

${ }^{1}$ Agrocampus Ouest, UMR 985 Agrocampus Ouest/INRA Écologie et Santé des Écosystèmes, 65 rue de Saint-Brieuc, CS 84215, 35042 Rennes, France

2 IFREMER, Unité Biogéochimie et Écotoxicologie (BE), Laboratoire de Biogéochimie des Contaminants

Métalliques (LBCM), rue de l'lle d'Yeu, BP 21105, 44311 Nantes Cedex 03, France

${ }^{3}$ Laboratoire des sciences de l'Environnement MARin (LEMAR), UMR 6539

IFREMER/UBO/CNRS/IRD, Technopôle Brest-Iroise, 29280 Plouzané, France

${ }^{4}$ Observatoire des Sciences de l'Univers, UMS 3113, Institut Universitaire Européen de la MER, Technopôle Brest-Iroise, 29280 Plouzané, France

${ }^{5}$ IFREMER, Unité Études des Écosystèmes Profonds (EEP), Laboratoire Environnement Profond (LEP), ZI de la Pointe du Diable, CS 10070, 29280 Plouzané, France

* Corresponding authors : Tiphaine Chouvelon, Tel.: +33 (0) 240374178 ; email address : tiphaine.chouvelon@ifremer.fr ;

Hervé Le Bris, +33 (0) 223485928 ; email address : herve.lebris@agrocampus-ouest.fr

\begin{abstract}
:
Anthropogenic activities and land-based inputs into the sea may influence the trophic structure and functioning of coastal and continental shelf ecosystems, despite the numerous opportunities and services the latter offer to humans and wildlife. In addition, hydrological structures and physical dynamics potentially influence the sources of organic matter (e.g., terrestrial versus marine, or fresh material versus detrital material) entering marine food webs. Understanding the significance of the processes that influence marine food webs and ecosystems (e.g., terrestrial inputs, physical dynamics) is crucially important because trophic dynamics are a vital part of ecosystem integrity. This can be achieved by identifying organic matter sources that enter food webs along inshore-offshore transects. We hypothesised that regional hydrological structures over wide continental shelves directly control the benthic trophic functioning across the shelf. We investigated this issue along two transects in the northern ecosystem of the Bay of Biscay (north-eastern Atlantic). Carbon and nitrogen stable isotope analysis (SIA) and fatty acid analysis (FAA) were conducted on different complementary ecosystem compartments that include suspended particulate organic matter (POM), sedimentary organic matter (SOM), and benthic consumers such as bivalves, large crustaceans and demersal fish. Samples were collected from inshore shallow waters (at $\sim 1 \mathrm{~m}$ in depth) to more than $200 \mathrm{~m}$ in depth on the offshore shelf break. Results indicated strong discrepancies in stable isotope (SI) and fatty acid (FA) compositions in the sampled compartments between inshore and offshore areas, although nitrogen SI $(\delta 15 \mathrm{~N})$ and FA trends were similar along both transects. Offshore the influence of a permanently
\end{abstract}


stratified area (described previously as a "cold pool") was evident in both transects. The influence of this hydrological structure on benthic trophic functioning (i.e., on the food sources available for consumers) was especially apparent across the northern transect, due to unusual carbon isotope compositions $(\delta 13 \mathrm{C})$ in the compartments. At stations under the cold pool, SI and FA organism compositions indicated benthic trophic functioning based on a microbial food web, including a significant contribution of heterotrophic planktonic organisms and/or of SOM, notably in stations under the cold pool. On the contrary, inshore and shelf break areas were characterised by a microalgae-based food web (at least in part for the shelf break area, due to slope current and upwelling that can favour fresh primary production sinking on site). SIA and FAA were relevant and complementary tools, and consumers better mediumto long-term system integrators than POM samples, for depicting the trophic functioning and dynamics along inshore-offshore transects over continental shelves.

\section{Highlights}

- Benthic food web functioning was investigated across a wide continental shelf. Biogeochemical markers were used to understand food sources entering these food webs. Stable isotope and fatty acid compositions showed inshore versus offshore variations. Consumer patterns were more informative than patterns in the "source" compartments. Deeper areas exhibited the probable influence of a "cold pool" structure. 


\section{Introduction}

While marine ecosystems provide considerable services to humans, they encounter unprecedented threats as a result of anthropogenic activities, global change and land-based inputs into the sea (Millenium Ecosystem Assessment, 2005; OSPAR, 2010). Coastal zones and continental shelves are particularly affected by these phenomena, because of their high biological productivity and easier access compared to offshore or deep-water areas. These areas often support important fisheries, and their trophic dynamics are central in the general structure and functioning of ecosystems. Understanding the trophic functioning of vulnerable marine ecosystems is crucially important to maintain their services and integrity as it may induce changes in the production or productivity of potentially exploitable resources in these systems (e.g., commercial fisheries). The trophic functioning of marine systems is controlled by different types of energy flows such as bottom-up control (control by primary producers), top-down control (control by predators - possibly including commercial fisheries) and waspwaist control (control by numerically dominant species), although bottom-up control predominates in most ecosystems (Cury et al., 2003).

Trophic functioning in the bottom-up control is potentially directly influenced by human landbased inputs in coastal areas. The induced changes are either negative (e.g., as observed with excessive inputs causing eutrophication problems; Cloern, 2001), or positive (e.g., when river discharges stimulate productivity and in turn enhance coastal fisheries; Loneragan et al., 1999). Trophic functioning across continental shelves or on the continental slopes is possibly influenced by other factors that are not necessarily linked to anthropogenic activities, such as hydrological structures or physical dynamics of water masses (e.g., eddies, upwelling, and slope currents; Waite et al., 2007; Alt-Epping et al., 2007; Kolasinski et al. 2012).

In recent decades, stable carbon and nitrogen isotope ratios $\left(\delta^{13} \mathrm{C}\right.$ and $\delta^{15} \mathrm{~N}$ values) have demonstrated their suitability as biogeochemical tracers of food web structure and functioning in the marine environment (e.g., Michener and Kaufman, 2007). The primary producers in an ecosystem generally have different isotopic compositions due to the different nutrients they fix, the biochemical cycle they use for photosynthesis, and their physiology (e.g., growth rates, cell sizes, and nutrient capture mechanisms (Peterson and Fry, 1987)). The enrichment in ${ }^{13} \mathrm{C}$ and ${ }^{15} \mathrm{~N}$ between a source and its consumer is then relatively predictable. It is lower for $\mathrm{C}$ (generally $\leq 1-2 \%$ ) than for $\mathrm{N}(2.5-4 \%$, on average) (Minagawa and Wada, 1984; Post, 2002; Vanderklift and Ponsard, 2003; Caut et al, 2009). Values of $\delta^{13} \mathrm{C}$ are often considered a conservative tracer of organic matter origins or of primary producers at the base of food chains (e.g., Dubois et al., 2007; Schaal et al., 2010), discriminating for example organic matter from terrestrial versus marine origins over continental shelves (Nagao et al., 2005; Alt-Epping et al., 2007), or benthic versus pelagic primary producers sustaining food webs in coastal areas (France, 1995). Values of $\delta^{15} \mathrm{~N}$ have been more commonly used to depict the trophic position of organisms in various ecosystems (e.g., Lesage et al., 2001; Le Loc'h et al., 2008). Values of $\delta^{15} \mathrm{~N}$ are also able to trace ${ }^{15} \mathrm{~N}$ enriched anthropogenic inputs in coastal ecosystems (McClelland et al., 1997; Vizzini and Mazzola, 2006; Zvab Rozic et al., 2014).

Despite apparent advantages, stable isotope analysis (SIA) alone may not be sufficient to unravel food web dynamics in complex aquatic ecosystems, mostly because it fundamentally implies that sources entering food webs have distinct isotopic signatures. The use of stable isotope (SI) tracers of food web structure and functioning are also complicated by uncertain temporal and spatial variation at the base of food webs and by variable integration time during tissue biosynthesis in animals (Martínez del Rio et al. 2009). In addition, isotope tracers may fail to provide taxonomic resolution of food sources, but the combination of several tools can address this difficulty. Combining SIA and fatty acid analysis (FAA) has 
been particularly useful for identifying sources of organic matter that sustain organisms in various systems (e.g., Kharlamenko et al., 2001; Allan et al., 2010; Lebreton et al., 2011; Pernet et al., 2012). Primary producers and heterotrophic microorganisms can synthesise specific fatty acids (FAs) that cannot be synthesised de novo by marine animals. Marine bacteria, diatoms, (dino)flagellates, seagrasses and terrestrial plants, and even different species within the same taxonomic group have been shown to differ in FA composition (Graeve et al., 1994; Napolitano et al., 1997; Dalsgaard et al., 2003; Kelly and Scheibling, 2012; Sahu et al., 2013). Consumers acquire these FAs from their food, and FAs are deposited relatively unchanged into their adipose tissues, providing an integrated record of dietary intake over time (Budge et al., 2006). For several years, FAA has thus served as a useful trophic marker to depict food sources at the base of food webs and trophic relationships in the marine environment (e.g., Graeve et al., 2002; Iverson et al., 2004; Wilson et al., 2010).

In recent years, several studies used biogeochemical markers, especially SIA, to depict the origin of organic matter or trophic functioning in the marine environment, particularly over continental shelves (e.g., Darnaude et al., 2004; Nagao et al., 2005; Alt-Epping et al., 2007), or to investigate the potential influence of hydrological structures on trophic functioning at the meso-scale (e.g., Kolasinski et al., 2012; Nerot et al., 2012; Kopp et al., 2015; Schaal et al., under review). SIA is generally done in suspended particulate organic matter (POM), sediment organic matter (SOM) or in consumers. Isotopic variations have been analysed according to a variety of environmental variables such as temperature, salinity, depth and/or distance to the coast (e.g., Fry, 1988; Jennings and Warr, 2003; Barnes et al., 2009; Nerot et al., 2012; Radabaugh et al., 2013). In these studies, strong discrepancies and strong isotopic gradients were generally found and linked to environmental gradients between samples or organisms from shallow versus deeper stations. From these results, researchers have highlighted the crucial need for wide spatio-temporal sampling and/or modelling when further developing food web models based on stable isotopes (Jennings and Warr, 2003; Barnes et al., 2009; Radabaugh et al., 2013), and for developing combined approaches in future studies.

In this context, the present study addresses these ecological issues by: 1) applying a multisource (i.e., surface and bottom POM, SOM) and a multi-trophic-level consumer approach (i.e., bivalves, crustaceans, fish); 2) applying a multi-tool approach (i.e., SIA and FAA); and 3) comparing two inshore-offshore transects in the northern part of the Bay of Biscay. The Bay of Biscay is a large bay that opens onto the north-eastern Atlantic Ocean. Along the French coast, the continental shelf covers over $220,000 \mathrm{~km}^{2}$ and extends more than $250 \mathrm{~km}$ offshore in its northern part. Recently, ecological network analysis of the Bay of Biscay continental food web provided evidence that bottom-up processes play a significant role in the global structuring of this marine ecosystem (Lassalle et al. 2011). This ecosystem is therefore particularly interesting for studying trophic functioning, and the potential influence of hydrological structures across continental shelves and/or depth gradients on food sources at the base of food webs. The general objectives of the present study were: (1) to determine the origin of organic matter entering benthic food webs, and consequently trophic functioning over the highly productive Bay of Biscay continental shelf, and (2) to assess the potential influence of hydrological structures on trophic functioning at the meso-scale. The specific objectives of this study were (1) to investigate differences in SI and FA compositions of selected biota between two transects with similar offshore conditions but contrasting coastal dynamics, and (2) to understand the contribution of FAA in explaining and supplementing the information provided by SIA along both transects. Combined analysis of $\mathrm{SI}$ and FA compositions in different sources and consumers, and along two contrasting transects, should provide much information about the extent of terrestrial influence on relatively wide marine continental shelves. For instance concerning SI compositions, decreasing $\delta^{15} \mathrm{~N}$ values from the coast to offshore waters is expected, because rivers are a potential vector of ${ }^{15} \mathrm{~N}$-enriched organic matter in coastal waters, and because fixation of atmospheric $\mathrm{N}_{2}$ by 
diazotrophic organisms (e.g., cyanobacteria) in offshore or oligotrophic waters may lower $\delta^{15} \mathrm{~N}$ values of the residual $\mathrm{NO}_{3}^{-}$pool available for other primary producers in these areas (Montoya, 2007). Concerning FA compositions, we expect that "source" compartments (POM, SOM) and consumers will have FA markers of diatom primary producers in coastal and/or productive areas, and more FA markers of (dino)flagellates or of carnivory (i.e., heterotrophic processes) in deep water areas. The combination of tools used in this study should provide information about the contribution of primary production (i.e., herbivorous or microalgae-based trophic functioning) versus detrital or regenerated material (i.e., microbialloop based trophic functioning), or indicate the significant contribution of heterotrophic organisms at the base of benthic food webs over the shelf.

\section{Materials and methods}

\subsection{Study area, selected transects and sample collection}

Sampling was performed in two inshore-offshore transects (transects $A$ and $B$, respectively) in the northern part of the Bay of Biscay (Fig. 1). The two transects had both similarities and differences in physical dynamics and hydrological structures from coastal areas to the shelf break (Table 1).

Samples were collected during two scientific cruises in June-July 2012. Respectively, 10 and 11 at-sea stations were covered over the two inshore-offshore transects (Fig. 1). Whenever possible, three replicates of surface and bottom seawater were sampled using a Niskin bottle to collect surface and bottom POM at each station. Bottom POM was collected $1 \mathrm{~m}$ above the sediment. In coastal areas, surface POM samples were also collected in the rivers flowing to sea. Water was filtered $(2 \mathrm{~L}$ per station and per depth) through pre-combusted (6h, $\left.450^{\circ} \mathrm{C}\right) \mathrm{GF} / \mathrm{F}$ Whatman filters. Filters were then briefly acidified $(\mathrm{HCl} 1 \mathrm{~N})$ and rinsed with distilled water to remove inorganic carbonates and sea-salt, and were stored aboard at $20^{\circ} \mathrm{C}$. Three replicates of the upper sediment layer $(2 \mathrm{~mm})$ were sampled to collect SOM with a Van Veen grab and stored at $-20^{\circ} \mathrm{C}$ for further processing before SIA. POM and SOM samples are considered the "source" compartments because they are thought to contain the bulk organic matter (i.e., mixture of fresh and detrital material in varying proportions for both types of samples) that potentially enters the benthic food webs.

We selected consumer species with relatively wide distributions over the continental shelf or closely related (from a taxo-functional viewpoint) species that partially overlapped along the inshore-offshore transects. We also chose species with relatively low mobility and from different trophic levels or trophic guilds. The selection then included 2-3 bivalve mollusc species (Pecten maximus, Venus casina and/or Aequipecten opercularis) as primary consumers/POM filter-feeders, one fish species (Callionymus lyra) as a predator feeding on small benthic invertebrates such as small decapod crustaceans and occasionally on worms (Griffin et al., 2012), and 2-3 decapod crustacean species (Inachus spp - including I. dorsettensis and/or I. leptochirus - and Macropipus tuberculatus) as omnivorous secondary to tertiary consumers and/or scavengers feeding on small epibenthic invertebrates, fish, dead animals, or algae (Hartnoll, 1963; Abello, 1989; Rorandelli et al., 2007). Whenever possible, 1-3 individuals of each species were collected at each station and stored aboard at $-20^{\circ} \mathrm{C}$. All samples were transferred at $-80^{\circ} \mathrm{C}$ back to the laboratory (a few days later). Consumers (i.e., bivalves, crustaceans and fishes) were dissected in the laboratory to collect muscle (for SIA), and digestive glands or livers (for FAA). This was performed as quickly as possible to avoid excessive thawing. Subsamples were freeze-dried and stored at $-80^{\circ} \mathrm{C}$ for further treatment before analyses. 
Only a few samples were selected for FAA: surface and bottom POM samples, SOM samples, individuals of the bivalve $P$. maximus and individuals of the fish $C$. lyra. They were collected at four stations along the transects (Fig. 1; stations A1-A4 for transect A, B1-B4 for transect B). Organisms were selected according to their trophic guild (i.e., "source" compartments, one filter-feeding primary consumer and one secondary consumer), and the stations were selected according to the isotopic variations observed along the transects.

\subsection{Stable isotope analyses}

POM filters and SOM samples, stored at $-20^{\circ} \mathrm{C}$ aboard, were freeze-dried. Dried filters were then folded and placed into tin capsules. Dried SOM samples were sieved ( $250 \mu \mathrm{m}$ mesh), and the fine fraction was ground into powder. For carbon isotope composition, a subsample (1 g) of sediment powder was decarbonated using $1 \mathrm{~mL} \mathrm{HCl}(1-2 \mathrm{~N}$ according to the effervescence), centrifuged to recover the subsample, rinsed with distilled water, centrifuged and freeze-dried again before being placed in a tin capsule. Two capsules were prepared for each SOM sample (one for carbon - acidified, and one for nitrogen isotope ratios - no pretreatment). Freeze-dried muscle samples of bivalves, crustaceans and fish were ground into a fine powder, and $0.40 \pm 0.05 \mathrm{mg}$ subsamples of powder were weighed in tin capsules. These animal samples were not lipid-extracted before SIA (as it is sometimes advised to avoid potential effects of lipid components on $\delta^{13} \mathrm{C}$ values in animal tissues; De Niro and Epstein, 1977). However, all C:N ratios of the samples were measured and none exceeded 3.5 , i.e., the ratio above which lipid extraction or normalisation is generally recommended for animal tissues (Post et al., 2007).

Isotopic analyses of POM and SOM samples were performed with a Costech 4010 elemental analyser coupled with a Finningan Delta Plus or a Finningan Delta Plus XP mass spectrometer (SINLAB laboratory, New Brunswick, Canada). Bivalve, crustacean and fish samples were analysed with a Thermo Scientific Flash EA1112 elemental analyser coupled with a Thermo Scientific Delta $\vee$ Advantage mass spectrometer (LIENSs laboratory, La Rochelle, France). Results are expressed as isotope ratios $\delta \mathrm{X}(\%)$ relative to international standards (Pee Dee Belemnite for carbon and atmospheric $\mathrm{N}_{2}$ for nitrogen) according to the formula: $\delta X=\left[\left(R_{\text {sample }} / R_{\text {standard }}\right)-1\right] \times 10^{3}$, where $X={ }^{13} \mathrm{C}$ or ${ }^{15} \mathrm{~N}$ and $\mathrm{R}={ }^{13} \mathrm{C} /{ }^{12} \mathrm{C}$ or ${ }^{15} \mathrm{~N} /{ }^{14} \mathrm{~N}$ (Peterson and Fry, 1987). Replicate measurements of internal laboratory standards (acetanilide) indicated an analytical precision of $<0.15 \%$ for both $\delta^{13} \mathrm{C}$ and $\delta^{15} \mathrm{~N}$ values.

\subsection{Lipid extraction and fatty acid analyses (FAA)}

Extraction of total lipids followed the method described by Folch et al. (1957), although dichloromethane $\left(\mathrm{CH}_{2} \mathrm{Cl}_{2}\right)$ was used instead of the original chloroform $\left(\mathrm{CHCl}_{3}\right)$ because of its lower toxicity (but similar properties). Because different matrices were analysed (filters for POM, sediment samples for SOM, digestive gland for $P$. maximus and liver for $C$. lyra), the procedures differed slightly among the samples. For POM samples, filters were inserted into glass test tubes with a dichloromethane-methanol mixture $\left(\mathrm{CH}_{2} \mathrm{Cl}_{2}-\mathrm{MeOH}, 2: 1 \mathrm{v} / \mathrm{v}\right)$, the samples were sonicated, a volume of $0.75 \%$ sodium chloride (corresponding to $20 \%$ of the $\mathrm{CH}_{2} \mathrm{Cl}_{2}-\mathrm{MeOH}$ mixture) was added, and the tubes were shaken. After centrifuging samples, the lower phase (containing lipids) was kept, and a second volume of $\mathrm{CH}_{2} \mathrm{Cl}_{2}$ was added to ensure that the maximum total lipid content was extracted for each filter. For SOM samples, lipid extraction was performed on aliquots of sediments (approximately $1 \mathrm{~g}$ ) with an Accelerated Solvent Extractor system. Samples were then mixed with diatomite powder and lipid-extracted with $\mathrm{CH}_{2} \mathrm{Cl}_{2}$ at high temperature $\left(100^{\circ} \mathrm{C}\right)$ and under high pressure. A volume of $0.75 \%$ sodium chloride ( $\mathrm{NaCl}$ ) (corresponding to $20 \%$ of the $\mathrm{CH}_{2} \mathrm{Cl}_{2}-\mathrm{MeOH}$ mixture as 
above) was added, vials were shaken, placed at $-20^{\circ} \mathrm{C}$ for $2 \mathrm{~h}$, and the lower phase (containing lipids) was kept. For animal tissues, aliquots of dried samples (approximately 100 $\mathrm{mg}$ for bivalve digestive glands and $30 \mathrm{mg}$ for fish livers) were rehydrated with distilled water, an "inverse" $\mathrm{CH}_{2} \mathrm{Cl}_{2}-\mathrm{MeOH}$ mixture (i.e., 1:2 v/v) was added, samples were homogenised and centrifuged, and the supernatant (containing lipids) was kept. $\mathrm{A} \mathrm{CH}_{2} \mathrm{Cl}_{2}-\mathrm{MeOH}$ mixture $(2: 1 \mathrm{v} / \mathrm{v})$ was added to the lower phase (containing the remaining tissue sample), samples were shaken and centrifuged, and the supernatant (containing remaining lipids) was added to the first supernatant. A volume of $0.75 \% \mathrm{NaCl}$ was added to supernatants, which were shaken and centrifuged again, and the lower phase (containing lipids) was kept. All extracted lipid contents (from the different matrices) were stored under nitrogen atmosphere at $-20^{\circ} \mathrm{C}$ for further treatment. Samples were always kept frozen (on ice) and under nitrogen atmosphere to prevent oxidation throughout the preparation for FAA.

Neutral lipids (NLs) are thought to better reflect the FA composition of consumed food and to reveal information about trophic sources, whereas FA in the polar lipids (PLs) are less sensitive to dietary changes (Dalsgaard et al., 2003). NLs and PLs were thus separated in all samples after total lipid extraction. To this end, extracted lipids were placed at the top of a $\mathrm{SiOH}$ Chromafix micro-column; NLs were eluted with a $\mathrm{CH}_{2} \mathrm{Cl}_{2}-\mathrm{MeOH}$ mixture $(98: 2 \mathrm{v} / \mathrm{v})$ and PLs were eluted with pure methanol. Only NLs were subjected to the following procedure before FAA: they were saponified by adding a $2 \mathrm{M}$ methanolic potassium mixture $(\mathrm{KOH}-$ $\mathrm{MeOH}$ ), and samples were placed under nitrogen atmosphere at $90^{\circ} \mathrm{C}$. The unsaponifiable portion of NL samples was extracted by adding distilled water and absolute ethanol to samples, and hexane was added to solubilise the unsaponifiable portion. Samples were shaken and centrifuged, and the upper phase (containing hexane + unsaponifiable components) was discarded. After adding hexane a second time to the lower phase to ensure that the entire unsaponifiable portion was extracted. FAs were recovered by adding $6 \mathrm{~N}$ hydrochloric acid $(\mathrm{HCl})$ to the lower phase (containing the saponified FAs of interest), followed by hexane to resolubilise the FAs. Samples were centrifuged, the upper phase (containing hexane + FAs) was kept, and a second addition of hexane ensured the recovery of all FAs. Hexane was evaporated, and FAs were transformed into fatty acid methyl esters (FAMEs) by adding a volume of $2.5 \% \mathrm{HCl}(0.7 \mathrm{M})$ in methanol to the FAs; afterwards, samples were placed under nitrogen atmosphere at $90^{\circ} \mathrm{C}$. Distilled water and hexane were added, samples were shaken and centrifuged, and most of the upper phase (containing FAMEs) was kept. A second addition of hexane ensured the recovery of all FAMEs.

The FAMEs obtained were finally analysed in a gas chromatograph (Clarus 500 ) with an oncolumn injector, a SGE Analytical Science BPx70 capillary column (30 m x $0.22 \mathrm{~mm} ; 0.25$ $\mu \mathrm{m}$ film thickness), and a flame ionisation detector. Blank samples (i.e., without any organic matter) were subjected to the same lipid extraction, lipid separation and additional treatment of NLs and then analysed to ensure that samples had been prepared correctly. FAs were identified by comparing their retention times to those of standards.

\subsection{Data analysis}

In the northern part of the Bay of Biscay, the continental shelf is wide and the distance to the coast and the depth co-vary (Fig. 1). Isotopic trends along the two inshore-offshore transects were thus analysed as a function of depth. Smoothing lines (robust, locally weighted scatterplot smoothing system based on the LOWESS algorithm with the software R; Crawley, 2007) were added to represent the fitted non-linear trend of isotope values for SOM, the bivalve $P$. maximus and the fish $C$. lyra that were sampled all along the two transects.

Variations in the mean difference for $\delta^{15} \mathrm{~N}$ or $\delta^{13} \mathrm{C}$ values calculated between two theoretical trophic levels were also analysed along the two transects: i.e., between the fish $C$. lyra (as a 
secondary to tertiary consumer $-\mathrm{C} 2$ ) and $P$. maximus (as a primary consumer $-\mathrm{C} 1$ ). Later in the article, and for comparison with the literature, this is referred to the "apparent Trophic Enrichment Factor (TEF)", as it does not strictly concern prey-predator relationships but is only an estimation of the enrichment factor between two theoretical trophic levels.

To analyse FA data, only FAs that contributed $\geq 1 \%$ of total FAs in at least one sample or that had a potential trophic interpretation (Table 2) were considered. The exceptions were the odd and short saturated FAs (SFAs) and branched FAs (BFAs) that are generally found in low proportions and correspond to FAs synthesised by bacteria (Budge et al., 2001; Dalsgaard et al., 2003); they were grouped as "bacterial FAs" (Table 2). Principal component analysis (PCA) was performed on the overall FA dataset to identify the FAs that contributed most to its variance. Totals were calculated for SFAs, BFAs, monounsaturated FAs (MUFAs) and polyunsaturated FAs (PUFAs). The unsaturation index (UI) was estimated for each sample, as the sum of the percentage of each unsaturated FA multiplied by the number of double bonds within it (Logue et al., 2000). When possible (i.e., when the number of samples was $\geq 2$ within each of the four stations selected for FAA), Kruskal-Wallis tests followed by multiple-comparison tests with Holm's adjustment method were performed to test interstation differences in total SFAs, total BFAs, total MUFAs, total PUFAs, UI values, and differences in the proportions of FAs commonly used as potential trophic markers (Table 2).

\section{Results}

\subsection{Variations in isotope and "apparent Trophic Enrichment Factor" values along depth gradients}

\subsubsection{Variations in isotope values of POM}

POM $\delta^{15} \mathrm{~N}$ and $\square \delta^{13} \mathrm{C}$ values did not differ greatly among the rivers. In transect $\mathrm{A}$, the Aulne and Elorn rivers had similar mean $( \pm$ standard deviation $(S D)) \delta^{15} \mathrm{~N}$ values $(4.8 \pm 0.6 \%$ and $4.8 \pm 0.4 \%$, respectively), while in transect $B$, the Odet and Moros rivers differed only slightly $\left(6.3 \pm 0.3 \%\right.$ and $5.6 \pm 0.4 \%$, respectively). Similarly, $\square$ mean POM $\delta^{13} \mathrm{C}$ values did not differ greatly: $-30.2 \pm 0.2 \%$ and $-29.1 \pm 0.2 \%$, respectively, for the Aulne and Elorn rivers in transect $A$, and $-30.1 \pm 0.2 \%$ and $-30.3 \pm 0.4 \%$, respectively, for the Odet and Moros rivers in transect $B$.

Over the continental shelf, in the middle and offshore portions of both transects, surface and bottom POM samples had unusually low mean $\delta^{13} \mathrm{C}$ values. Although this pattern (low $\delta^{13} \mathrm{C}$ values on these portions) was consistent with observations for SOM and consumers, POM data are not shown because of high variability observed in the results (i.e., between replicates), possibly due to poorly constrained blanks for these samples. In the remainder of this article, only the qualitative results for lower isotope values of POM in the deeper part of the shelf (especially lower $\delta^{13} \mathrm{C}$ values) are then reported and discussed.

\subsubsection{Variations in isotope values of SOM and consumers}

SOM $\delta^{15} \mathrm{~N}$ values remained relatively stable from the more coastal stations to those more offshore, and replicates from the same station had low variability (Fig. 2). Mean values varied 
only from $7.2 \pm 0.0 \%$ o to $7.9 \pm 0.2 \%$ o in transect $A$, and from $5.9 \pm 0.2 \%$ o to $8.3 \pm 0.1 \%$ o in transect $\mathrm{B}$. SOM $\delta^{13} \mathrm{C}$ values also varied very little along the two transects, although they were slightly higher at the stations located at depths of $100-160 \mathrm{~m}$ in transect A (Fig. 2). Mean SOM $\delta^{13} \mathrm{C}$ values ranged from $-20.5 \pm 0.0 \%$ to $-22.1 \pm 0.1 \%$ in transect $A$, and from $21.0 \pm 0.0 \%$ o to $-21.8 \pm 0.1 \%$ in transect $B$.

All consumer $\delta^{15} \mathrm{~N}$ values decreased considerably from coastal stations to stations located on the shelf break along both transects (Fig. 2). For individuals of the bivalve (primary consumer) $P$. maximus sampled along the two transects, mean $\delta^{15} \mathrm{~N}$ values steadily decreased from $9.5 \pm 0.2 \%$ to $4.6 \%$ from the shallowest to the deepest station in transect $A$, and from $9.3 \%$ to $2.8 \pm 0.1 \%$ in transect $B$. For individuals of the fish (secondary to tertiary consumer) C. lyra, mean $\delta^{15} \mathrm{~N}$ values decreased from $12.7 \%$ to $10.2 \%$ in transect $A$, and from $12.8 \pm 0.6 \%$ to $8.6 \pm 0.4 \%$ in transect $B$. As it was the case for SOM, the replicates from the same station had low variability in $\delta^{15} \mathrm{~N}$ values for consumers (Fig. 2), and consumer $\delta^{15} \mathrm{~N}$ values always had the same ranking: secondary to tertiary consumers (i.e., crustaceans and fish) $>$ primary consumers (i.e., bivalves).

For $\delta^{13} \mathrm{C}$ values in the transect $\mathrm{A}$, consumers displayed a "hollow" pattern with particularly low values at the stations at depths of $100-160 \mathrm{~m}$ (Fig. 2). Specifically, individuals of the bivalve $P$. maximus and the fish $C$. lyra had similar $\delta^{13} \mathrm{C}$ values at both the shallowest $(9 \mathrm{~m})$ and deepest $(272 \mathrm{~m})$ stations $(-17.6 \pm 0.7 \%$ and $-17.2 \%$, respectively, for $P$. maximus,; $18.3 \%$ and $-18.0 \%$, respectively, for $C$. lyra). Their $\delta^{13} \mathrm{C}$ values were the lowest at station A3 $(127 \mathrm{~m})(-19.1 \pm 0.3 \%$ and $-18.6 \pm 0.5 \%$ for $P$. maximus and $C$. lyra, respectively). Along transect $B$, all consumers showed a marked decrease in $\delta^{13} C$ values from the coastline to the shelf break (Fig. 2). For instance, $\delta^{13} \mathrm{C}$ values for P. maximus decreased from $-15.9 \%$ to $19.2 \pm 0.4 \%$ from the shallowest $(5.5 \mathrm{~m})$ to the deepest sation $(170 \mathrm{~m})$. Values of $\delta^{13} \mathrm{C}$ for $C$. lyra sampled at the same stations decreased from $-16.7 \pm 0.4 \%$ to $-19.1 \pm 0.5 \%$. Unfortunately, no sampling occurred beyond a depth of $170 \mathrm{~m}$ in transect $\mathrm{B}$ (unlike transect A) because it reached the shelf break.

\subsubsection{Variations in "apparent TEF" values}

Along both depth gradients, the mean apparent TEF calculated in $\delta^{15} \mathrm{~N}$ between the theoretical C2 (secondary consumer: fish $C$. lyra) and C1 (primary consumer: bivalve $P$. maximus) remained positive, although it increased with depth (Fig. 3). It varied from 3.0\%o and $3.2 \%$ in the more coastal stations to $5.5 \%$ and $5.7 \%$ at the deepest stations in transects $A$ and $B$, respectively. Apparent TEF values for $\delta^{13} \mathrm{C}$ were less variable and remained close to 0 , ranging from $-1.0 \%$ to $1.1 \%$ along both transects, without any trend (Fig. 3 ).

\subsection{FA compositions of sources and consumers along depth gradients}

All results of FA compositions of both sources and consumers concern the NL fraction. Details of these FA compositions and specifically the relative percentages of FAs at concentrations $\geq 1 \%$ of total FAs in at least one sample over the whole dataset can be found in the supplemental material provided. 


\subsubsection{General trends}

The first two principal components of the PCA accounted for $41.8 \%$ of the total variation in the dataset of FA compositions (26.6\% and $15.2 \%$ for axis 1 and 2 , respectively). The FAs that contributed significantly to the first axis were the SFAs $16: 0$ (15.2\% contribution), 22:0 $(8.0 \%)$ and $18: 0(6.1 \%)$ on the one hand, and the MUFAs and PUFAs $22: 6 n-3(12.8 \%)$, 20:5n-3 (12.7\%), 20:1n-11 (11.8\%), 20:1n-9 (11.6\%) and 20:4n-6 (5.4\%) on the other hand of the axis 1 (Fig. 4). The second axis was influenced mostly by the MUFAs 18:1n-7 (14.7\% contribution), $16: 1 \mathrm{n}-7(12.1 \%), 16: 1 \mathrm{n}-9$ (8.8\%) as well as the bacterial FAs $(11.4 \%)$ and the SFA $14: 0(10.3 \%)$ on the one hand, and by the SFA $18: 0(11.3 \%)$ and the PUFA $18: 2 n-6(7.4 \%)$ on the other hand (Fig. 4). When samples were grouped by type of compartment, axis 1 segregated the "sources" (i.e., POM and SOM samples with higher percentages of SFAs) and the consumers (i.e., $P$. maximus and $C$. lyra with higher percentages of MUFAs and PUFAs, at least those influencing axis 1). When samples were grouped by station, FA compositions of all samples from stations A3 and B3, in particular, differed from those of other stations with FA results (Fig. 4).

Histograms of total BFAs, SFAs, MUFAs and PUFAs (relative to total FAs, in \%) and the calculated UI confirmed and complemented the general trends highlighted by the PCA (Fig. 5). Overall, POM and SOM samples tended to show higher percentages of BFAs and SFAs (i.e., bacterial FAs) than $P$. maximus and $C$. lyra, and the consumers clearly showed higher percentages of PUFAs and consequently higher values of UI than the "sources". Among consumers, $P$. maximus generally showed higher percentages of PUFAs and thus higher values of $\mathrm{UI}$ than $C$. lyra along both transects, and the fish consistently showed higher percentages of MUFAs than the bivalve (Fig. 5).

\subsubsection{Variations in FA compositions of "sources" among stations}

For POM and SOM samples, the percentage of BFAs and short and odd SFAs (i.e., bacterial FAs relative to total FAs) tended to be significantly lower at stations A3 and B3 (depths of $127 \mathrm{~m}$ and $120 \mathrm{~m}$ in transects $\mathrm{A}$ and $\mathrm{B}$, respectively). The percentage of PUFAs and UI values in these "source" compartments were significantly higher in these stations (Fig. 5). In addition, the PUFAs/SFAs ratio was always the highest at stations A3 and B3 (Fig. 6); however, this pattern was only significant in SOM samples. In contrast, the ratio of FAs 20:5n-3/22:6n-3 was generally lower in these stations, although not always significantly (Fig. 6). Concerning other FA ratios or sums of FAs investigated as potential biomarkers (see Table 2), POM and SOM samples generally showed highly variable patterns among stations and between transects. For instance, in surface POM samples, the ratio of FAs 22:6n$3 / 20: 5 n-3$ was significantly the highest at stations A4 and B3. Conversely, the sum of FAs $18: 2 n-6+18: 3 n-3$ and the ratio of FAs $18: 1 n-9 / 18: 1 n-7$ exhibited different patterns between the two transects. These FAs had the highest percentages at stations $A 1$ and $A 4$ in transect $A$, and the highest percentages at intermediate stations B2 and B3 in transect B (Fig. 7). In bottom POM samples, no pattern appeared for the sum of FAs 18:2n-6 + 18:3n-3 in transect A, while a higher value was found for these FAs at station B3. The ratio of FAs 18:1n9/18:1n-7 had the highest value in bottom POM samples from the $A 3$ station in transect $A$ (although not significantly), and in samples from stations B3 and B4 in transect B (Fig. 7). In SOM samples, station $A 3$ had significantly higher values of the sum of $F A s 18: 2 n-6+18: 3 n-3$ and the ratio of FAs $18: 1 n-9 / 18: 1 n-7$, while station $B 4$ had the highest values in transect $B$ (Fig. 7). 


\subsubsection{Variations in FA compositions of consumers among stations}

Unlike the "source" compartments, the two consumer species (the bivalve $P$. maximus and the fish $C$. lyra) had patterns of FAs that were more consistent between consumers and between transects. For both consumers, the percentages of PUFAs and UI values were generally higher in individuals sampled at the deepest stations (notably A3-A4 and B3-B4) than those sampled at the more coastal stations (A1 and B1) (Fig. 5). Both consumers generally showed similar spatial patterns in FA compositions along the two depth gradients. They generally had lower ratios of FAs $\Sigma$ 16:1/16:0, $\Sigma$ C16/ $\Sigma$ C18 and 20:5n-3/22:6n-3 at the deepest stations, particularly A3 and B3-B4 (Fig. 6). When they could be tested, the ratios of FAs $22: 6 n-3 / 20: 5 n-3,18: 1 n-9 / 18: 1 n-7$, and the sum of FAs $18: 2 n-6+18: 3 n-3$ where significantly higher at stations A3 and B3-B4 (Fig. 7). In addition, in these stations, the PUFAs/SFAs ratio was always the highest (although not always significantly so).

\section{Discussion}

Because offshore areas and wide continental shelves are less accessible, their ecological functioning is less documented than that of coastal areas. The general objectives of the present study were: (1) to determine the origin of organic matter entering benthic food webs and the trophic functioning over the highly productive Bay of Biscay continental shelf; and (2) to assess the potential influence of hydrological structures on the trophic functioning at the meso-scale. The original combination of analysing different matrices (POM, SOM and consumers), employing different tools (SIA and FAA) used as trophic markers, and comparing two contrasting inshore-offshore transects helped reveal trophodynamic variability over the continental shelf studied. Certain patterns that were observed are likely explained by the environmental gradients and water mass dynamics known to occur in the Bay of Biscay. In addition, from the results, consumer organisms seem better system integrators of mediumto long-term hydrological influences on trophodynamic patterns than POM samples, which probably vary more in SI and FA compositions at short time scales.

\subsection{Highly variable inshore-offshore trends in the "source" compartments}

The $\delta^{13} \mathrm{C}$ and $\delta^{15} \mathrm{~N}$ values of the four river POM surface samples were similar to those reported for temperate freshwater (e.g., France, 1995; Darnaude et al., 2004; Kostecki et al., 2010). Over the northern continental shelf of the Bay of Biscay, SIA and FAA performed in "source" compartments (i.e., surface and bottom POM, SOM samples) then showed highly variable and different patterns along the two inshore-offshore transects, although POM isotope values could only be assessed qualitatively (due to poorly constrained blanks for these samples that precluded the use of quantitative data). Inshore or nearshore versus offshore patterns have been similarly investigated across continental shelves in different marine ecosystems and compartments (SOM, POM or consumers) (Table 3). Several authors investigated the origin of organic matter (e.g., terrestrial versus marine) using SIA of SOM samples collected from coastal to offshore areas (e.g., Nagao et al., 2005; Alt-Epping et al., 2007). They observed that the organic fraction of shelf sediment was generally a mixture of materials of different origins (i.e., resulting from shoreline erosion, suspended river particles, resuspended sediments and organic matter produced in the water column; Nagao et al., 2005), or that the marine influence prevailed (Alt-Epping et al., 2007), except near large rivers where large amounts of terrestrial sediments can contribute to shelf sediment. In our case, we can directly compare our results to recent studies that investigated the origin of organic matter in bottom POM and/or in SOM samples using SIA in the northern Bay of 
Biscay (Nerot et al., 2012; Schaal et al., under review), where the continental shelf is much wider than in previously cited systems.

In the present study, $\delta^{13} \mathrm{C}$ and $\delta^{15} \mathrm{~N}$ values of SOM samples varied little along the two transects, probably reflecting the "long-term mixture" of sinking particles it represents (i.e., a mixture of potentially isotopically different particles accumulating on surface sediment, which likely tend to an average and stable isotopic signature of this mixture). However, slightly higher SOM $\delta^{13} \mathrm{C}$ values were found in transect $A$ at stations located at depths of $100-160 \mathrm{~m}$ (including station A3). In direct comparison, this differed from results of Schaal et al. (under review) who found no particular trend in $S O M \delta^{13} \mathrm{C}$ values across a southern transect of the Bay of Biscay continental shelf (in front of the Vilaine river), but observed a pattern of decreasing $\delta^{15} \mathrm{~N}$ for SOM along the depth gradient, which likely reflects the dilution of ${ }^{15} \mathrm{~N}$ enriched inputs from the Vilaine river. The Vilaine river catchment is effectively larger than those of the rivers reaching the coastal zones investigated in the present study, and the influence of the Vilaine river (high $\delta^{15} \mathrm{~N}$ values reported in freshwater POM) is likely high in the coastal zone. In the present study, the higher SOM $\delta^{13} \mathrm{C}$ values found in the middle of the continental shelf in the northern transect $(A)$ also corresponded to specific FA compositions. Significantly higher percentages of two potential flagellate markers were effectively found in samples from station $A 3$, in particular (i.e., the sum 18:2n-6 + 18:3n-3 and the ratio 18:1n9/18:1n-7; Table 2), along with significantly higher PUFAs/SFAs ratios at stations A3 and B3 along the two transects, which possibly indicates colonisation of degrading organic matter by bacteria in these offshore areas (Balzano et al., 2011).

Although POM data could not be used quantitatively, from a qualitative viewpoint both surface and bottom POM samples generally had lower $\delta^{13} \mathrm{C}$ values, particularly in the middle and offshore portions of both transects. A similar inshore-offshore decreasing pattern of $\delta^{13} \mathrm{C}$ values was previously found for bottom POM in the Bay of Biscay (Nerot et al., 2012; Schaal et al., under review). Several authors reported preferential degradation of ${ }^{13} \mathrm{C}$-rich compounds with depth to explain lower POM $\delta^{13} \mathrm{C}$ values in deeper areas (e.g., Nakatsuka et al., 1997), however, several factors may induce considerable variations in POM $\delta^{13} \mathrm{C}$ values across continental shelves (i.e., differences in samples of surface POM) or with depth (i.e., differences between surface and bottom POM). They include: 1) degradation and remineralisation processes (e.g., Nakatsuka et al., 1997; Liu et al., 2007); 2) temperature (influencing carbon isotopic fractionation in phytoplankton, e.g., Fontugne and Duplessy, 1981; Goericke and Fry 1994; Rau et al., 1997; Lara et al., 2010); 3) partial pressure and molecular $\mathrm{CO}_{2}$ concentration in ambient waters (e.g. Rau et al., 1997; Liu et al., 2007); 4) cell size, cell surface area/volume or cell geometry (e.g. Popp et al., 1998); 5) POM and/or phytoplankton composition (e.g., Darnaude et al., 2004; Harmelin-Vivien et al., 2008); etc. For instance, diatoms can have higher $\delta^{13} \mathrm{C}$ values than other phytoplankton groups such as dinoflagellates (e.g., Fry and Wainwright, 1991; Waite et al., 2005). Also, regarding the FA compositions measured in POM samples in the present study, the main difference between surface and bottom POM was found at the deepest stations in transect B (B3 and B4). FAA revealed higher percentages of flagellate markers (e.g., ratio 18:1n-9/18:1n-7) in bottom POM samples than in surface POM samples at these stations. A final hypothesis for low $\mathrm{POM} \delta^{13} \mathrm{C}$ values (particularly bottom POM) in deep waters is sporadic or localised methane production and seepage of local sediments, or oil pollution (e.g. Ogrinc et al., 2005), as methane and petroleum typically have very low $\delta^{13} \mathrm{C}$ values (e.g., Wilson et al. 2015). However, this last hypothesis seems invalidated by the mean SOM $\delta^{13} \mathrm{C}$ values measured which were relatively high and invariant (from $-20.5 \pm 0.0 \%$ o to $-22.1 \pm 0.1 \%$ ) along both transects.

Certain isotope values measured in the "source" compartments were not totally expected, particularly compared to previous studies in the northern Bay of Biscay that also analysed bottom POM and/or SOM along inshore-offshore transects (Nerot et al., 2012; Schaal et al., under review). Deciphering the relative importance of factors influencing the POM or SOM 
values was beyond the scope of this study. FA compositions provided complementary information to SIA, particularly for SOM data. However, results generally suggested that the analysis of "source" compartments is insufficient to accurately understand trophic functioning over continental shelves (i.e, POM probably varies too much temporally, and SOM represents an overly large mixture of materials of different origins). Animal consumer species, as long-lived organisms, were expected to provide more accurate information about the origin of organic matter entering benthic food webs in the medium to long-term (e.g., North et al., 2014).

\subsection{Inshore-offshore trends in consumers: evidence for the influence of hydrological structures}

To understand the influence of environmental gradients on the trophic functioning at the meso-scale in various marine ecosystems, particularly in the Bay of Biscay, several studies considered the variability of isotope values measured in one or several types of consumers sampled across marine continental shelves (Table 3). In most of these studies using SIA, beyond the close vicinity of large rivers in more coastal areas where organisms are directly influenced by ${ }^{13} \mathrm{C}$-depleted material from river run-offs (e.g., Fry et al., 1984; Fry and Sherr 1984 ) or by ${ }^{15} \mathrm{~N}$-enriched anthropogenic inputs derived from human waste, for instance (e.g., McClelland et al., 1997; Vizzini and Mazzola 2006), offshore organisms generally had lower $\delta^{15} \mathrm{~N}$ and $\delta^{13} \mathrm{C}$ values than nearshore organisms (e.g., Jennings and Warr, 2003; Sherwood and Rose 2005; Barnes et al., 2009; Chouvelon et al., 2012; Nerot et al., 2012). These inshore-offshore differences were related to processes occurring at the level of dissolved inorganic carbon or nitrogen by authors, and consequently to the isotope values of the nutrients available to primary producers present in the food webs over shelves, which finally influence the isotope values of local food chains and of local higher trophic level consumers. A recent study in the northern Bay of Biscay also investigated FA trends in the primary consumer $P$. maximus sampled at multiple stations along an inshore-offshore transect (Nerot et al., under review), although not concomitantly with the "source" compartments. The originality of the present study is its inclusion of all the compartments across two transects and its combination of tools.

Values of $\delta^{15} \mathrm{~N}$ decreased with depth for all consumers, and along the two transects. This trend and the range of $\delta^{15} \mathrm{~N}$ values for consumers were in the same order of magnitude as those reported in previous studies in the same area (Chouvelon et al. 2012; Nerot et al. 2012; Schaal et al. under review). A strong difference between the two transects in the patterns of consumers' $\delta^{13} \mathrm{C}$ values with depth was initially observed. A clear "hollow pattern" occurred in transect $A$, while $\delta^{13} \mathrm{C}$ values significantly and consistently decreased in transect B. However, it was not possible to collect samples below a depth of $170 \mathrm{~m}$ in transect $B$ (unlike the $270 \mathrm{~m}$ in depth in transect A). Therefore, there is no certainty that consumers' $\delta^{13} \mathrm{C}$ values would at deeper stations (not sampled) in transect $\mathrm{B}$. In a previous study, Kline (2009) demonstrated that hydrological structures, such as eddies, strongly influence the occurrence of diatom blooms in the marine environment;. The study found high $\delta^{13} \mathrm{C}$ values in low trophic level consumers in these eddy areas, which may indicate the occurrence of diatom blooms at the meso-scale. Conversely, in our study, low consumers' $\delta^{13} \mathrm{C}$ values were observed at the deepest stations (from $100-160 \mathrm{~m}$ deep in the first transect, and $>100 \mathrm{~m}$ deep in the second transect). According to Kline's (2009) assumption that high $\delta^{13} \mathrm{C}$ values in consumers suggest diatom blooms at the base of food webs, the low $\delta^{13} \mathrm{C}$ values found in the present study are potentially related to the importance of heterotrophic organisms (e.g., flagellates) at the base of food webs supporting consumers in these deep areas.

The "apparent TEF" between two theoretical trophic levels (fish $C$. lyra $\mathrm{C} 2$ - bivalve $P$. maximus $\mathrm{C} 1$ ) remained relatively stable and close to 0 for $\mathrm{C}$, while it increased with increasing depth for $\mathrm{N}$ (although remaining in the range of a few \%o). TEF is supposed to be 
low in C between two successive trophic levels (generally $\leq 1-2 \%$ ), and theoretically higher in N (2.5-4\%o on average; Minagawa and Wada, 1984; Post, 2002; Vanderklift and Ponsard, 2003; Caut et al, 2009). Studying the "apparent TEF" between two other theoretical trophic levels along depth gradients in the Bay of Biscay (i.e., between the bivalve $P$. maximus $\mathrm{C} 1$ and its theoretical food source, bottom POM), Nerot et al. (2012) and Schaal et al. (under review) found strong discrepancies with literature data (i.e., negative values of TEF for $\mathrm{N}$ with increasing depth, values of TEF for $C$ strongly increasing with increasing depth). They hypothesised that the discrepancies were possibly linked to: 1) different food sources than those expected that sustain consumers in the deepest areas (e.g., another source of organic matter than whole bottom POM for filter-feeding bivalves), or that a change in the trophic level of consumers occurs at these depths (which may explain the increase in apparent TEF for $\mathrm{N}$ we observed); or 2) a change in isotope fractionation occurring between sources and consumers at greater depths, which results from metabolic and physiological processes in organisms subjected to specific temperature and pressure conditions in these areas. Both phenomena may occur. Much of the literature reports that both environmental/abiotic factors (e.g., temperature) and biotic/trophic factors (e.g., age of organisms, type and quality of food) can impact isotope fractionation and TEF values, and consequently differences in isotope values between consumers and their sources/prey (Vanderklift and Ponsard, 2003; Caut et al., 2009; Bloomfield et al., 2011). In addition, "isotopic routing" (i.e., differential allocation of isotopically distinct dietary components to different tissues in consumers; Martínez del Rio et al., 2009) may differ between individuals from shallower versus deeper waters, especially as the consumers considered (i.e., $P$. maximus and $C$. lyra) are mostly neritic species that are at their limit of distribution in the deeper areas. Both types of consumers ( $C 1$ and $\mathrm{C} 2$ ) showed the same decrease in $\delta^{15} \mathrm{~N}$ values with depth, which suggests that the first hypothesis may be correct (i.e., the main source of organic matter sustaining benthic food webs changes between coastal and deeper areas, and/or organisms change their trophic level or feeding strategies). FA compositions of both types of consumers (bivalves and fish) were expected to provide complementary information to explain such $\delta^{13} \mathrm{C}$ and $\delta^{15} \mathrm{~N}$ trends and TEF variations along depth gradients.

Despite the relatively small sample size for FAA, the PCA performed on the overall FA dataset and the spatial trends for each organism highlighted a common trend of particular FA compositions in local food webs at the deepest stations (stations A3 and B3-B4, in particular). These stations are located at depths of around $120 \mathrm{~m}$. This area of the continental shelf is likely under the influence of a "cold pool", first described by Vincent and Kurc (1969) in the Bay of Biscay ecosystem (Puillat et al., 2004 and reference therein). This cold pool, or water mass isolated from surrounding water masses (especially in terms of temperature) is supposed to limit exchanges between the surface mixed layer and deep water. Trends in FA compositions of "sources" (especially POM samples) varied greatly between transects; in contrast, the primary and secondary consumers $P$. maximus and $C$. lyra displayed similar and consistent patterns in inter-station differences in FA compositions between transects. In both consumers, diatom markers (i.e., ratios of FAs $\Sigma$ 16:1/16:0, $\Sigma$ C16/ C18 and 20:5n-3/22:6n-3; Table 2) always had low percentages at the deepest stations, while the percentages of the (dino)flagellate and carnivory/heterotrophic flagellate markers (i.e., ratios or sums of FAs 22:6n-3/20:5n-3, 18:2n-6 + 18:3n-3 and 18:1n-9/18:1n-7) were high. The percentages of PUFAs and UI values were also generally higher in consumers at these stations (and also in the SOM samples). From a physiological viewpoint, temperature may influence the FA composition of animals. NLs can be mobilised if they are in a fluid state, and ectothermic animals living at low temperature can respond by incorporating unsaturated FAs (e.g., Pernet et al., 2007). It is then possible that deep-sea consumers counteract the rigidifying effect of low temperatures on their reserve lipids by incorporating more unsaturated FA than their coastal counterparts. However, FA compositions of the NLs considered here generally reflect well that of the food consumed (Dalsgaard et al., 2003), and in general, microbial-loop based food chains have low proportions of PUFAs. This is because microalgae are considered an important source of 
PUFAs in the marine environment (Daalsgard et al., 2003), although some authors demonstrated that heterotrophic flagellates from the microbial loop may also represent an important source of PUFAs (such as 18:2n-6), as well as a source of the MUFA 18:1n-9 (e.g., Zhukova and Kharlamenko, 1999; Véra et al., 2001). This could explain such high percentages of $18: 2 n-6$ and $18: 1 n-9$ in consumers from stations $A 3$ and B3. In addition, a high PUFAs/SFAs ratio may be considered an indicator of carnivory in consumers from offshore areas (e.g., Cripps and Atkinson, 2000) or indicate colonisation of degrading organic matter by bacteria (e.g., Balzano et al., 2011). This ratio was often high at these stations. From FA results, it therefore appeared that microbial loop-based trophic functioning likely drives these stations under the cold pool influence, or that heterotrophic planktonic organisms at the base of the food webs have a significant role, or that a fraction of the sedimentary detrital organic matter enters benthic food webs at stations under the cold pool. For SOM at these stations, particularly station $A 3$, station-specific $\delta^{13} \mathrm{C}$ values and $\mathrm{FA}$ compositions were also observed (like for consumers), although no station-specific $\delta^{15} \mathrm{~N}$ values. Alternatively, coastal stations and/or shelf-break stations likely have herbivorous or microalgae-based (i.e., fresh organic matter or phytoplankton) trophic functioning. However, at first sight, at stations under the cold pool, the low $\delta^{15} \mathrm{~N}$ values of consumers might seem inconsistent with microbial processing or remineralisation of organic matter at the base of food webs, which usually results in high $\delta^{15} \mathrm{~N}$ values (e.g. Jennings and Warr 2003, MacKenzie et al. 2014). An alternative hypothesis is that cold pool stations are relatively stagnant and act as "traps" for a certain production that occurs elsewhere (e.g., north or south of the transects studied) and whose occasional inputs are reflected in long-lived consumers. Besides, low $\delta^{15} \mathrm{~N}$ values in consumers may indicate particularly oligotrophic trophic functioning (Montoya, 2007) in these water masses compared to the more coastal or the more offshore stations. Most of the organic matter is dissolved in such oligotrophic environments, which support predominantly microbial food web (Biddanda et al., 2001). Schaal et al. (under review) found the same pattern of particularly low $\delta^{15} \mathrm{~N}$ values in consumers from deeper areas along a southern transect in the Bay of Biscay (i.e., in front of the Vilaine river).

Changes in food sources entering benthic food webs due to the occurrence or disappearance of particular hydrological structures have been observed in specific areas of the world (e.g., seasonal sea ice cover in the Bering Sea; North et al. 2014). From isotope and FA results, authors of the latter study suggested that a reduction in annual sea ice cover would increase production of phytoplankton during longer ice-free periods and replace inputs of ice-associated microalgae to the sediment food bank used by deposit-feeders. In addition, their results suggested that most animal carbon derives from a small consistent fraction of the sediment carbon pool, which partly corresponds to our results for stations under the cold pool. Interestingly, percentages of bacterial FAs were not particularly high in samples from stations under the cold pool influence (i.e., supposedly under microbial loop-based trophic functioning), although the high percentages of MUFAs and PUFAs originating from flagellates may mask these percentages. In contrast, bacterial FAs were abundant in organisms from stations at the shelf break, and/or coastal stations. In samples from the shelfbreak, diatom markers also contributed to FA composition to a non-negligible degree, often in higher percentages than at stations under the cold pool and sometimes in similar proportions to those of more coastal stations. This suggests an intermediate trophic functioning (i.e., combining both herbivorous/microalgae-based and microbial loop-based trophic functioning) for the stations on the shelf break. Slope currents at the shelf break may generate strong vertical mixing and nutrient inputs (Pingree et al., 1982; Koutsikopoulos and Le Cann, 1996) that create favourable conditions for primary production (Holligan and Groom, 1986; Joint et al., 2001). These offshore stations might benefit from diatoms sinking from blooms in surface waters. In addition, the FA patterns for both types of consumers (C1 and C2) correspond to those described for P. maximus by Nerot et al. (under review). The authors found similar discrepancies in FA compositions between individuals collected in coastal stations versus stations under the cold pool and on the shelf break. 


\subsection{Concluding remarks}

Comparing two transects in the northern Bay of Biscay improved our understanding of the importance of the cold pool in this ecosystem and the extent of its influence on the area's trophic functioning. The combination of two trophic markers also helped identify the food sources that support benthic food webs along the two inshore-offshore transects. More generally, it indicated that the cold pool acts as a strong physical barrier limiting benthicpelagic coupling and exchanges between the surface and the bottom of the northern Bay of Biscay ecosystem. At stations located under the cold pool, benthic trophic functioning appeared to be based on a microbial food web, including a significant contribution of heterotrophic planktonic organisms, whereas inshore and shelf break areas were based on a microalgae-based food web (at least in part for the shelf break due to slope current and upwelling favouring primary production that eventually settles). While several studies on continental shelves predicted that shelf ecosystems may have a consistent food web structure and functioning beyond the influence of large rivers, or that the patterns of changes may be linear along depth gradients (e.g., Fry and Sherr, 1984 and other studies in Table 3), the present study clearly demonstrated the importance of local hydrological structures such as the cold pool on trophic dynamics at the meso-scale, in the medium to long-term in this ecosystem. As shown only sporadically in other areas (e.g., Bering Sea and sea ice cover variations; North et al., 2014), our results therefore demonstrate that changes in benthic trophic functioning occur associated with site-specific productivity fronts.

From a methodological viewpoint, SI and FA compositions of "sources", and particularly POM samples, varied greatly among transects (present study) and between years of sampling (i.e., when compared to previous studies conducted in the area and using SIA; Nerot et al., 2012 and Schaal et al., under review). The patterns observed in the consumers we studied appeared more consistent and less variable than those observed in POM, like in other studies of food web ecology that use consumers as an "animal-providing-the-average-trend" (e.g., Post et al., 2002). Like authors who advocate the use of primary consumers (instead of primary producers or POM) as baselines to determine trophic levels derived from SI values (e.g., Vander Zanden and Rasmussen, 1999), we recommend the use of low trophic level consumers (and/or relatively sessile organisms), such as bivalves, to depict trophic dynamics and marine food web functioning along continental shelf depth gradients in future studies.

\section{Acknowledgements}

The authors wish to thank Hervé Le Delliou and Claudie Quéré (IFREMER, Brest) for their help with FAA, and the LIENSs and SINLAB laboratories for SIA. We are particularly grateful to the crew of the Research Vessel "Gwen Drez" (IFREMER/GENAVIR) for sampling facilities and assistance during the work at sea. We also thank the anonymous reviewers for their helpful comments on the manuscript. This work was financially supported by the CNRS-Insu (EC2CO RETROCAN Project) and the Regional Council of Brittany (RECOMAB Project).

\section{References}

Abelló, P., 1989. Feeding habits of Macropipus tuberculatus (Brachyura, Portunidae) off the Catalan coast (NW Mediterranean). Miscellania Zoologica 13, 45-50.

Allan, E.L., Ambrose, S.T., Richoux, N.B., Froneman, P.W., 2010. Determining spatial changes in the diet of nearshore suspension-feeders along the South African 
coastline: stable isotope and fatty acid signatures. Estuarine, Coastal and Shelf Science 87, 463-471.

Alt-Epping, U., Mil-Homens, M., Hebbeln, D., Abrantes, F., Schneider, R.R., 2007. Provenance of organic matter and nutrient conditions on a river- and upwelling influenced shelf: a case study from the Portuguese Margin. Marine Geology 243, 169179.

Balzano, S., Pancost, R.D., Lloyd, J.R., Statham, P.J., 2011. Changes in fatty acid composition in degrading algal aggregates. Marine Chemistry 124, 2-13.

Barnes, C., Jennings, S., Barry, J.T., 2009. Environmental correlates of large-scale spatial variation in the ${ }^{13} \mathrm{C}$ of marine animals. Estuarine, Coastal and Shelf Science 81, 368374.

Biandolino, F., Prato E., Carappo, C., 2008. Preliminary investigation on the phytoplankton contribution to the mussel diet on the basis of fatty acids analysis. Journal of the Marine Biological Association of UK 88, 1009-1017.

Biddanda, B., Ogdahl, M., Cotner, J., 2001. Dominance of bacterial metabolism in oligotrophic relative to eutrophic waters. Limnology and Oceanography 46, 730-739.

Blanchet-Aurigny, A., Dubois, S.F., Quéré, C., Guillou, M., Pernet, F., 2015. Trophic niche of two co-occurring ophiuroid species in impacted coastal systems, derived from fatty acid and stable isotope analyses. Marine Ecology Progress Series 525, 127-141.

Bloomfield A.J., Elsdon T.S., Walther B.D., Gier E.J., Gillanders B.M., 2011. Temperature and diet affect carbon and nitrogen isotopes of fish muscle: can amino acid nitrogen isotopes explain effects? Journal of Experimental Marine Biology and Ecology 399, 48-59.

Budge, S. M., Parrish, C. C., McKenzie, C. H., 2001. Fatty acid composition of phytoplankton, settling particulate matter and sediments at a sheltered bivalve aquaculture site. Marine Chemistry 76, 285-303.

Budge, S.M., Iverson, S.J., Koopman, H.N., 2006. Studying trophic ecology in marine ecosystems using fatty acids: a primer on analysis and interpretation. Marine Mammal Science 22, 759-801.

Caut, S., Angulo, E., Courchamp, F., 2009. Variation in discrimination factors $\left(\Delta^{15} \mathrm{~N}\right.$ and $\left.\Delta^{13} \mathrm{C}\right)$ : the effect of diet isotopic values and applications for diet reconstruction. Journal of Applied Ecology 46, 443-453.

Chouvelon, T., Spitz, J., Caurant, F., Mèndez-Fernandez, P., Chappuis, A., Laugier, F., Le Goff, E., Bustamante, P., 2012. Revisiting the use of $\delta^{15} \mathrm{~N}$ in meso-scale studies of marine food webs by considering spatio-temporal variations in stable isotopic signatures - The case of an open ecosystem: The Bay of Biscay (North-East Atlantic). Progress in Oceanography 101, 92-105.

Cloern, J.E., 2001. Our evolving conceptual model of the coastal eutrophication problem. Marine Ecology Progress Series 210, 235-265.

Crawley, M.J., 2007. The R Book. John Wiley and Sons, Ltd.

Cripps, G.C., Atkinson, A., 2000. Fatty acid composition as an indicator of carnivory in Antarctic krill, Euphausia superba. Canadian Journal of Fisheries and Aquatic Sciences 57, 31-37.

Cury, P., Shannon, L., Shin, Y.J., 2003. The functioning of marine ecosystems: a fisheries perspective. In: Sinclair, M., Valdimarsson, G., (Eds.). Responsible fisheries in the marine ecosystem. FAO, pp. 103-123.

Dalsgaard, J., St. John, M., Kattner, G., Muller-Navarra, D., Hagen, W., 2003. Fatty acid trophic markers in the pelagic marine environment. Advances in Marine Biology 46, 225-340.

Darnaude, A.M., Salen-Picard, C., Harmelin-Vivien, M.L., 2004. Depth variation in terrestrial particulate organic matter exploitation by marine coastal benthic communities off the Rhone River delta (NW Mediterranean). Marine Ecology Progress Series 275, 47-57.

Davenport, S.R., Bax, N.J., 2002. A trophic study of a marine ecosystem off southeastern Australia using stable isotopes of carbon and nitrogen. Canadian Journal of Fisheries and Aquatic Sciences 59, 514-530. 
De Niro, M.J., Epstein, S., 1977. Mechanism of carbon fractionation associated with lipid synthesis. Science 197, 261-263.

Dubois, S., Orvain, F., Marin-Léal, J.C., Ropert, M., Lefebvre, S., 2007. Small-scale spatial variability of food partitioning between cultivated oysters and associated suspensionfeeding species, as revealed by stable isotopes. Marine Ecology Progress Series 336, 151-160.

France, R.L., 1995. Carbon-13 enrichment in benthic compared to planktonic algae: food web implications. Marine Ecology Progress Series 124, 307-312.

Fry, B., Wainwright, S.C., 1991. Diatom sources of C-rich carbon in marine food webs. Marine Ecology Progress Series 76, 149-157.

Folch, J., Lees, M., Sloane-Stanlez, G.H., 1957. A simple method for the isolation and purification of total lipids from animal tissues. Journal of Biological Chemistry 226: 497-509. Global Biogeochemical Cycles 8, 85-90.

Fontugne, M.R., Duplessy, J.C., 1981. Organic carbon isotopic fractionation by marine plankton in the temperature range -1 to $31^{\circ} \mathrm{C}$. Oceanologica Acta 4, 85-90.

Fry, B., 1988. Food web structure on Georges Bank from stable C, N, and S isotopic compositions. Limnology and Oceanography 33, 1182-1190.

Fry, B., Anderson, R.K., Entzeroth, L., Bird, J.L., Parker, P.L., 1984. ${ }^{13}$ C enrichment and oceanic food web structure in the northwestern Gulf of Mexico. Contributions in marine Science 27, 49-63.

Fry, B., Sherr, E., 1984. ${ }^{13} \mathrm{C}$ measurements as indicators of carbon flow in marine and freshwater ecosystems. Contributions in Marine Science 27, 13-47.

Goericke, R., Fry, B., 1994. Variations of marine plankton $\delta^{13} \mathrm{C}$ with latitude, temperature, and dissolved $\mathrm{CO}_{2}$ in the world ocean. Global Biogeochemical Cycles 8, 85-90.

Graeve, M., Kattner, G., Hagen, W., 1994. Diet-induced changes in the fatty acid composition of Arctic herbivorous copepods: Experimental evidence of trophic markers. Journal of Experimental Marine Biology and Ecology 182, 97-110.

Graeve, M., Kattner, G., Wiencke, C., Karsten, U., 2002. Fatty acid composition of Arctic and Antarctic macroalgae: indicator of phylogenetic and trophic relationships. Marine Ecology Progress Series 231, 67-74.

Gailhard-Rocher, I., Huret, M., Lazure, P., Vandermeirsch, F., Gatti, J., Garreau, P., Gobin, F., 2012. Identification de "paysages hydrologiques" dans les eaux marines sous juridiction française (France métropolitaine). IFREMER internal report (R.INT.ODE/DYNECO/D 12-4).

Griffin, R., Pearce, B., Handy, R.D., 2012. Dietary preference and feeding selectivity of common dragonet Callionymus lyra in U.K. Journal of Fish Biology 81, 1019-1031.

Harmelin-Vivien, M., Loizeau, V., Mellon, C., Beker, B., Arlhac, D., Bodiguel, X., Ferraton, F., Hermand, R., Philippon, X., Salen-Picard, C., 2008. Comparison of C and N stable isotope ratios between surface particulate organic matter and microphytoplankton in the Gulf of Lions (NW Mediterranean). Continental Shelf Research 28, 1911-1919.

Hartnoll, R.G., 1963. The biology of Manx Spider Crabs. Proceddings of the Zoological Society of London 141, 423-496.

Holligan, P.M., Groom, S.B., 1986. Phytoplankton distributions along the shelf break. Proceedings of the Royal Society of Edinburgh B 88, 239-263.

Iverson, S.J., Field, C., Bowen, W.D., Blanchard, W., 2004. Quantitative fatty acid signature analysis: a new method of estimating predator diets. Ecological Monograph 74, 211235.

Jennings, S., Warr, K.J., 2003. Environmental correlates of large-scale spatial variation in the $\delta^{15} \mathrm{~N}$ of marine animals. Marine Biology 142, 1131-1140.

Joint, I., Wollast, R., Chou, L., Batten, S., Elskens, M., Edwards, E., Hirst, A., Burkill, P., Groom, S., Gibb, S., Miller, A., Hydes, D., Dehairs, F., Antia, A., Barlow, R., Rees, A., POMroy, A., Brockmann, U., Cummings, D., Lampitt, R., Loijens, M., Mantoura, F., Miller, P., Raabe, T., Alvarez-Salgado, X., Stelfox, C., Woolfenden, J., 2001. Pelagic production at the Celtic Sea shelf break. Deep Sea Research Part II 48, 3049-3081. 
Kelly, J.R., Scheibling, R.E., 2012. Fatty acids as dietary tracers in benthic food webs. Marine Ecology Progress Series 446, 1-22.

Kharlamenko, V.I., Kiyashko, S.I., Imbs, A.B., Vyshkvartzev, D.I., 2001. Identification of food sources of invertebrastes from the seagrass Zostera marina community using carbon and sulfur stable isotope ratio and fatty acid analyses. Marine Ecology Progress Series 220, 103-117.

Kline JR, T.C., 2009. Characterization of carbon and nitrogen stable isotope gradients in the northern Gulf of Alaska using terminal feed stage copepodite-V Neocalanus cristatus. Deep Sea Research Part II 56, 2537-2552.

Kolasinski, J., Kaehler, S., Jaquemet, S., 2012. Distribution and sources of particulate organic matter in a mesoscale eddy dipole in the Mozambique Channel (southwestern Indian Ocean): Insight from $\mathrm{C}$ and $\mathrm{N}$ stable isotopes. Journal of Marine Systems 96-97, 122-131.

Kopp, D., Lefebvre, S., Cachera, M., Villanueva, M.C., Ernande, B., 2015. Reorganization of a marine trophic network along an inshore-offshore gradient due to stronger pelagicbenthic coupling in coastal areas. Progress in Oceanography, 130, 157-171.

Kostecki, C., Le Loc'h, F., Roussel, J.M., Desroy, M., Huteau, D., Riera, P., Le Bris, H., Le Pape, O., 2010. Dynamics of an estuarine nursery ground: the spatio-temporal relationship between the river flow and the food web of the juvenile common sole (Solea solea, L.) as revealed by stable isotopes analysis. Journal of Sea Research 64, 54-60.

Koutsikopoulos, C., Le Cann, B., 1996. Physical processes and hydrological structures related to the Bay of Biscay anchovy. Scientia Marina 60, 9-19.

Lara, R.J., Alder, V., Franzosi, C.A., Kattner, G., 2010. Characteristics of suspended particulate organic matter in the southwestern Atlantic: influence of temperature, nutrient and phytoplankton features on the stable isotope signature. Journal of Marine Systems 79, 199-209.

Lassalle, G., Lobry, J., Le Loc'h, F., Bustamante, P., Certain, G., Delmas, D., Dupuy, C., Hily, C., Labry, C., Le Pape, O., Marquis, E., Petitgas, P., Pusineri, C., Ridoux, V., Spitz, J., Niquil, N., 2011. Lower trophic levels and detrital biomass control the Bay of Biscay continental shelf food web: implications for ecosystem management. Progress in Oceanography 91, 561-575.

Lazure, P., Garnier, V., Dumas, F., Herry, C., Chifflet, M., 2009. Development of a hydrodynamic model of the Bay of Biscay. Validation of hydrology. Continental Shelf Research 29, 985-997.

Le Boyer, A., Cambon, G., Daniault, N., Herbette, S., Le Cann, B., Marié, L., Morin, P., 2009. Observations of the Ushant tidal front in September 2007. Continental Shelf Research 29, 1026-1037.

Lebreton, B., Richard, P., Galois, R., Radenac, G., Pfleger, C., Guillou, G., Mornet, F., Blanchard, G.F., 2011. Trophic importance of diatoms in an intertidal Zostera noltii seagrass bed: evidence from stable isotope and fatty acid analyses. Estuarine, Coastal and Shelf Science 92, 140-153.

Le Loc'h, F., Hily, C., Grall, J., 2008. Benthic community and food web structure on the continental shelf of the Bay of Biscay (North Eastern Atlantic) revealed by stable isotopes analysis. Journal of Marine Systems 72, 17-34.

Le Pape, O., Del Amo, Y., Menesguen, A., Aminot, A., Quequiner, B., Treguer., P., 1996. Resistance of a coastal ecosystem to increasing eutrophic conditions: the Bay of Brest (France), a semi-enclosed zone of Western Europe. Continental Shelf Research $16,1885-1907$.

Lesage, V., O'Hammill, M., Kovacs, K.M., 2001. Marine mammals and the community structure of the Estuary and Gulf of St Lawrence, Canada: evidence from stable isotope analysis. Marine Ecology Progress Series 210, 203-221.

Liu, K.K., Kao S.J., Hu, H.C., Chou, W.C., Hung, G.W., Tseng, C.M., 2007. Carbon isotopic composition of suspended and sinking particulate organic matter in the northern 
South China Sea - From production to deposition. Deep-Sea Research Part II 54, 1504-1527.

Logue, J., de Vries, A., Fodor, E. and Cossins, A., 2000. Lipid compositional correlates of temperature-adaptive interspecific differences in membrane physical structure. Journal of Experimental Biology 203, 2105-2115.

Loneragan, N.R., 1999. River flows and estuarine ecosystems: Implications for coastal fisheries from a review and a case study of the Logan River, southeast Queensland. Australian Journal of Ecology 24, 431-440.

MacKenzie K.M., Longmore, C., Preece, C., Lucas, C.H., Trueman, C.N., 2014. Testing the long-term stability of marine isoscapes in shelf seas using jellyfish tissues. Biogeochemistry 121, 441-454.

Martínez del Rio, C., Wolf, N., Carleton, S. A., and Gannes, L.Z., 2009. Isotopic ecology ten years after a call for more laboratory experiments. Biological Reviews of the Cambridge Philosophical Society 84, 91-111.

McClelland, J.M., Valiela, I., Michener, R.H., 1997. Nitrogen-stable isotope signatures in estuarine food webs: a record of increasing urbanization in coastal watersheds. Limnology and Oceanography 42, 930-937.

Michener, R.H., Kaufman, L., 2007. Stable isotope ratios as tracers in marine food webs: an update. In: Michener, R., Lajtha, K. (Eds.), Stable Isotopes in Ecology and Environmental Science. Blackwell Publishing Ltd., pp. 238-282.

Miller, T.W., Brodeur, R.D., Rau, G.H., 2008. Carbon stable isotopes reveal relative contribution of shelf-slope production to the northern California Current pelagic community. Limnology and Oceanography 53, 1493-1503.

Minagawa, M., Wada, E., 1984. Stepwise enrichment of $\delta^{15} \mathrm{~N}$ along food chains: further evidence and the relation between $\delta^{15} \mathrm{~N}$ and animal age. Geochimica et Cosmochimica Acta 48, 1135-1140.

Millennium Ecosystem Assessment, 2005. Ecosystems and human well-being: general synthesis. Island Press, Washington, DC, $137 \mathrm{p}$.

Montoya, J.P., 2007. Natural abundance of ${ }^{15} \mathrm{~N}$ in marine planktonic ecosystems. In: Michener, R., Lajtha, K. (Eds.), Stable Isotopes in Ecology and Environmental Science. Blackwell Publishing, pp. 76-201.

Nagao, S., Usui, T., Yamamoto, M., Minagawa, M., Iwatsuki, T., Noda, A., 2005. Combined use of $\Delta^{14} \mathrm{C}$ and $\delta^{13} \mathrm{C}$ values to trace transportation and deposition processes of terrestrial particulate organic matter in coastal marine environments. Chemical Geology 218, 63-72.

Nakatsuka, T., Handa, N., Harada, N., Sugimoto, T., Imaizumi, S., 1997. Origin and decomposition of sinking particulate organic matter in the deep water column inferred from the vertical distributions of its $\delta^{15} \mathrm{~N}, \delta^{13} \mathrm{C}$ and $\delta^{14} \mathrm{C}$. Deep Sea Research Part I 44, 1957-1979.

Napolitano, G.E., Pollero, R.J., Gayoso, A.M., MacDonald, B.A., Thompson, R.J., 1997. Fatty acids as trophic markers of phytoplankton blooms in the Bahia Blanca estuary (Buenos Aires, Argentina) and in Trinity Bay (Newfoundland, Canada). Biochemical Systematics and Ecology 25, 739-755.

Nerot, C., Lorrain, A., Grall, J., Gillikin, D.P., Munaron, J.M., Le Bris, H., Paulet, Y.M., 2012. Stable isotope variations in benthic suspension feeders across a large depth gradient on the continental shelf. Estuarine, Coastal and Shelf Science 96, 228-235.

Nerot, C., Kraffe, E., Meziane, T., Grall, J., Lorrain, A., Le Bris, H., Schaal, G., Paulet, Y.M. Spatial changes in fatty acids signatures of the great scallop Pecten maximus across the Bay of Biscay continental shelf $(15$ to $190 \mathrm{~m})$. Under review in Continental Shelf Research.

North, C.A., Lovvorn, J.R., Kolts, J.M., Brooks, M.L., Cooper, L.W., Grebmeier, J.M., 2014. Deposit-feeder diets in the Bering Sea: potential effects of climatic loss of sea icerelated microalgal blooms. Ecological Applications 24, 1525-1542. 
Ogrinc, N., Fontolan, G., Faganeli, J., Covelli, S., 2005. Carbon and nitrogen isotope compositions of organic matter in coastal marine sediments (the Gulf of Trieste, N Adriatic Sea): indicators of sources and preservation. Marine Chemistry 95, 163-181.

OSPAR, 2010. Quality Status Report 2010. OSPAR Commission, London, 176 p.

Parrish, C.C., Abrajano, T.A., Budge, S.M., Helleur, R.J., Hudson, E.D., Pulchan, K., Ramos, C., 2000. Lipid and phenolic biomarkers in marine ecosystems : analysis and applications. In: Wangersky, P. (Ed.), The Handbook of Environmental Chemistry. Vol. 5. Springer-Verlag, Berlin, Ch. Part D. Marine Chemistry.

Parrish, C., Deibel, D., Thompson, R., 2009. Effect of sinking spring phytoplankton blooms on lipid content and composition in suprabenthic and benthic invertebrates in a cold ocean coastal environment. Marine Ecology Progress Series 391, 33-51.

Pernet, F., Tremblay, R., Comeau, L., Guderley, H., 2007. Temperature adaptation in two bivalve species from different thermal habitats: energetics and remodelling of membrane lipids. Journal of Experimental Biology 210, 2999-3014.

Pernet, F., Malet, N., Pastoureaud, A., Vaquer, A., Quéré, C., Dubroca, L., 2012. Marine diatoms sustain growth of bivalves in a Mediterranean lagoon. Journal of Sea Research 68, 20-32.

Peterson, B.J., and Fry, B. 1987. Stable isotopes in ecosystem studies. Annual Review of Ecology and Systematics 18, 293-320.

Pingree, R.D., Mardell, G.T., Holligan, P.M., Griffiths, D.K., Smithers, J., 1982. Celtic Sea and Armorican current structure and the vertical distributions of temperature and chlorophyll. Continental Shelf Research 1, 99-116.

Popp, B.N., Laws, E.A., Bidigare, R.R., Dore, J.E., Hanson, K.L., Wakeham, S.G., 1998. Effect of phytoplankton cell geometry on carbon isotopic fractionation. Geochimica et Cosmochimica Acta 62, 69-77.

Post, D.M., 2002. Using stable isotopes to estimate trophic position: models, methods and assumptions. Ecology 83, 703-718.

Post, D.M., Layman, C.A., Arrington, D.A., Takimoto, G., Quattrochi, J., Montaña, C.G., 2007. Getting to the fat of the matter: models, methods, and assumptions for dealing with lipids in stable isotope analyses. Oecologia 152, 179-189.

Puillat, I., Lazure, P., Jégou, A.M., Lampert, L., Miller, P.I., 2004. Hydrographical variability on the French continental shelf in the Bay of Biscay, during the 1990s. Continental Shelf Research 24, 1143-1163.

Puillat, I., Lazure, P., Jégou, A.M., Lampert, L., Miller, P.I., 2006. Mesoscale hydrological variability induced by northwesterly wind on the French continental shelf of the Bay of Biscay. Scientia Marina 70S1, 15-26.

Radabaugh, K.R., Hollander, D.J., Peebles, E.B., 2013. Seasonal $\delta^{13} \mathrm{C}$ and $\delta^{15} \mathrm{~N}$ isoscapes of fish populations along a continental shelf trophic gradient. Continental Shelf Research 68, 112-122.

Rau, G.H., Riebesell, U., Wolf-Gladrow, D., 1997. $\mathrm{CO}_{2 a q}$-dependent photosynthetic ${ }^{13} \mathrm{C}$ fractionation in the ocean: A model versus measurements. Global Biogeochemical Cycles, 11, 267-278.

Rorandelli, R., Bartolini, F., Gomei, M., Cannicci, S., 2007. Observations in captivity of the activity patterns and resources utilization of the spider crab Inachus phalangium (Decapoda, Majidae). Marine Biology 151, 1111-1116.

Sahu, A., Pancha, I., Jain, D., Paliwal, C., Ghosh, T., Patidar, S., Bhattacharya, S., Mishra, S., 2013. Fatty acids as biomarkers of microalgae. Phytochemistry 89, 53-58.

Schaal, G., Nerot, C., Grall, J., Chouvelon, T., Lorrain, A., Savoye, N., Brind'Amour, A., Paulet, Y.M., Le Bris, H. Stable isotope ratios in bentho-demersal biota along a depth gradient in the Bay of Biscay: a multitrophic study. Under review in Estuarine, Coastal and Shelf Science.

Schaal, G., Riera, P., Leroux, C., 2010. Trophic ecology in a Northern Brittany (Batz Island, France) kelp (Laminaria digitata) forest, as investigated through stable isotopes and chemical assays. Journal of Sea Research 63, 24-35. 
Sherwood, G.D., Rose, G.A., 2005. Stable isotope analysis of some representative fish and invertebrates of the Newfoundland and Labrador continental shelf food web. Estuarine, Coastal and Shelf Science 63, 537-549.

Vanderklift, A., Ponsard, S., 2003. Sources of variation in consumer-diet $\delta^{15} \mathrm{~N}$ enrichments: a meta-analysis. Oecologia 136, 169-182.

Vander Zanden, M.J., Rasmussen, J.B., 1999. Primary consumer $\delta^{15} \mathrm{~N}$ and $\delta^{13} \mathrm{C}$ and the trophic position of aquatic consumers. Ecology 80, 1395-1404.

Véra, A., Desvilettes, C., Bec, A., Bourdier, G., 2001. Fatty acid composition of freshwater heterotrophic flagellates: an experimental study. Aquatic Microbial Ecology 25, 271275.

Vincent, A., Kurc, G., 1969. Hydrologie, variations saisonnières de la situation thermique du Golfe de Gascogne en 1967. Revue des Travaux l'Institut des Pêches Maritimes 33, 79-96.

Vizzini, S., Mazzola, A., 2006. The effects of anthropogenic organic matter inputs on stable carbon and nitrogen isotopes in organisms from different trophic levels in a southern Mediterranean coastal area. Science of the Total Environment 368, 723-731.

Waite, A.M., Gustafsson, Ö, Lindahl, O., Tiselius, P., 2005. Linking ecosystem dynamics and biogeochemistry: sinking fractionation of organic carbon in a Swedish fjord. Limnology and Oceanography 50, 658-671.

Waite, A.M, Muhlingb, B.A., Holl, C.M., Beckley, B.E., Montoyac, J.P., Strzelecki, J., Thompson, P.A., Pesant, S., 2007. Food web structure in two counter-rotating eddies based on $\delta^{15} \mathrm{~N}$ and $\delta^{13} \mathrm{C}$ isotopic analyses. Deep-Sea Research II 54, 1055-1075.

Wilson, R.M., Lapham, L.L., Riedel, M., Holmes, M.E., Chanton, J.P., 2015. Observing methane hydrate dissolution rates under sediment cover. Marine Chemistry 172, $12-$ 22.

Wilson, S.E., Steinberg, D.K., Chu, F.L.E., Bishop, J.K.B., 2010. Feeding ecology of mesopelagic zooplankton of the subtropical and subarctic North Pacific Ocean determined with fatty acid biomarkers. Deep-Sea Research Part I 57, 1278-1294.

Zhukova, V., Kharlamenko, V.I., 1999. Sources of essential fatty acids in the marine microbial loop. Aquatic Microbial Ecology 17, 153-157.

Zvab Rozic, P., Dolenec, T., Lojen, S., Kniewald, G., Dolenec, M., 2014. Using stable nitrogen isotopes in Patella sp. to trace sewage-derived material in coastal ecosystems. Ecological Indicators 36, 224-230. 


\title{
Tables
}

Table 1: Physical characteristics along the two transects studied in the northern Bay of Biscay.

\section{Coastal area:}

$\begin{array}{ll}\begin{array}{l}\text { Rivers } \\ \text { (approximate mean annual } \\ \text { flow) }\end{array} & \text { - Aulne }\left(20.4 \mathrm{~m}^{3} \cdot \mathrm{s}^{-1}\right) \\ \begin{array}{l}\text { Bays receiving freshwater }\left(5.5 \mathrm{~m}^{3} \cdot \mathrm{s}^{-1}\right) \\ \text { inputs }\end{array} & \begin{array}{l}\text { - Bay of Brest: semi-enclosed } \\ \text { embayment }\left(\sim 180 \mathrm{~km}^{2}\right) \text { connected to } \\ \text { oceanic waters by a narrow and } \\ \text { deep channel, allowing for } 40 \% \text { of } \\ \text { the waters to be well mixed and } \\ \text { renewed at each tide cycle }\end{array}\end{array}$

Miscellaneous events

- Odet $\left(7.5 \mathrm{~m}^{3} \cdot \mathrm{s}^{-1}\right)$
- Moros $\left(0.3 \mathrm{~m}^{3} \cdot \mathrm{s}^{-1}\right)$

- Bay of Bénodet $\left(\sim 38 \mathrm{~km}^{2}\right)$ and Bay of Concarneau $\left(\sim 160 \mathrm{~km}^{2}\right)$ : shallow areas (depth $<25 \mathrm{~m}$ ) opened onto oceanic waters

- Possible occurrence of upwelling due to northerly wind events

\section{Continental shelf:}

Hydrological fronts and structures

(approximate depth of occurrence)

\author{
- Iroise front (40-50 m) \\ - (no specific fronts) \\ - Ushant front $(\sim 100 \mathrm{~m})$ \\ - Before and between fronts: water \\ column well mixed)
}

- (for both transects: ) "Cold pool", from about a depth of $100 \mathrm{~m}$ : cold water mass isolated below warmer surface water; characterised by low interannual and seasonal fluctuations with small variations in temperature less than $1^{\circ} \mathrm{C}$ from spring to autumn; thought to limit exchange between the surface mixed layer and deep water $=$ water column particularly stratified, at least in temperature (except in winter)

\section{Shelf break:}

Hydrological characteristics

- (for both transects: ) Slope currents responsible for strong vertical mixing and nutrient inputs, which potentially creates suitable conditions for primary production

References: Vincent and Kurc, 1969; Pingree et al., 1982; Koutsikopoulos and Le Cann, 1996; Le Pape et al., 1996; Puillat et al., 2004, 2006 and references therein; Lazure et al., 2009; Le Boyer et al., 2009; Gailhard-Rocher et al., 2012. 
Table 2: Common fatty acid (FA) biomarkers investigated and discussed in the present study. FA compositions reported and analysed in the present study only correspond to the neutral lipid fraction (see text). In bold = FA biomarkers presented in Figs. 6 and 7. When redundant information was given by a single $F A$, or from a ratio or a sum containing this $F A$, the ratio or the sum was preferred (e.g., ratio $\Sigma$ 16:1/16:0 instead of single 16:1n-7, ratio $20: 5 n-3 / 22: 6 n-3$ instead of single $20: 5 n-3$, ratio $18: 1 n-9 / 18: 1 n-7$ instead of single $18: 1 n-9$, sum 18:2n-6 + 18:3n-3). Letters correspond to the reference(s) associated to the food source or the proposed trophic interpretation (when the same FA could be attributed to different food sources at the base of food webs).

\section{Food sources,}

or trophic interpretation (for consumers)

1 - In coastal areas: fresh algal material /phytoplankton (when high ratio) versus detritus (when low ratio)

\section{- In offshore areas and/or} when algal material or organic matter degrades (e.g., under the euphotic zone): carnivory (a) or bacterial colonisation (b) (when high ratio)

\section{Single fatty acid, sum or ratio}

References

Biandolino et al., 2008; BlanchetAurigny et al., 2015

$-\Sigma$ PUFAs/ $\Sigma$ SFAs

(a) Cripps and Atkinson, 2000

(b) Balzano et al., 2011
2 Diatoms

$$
\begin{aligned}
& -16: 1 \mathrm{n}-7 \\
& -\Sigma 16: 1 / 16: 0 \text { (when }>1.6) \\
& \text { (with 16:1=16:1n-7 + 16:1n-9 } \\
& \text { in the present study) } \\
& -\Sigma \text { C16/ } \mathbf{C} \text { C18 (when >2.0) } \\
& -20: 5 n-3 \\
& -20: 5 n-3 / 22: 6 n-3
\end{aligned}
$$

Ackman et al., 1968; Graeve et al., 1994; Budge and Parrish, 1998; Parrish et al., 2000; Budge et al., 2001; Kharlamenko et al., 2001; Dalsgaard et al., 2003

\section{3 (Dino)flagellates}

$-22: 6 n-3$

$-22: 6 n-3 / 20: 5 n-3$
Budge and Parrish, 1998;

Zhukova and Kharlamenko, 1999; Dalsgaard et al., 2003; Parrish et al., 2009
4 Terrestrial plants or Seagrasses (a)
or Flagellates (b)

(a) Budge and Parrish, 1998; Budge et al., 2001; Kharlamenko et al., 2001

(b) Zhukova and Kharlamenko, 1999; Véra et al., 2001
5 Carnivory (a) or Flagellates (b)
$-18: 1 n-9$

$-18: 1 n-9 / 18: 1 n-7$ (a) Graeve et al., 1997; Cripps and Atkinson, 2000

(b) Zhukova and Kharlamenko, 1999; Véra et al., 2001 
and BFAs

$(15: 0+$ iso15:0 + anteiso15:0 +

iso16:0 + 17:0 + iso17:0) al., 2003 
Table 3: Non-exhaustive synthesis of other case studies that have reported coastal or inshore versus oceanic or offshore trends in $\delta^{13} \mathrm{C}$ and $\delta^{15} \mathrm{~N}$ values of sedimentary organic matter (SOM) samples, surface particulate organic matter (POM), bottom POM, primary or secondary to tertiary consumers across continental shelves over the world. NS $=$ Not Specified.

\begin{tabular}{|c|c|c|c|c|c|}
\hline \multirow[t]{2}{*}{ Compartment } & \multirow[t]{2}{*}{$\begin{array}{l}\text { Ecosystem, and/or } \\
\text { gradient and/or } \\
\text { continental shelf studied }\end{array}$} & \multirow[t]{2}{*}{ Covered depth range $(\mathrm{m})$} & \multicolumn{2}{|c|}{$\begin{array}{c}\text { Coastal or nearshore versus oceanic or offshore } \\
\text { general trends in: }\end{array}$} & \multirow[t]{2}{*}{ Reference } \\
\hline & & & $\delta^{13} \mathrm{C}$ & $\delta^{15} \mathrm{~N}$ & \\
\hline \multirow[t]{5}{*}{ Som } & & & \multirow{2}{*}{\multicolumn{2}{|c|}{$\begin{array}{c}\text { Slight increase of values between nearshore and } \\
\text { offshore stations }\end{array}$}} & \\
\hline & $\begin{array}{l}\text { Continental shelf off } \\
\text { southeastern Australia }\end{array}$ & $20-200 \mathrm{~m}$ & & & $\begin{array}{l}\text { Davenport and Bax } \\
2002\end{array}$ \\
\hline & $\begin{array}{c}\text { Estuary, } \\
\text { continental shelf and slope } \\
\text { off the coast of Tokachi } \\
\text { River (Japan) }\end{array}$ & $0-1699 \mathrm{~m}$ & \multicolumn{2}{|l|}{$\begin{array}{l}\text { Increasing values from } \\
\text { Tokachi River (terrestrial } \\
\text { influence) to the slope } \\
\text { (marine influence) }\end{array}$} & Nagao et al., 2005 \\
\hline & $\begin{array}{c}\text { Vicinity of large rivers } \\
\text { (Douro and Tagus estuary) } \\
\text { versus canyon regions at } \\
\text { sea (Nazaré, Sines) } \\
\text { (Portugal) }\end{array}$ & Until approx.. $200 \mathrm{~m}$ & \multicolumn{2}{|c|}{$\begin{array}{l}\text { Lower values in the stations at the vicinity of large } \\
\text { rivers relative to offshore stations (terrestrial versus } \\
\text { marine influence) }\end{array}$} & Alt-Epping et al., 2007 \\
\hline & $\begin{array}{l}\text { Bay of Biscay continental } \\
\text { shelf (from the Vilaine River } \\
\text { to the continental slope) } \\
\text { (France) }\end{array}$ & $0-155 \mathrm{~m}$ & $\begin{array}{l}\text { Poorly variable values } \\
\text { along the depth gradient }\end{array}$ & $\begin{array}{l}\text { Slight decrease in the } \\
\text { values along the depth } \\
\text { gradient }\end{array}$ & $\begin{array}{l}\text { Schaal et al., under } \\
\text { review }\end{array}$ \\
\hline \multicolumn{6}{|l|}{ Bottom POM } \\
\hline & \multicolumn{2}{|l|}{$\begin{array}{l}\text { Bay of Biscay continental } \\
\text { shelf (from the Bay of Brest } \\
\text { to the continental slope) } \\
\text { (France) }\end{array}$} & \multicolumn{2}{|l|}{$\begin{array}{l}\text { Decreasing values along } \\
\text { the depth gradient } \\
\text { (although a slight increase } \\
\text { beyond } 200 \mathrm{~m} \text { in depth) }\end{array}$} & Nerot et al., 2012 \\
\hline & \multicolumn{2}{|l|}{$\begin{array}{l}\text { Bay of Biscay continental } \\
\text { shelf (from the Vilaine River } \\
\text { to the continental slope) } \\
\text { (France) }\end{array}$} & \multicolumn{2}{|c|}{ Decreasing values along the depth gradient } & $\begin{array}{l}\text { Schaal et al., under } \\
\text { review }\end{array}$ \\
\hline \multicolumn{6}{|l|}{ Surface POM } \\
\hline & $\begin{array}{l}\text { Northwestern shelf of the } \\
\text { Gulf of Mexico, Texas (USA) }\end{array}$ & $\begin{array}{l}\quad 0-100 \text { or } 160 \mathrm{~m} \\
\text { (depending on transects) }\end{array}$ & \multicolumn{2}{|l|}{$\begin{array}{l}\text { Increasing values from } \\
\text { large river mouths or }\end{array}$} & Fry et al., 1984 \\
\hline
\end{tabular}


estuaries (e.g.,

Mississippi) to offshore

stations

Continental shelf off

southeastern Australia

Vicinity of the Rhone River plume versus offshore areas near the Gulf of Fos,

Mediterranean (France)

California Current

ecosystem (USA)
$20-200 m$

0-100 m

$<150 m$ versus $>150 m$
No significant trends

Higher values at the vicinity of the Rhone river plume versus offshore areas

Higher values at the vicinity of the Rhone rive influence) versus offshore areas (marine influence)

Higher values in

nearshore stations relative to offshore stations
Davenport and Bax, 2002

Darnaude et al.,2004

\section{Benthic primary consumers / e.g.}

bivalves (such as $P$. maximus in the

present study)

\section{Georges Bank \\ (USA/Canada)}

Continental shelves of Irish

Sea, English Channel and

North Sea (Ireland, UK

$$
\text { France) }
$$

Continental shelves of Irish

Sea, English Channel and

North Sea (Ireland, UK,

$$
\text { France) }
$$

Bay of Biscay continental shelf (from the Bay of Brest

to the continental slope)

$$
\text { (France) }
$$

Bay of Biscay continental

shelf (from the Vilaine Rive

to the continental slope)

(France)
60-160 m

0-ca 165 m

0-ca $100 \mathrm{~m}$

$0-220 \mathrm{~m}$

0-155 m
Decreasing values along the depth gradient

No significant trends

Fry, 1988

Higher values in nearshore areas relative to offshore

$$
\text { areas }
$$

Higher values in

nearshore areas relative

to offshore areas

Barnes et al., 2009

Decreasing values along the depth gradient (although a slight increase beyond $200 \mathrm{~m}$ in depth)

Nerot et al., 2012

Decreasing values along the depth gradient review

\section{Benthic or demersal secondary to}

tertiary consumers / e.g.

crustaceans and fish (such as

C. Iyra in the present study) 
Northwestern shelf of the

Gulf of Mexico, Texas (USA)

Newfoundland and Labrador

(NL) continental shelves

(Canada)

Bay of Biscay continental shelf (France)

Vicinity of the Mississippi

River plume and coast of

peninsular Florida (USA)

Bay of Biscay continental shelf (from the Vilaine River

to the continental slope)

$$
\text { (France) }
$$

English Channel Sea

(France/England)
0-100/160 m (depending

on transects)

0-2250 m

9-102 m

0-155 m

$0-80 \mathrm{~m}$
Increasing values from

large river mouths or

estuaries (e.g.,

Mississippi) to offshore

stations, and/or no

significant trends

No significant trends

reported

values in

nearshore areas

relative to offshore

$$
\text { areas }
$$

Decreasing values from coastal to oceanic species / along the depth gradient

Higher values at the vicinity of the

Decreasing values with Mississippi river plume; depth

increasing values with

longitude (ca depth)

Decreasing values along the depth gradient

Slight decrease in the

values with depth

Decreasing values with (although non-significant) depth
Schaal et al., under review

Sherwood and Rose,

$$
2005
$$

Chouvelon et al., 2012

Radabaugh et al., 2013

Kopp et al., 2015 


\section{Caption to figures:}

Figure 1: Map of sampling locations along the two inshore-offshore transects over the northern Bay of Biscay continental shelf. Stations selected for fatty acid analysis are also indicated (i.e., A1-A4 in transect A, B1-B4 in transect B). The potential extent of the "cold pool" structure is also indicated (shaded area) from Vincent and Kurc (1969).

Figure 2: Mean $\delta^{15} \mathrm{~N}$ values (top figures) and $\delta^{13} \mathrm{C}$ values (bottom figures) \pm standard deviation (SD) as a function of depth for sedimentary organic matter (SOM) (i.e., one of the sources originally considered) and for muscle samples of Aequipecten opercularis, Pecten maximus, Venus casina, Inachus spp, Macropipus tuberculatus and Callionymus lyra (i.e., consumers) sampled along the two inshore-offshore transects investigated in the northern Bay of Biscay. The same scale has been applied for the two depth gradients, to make the comparison easier. For information, stations selected for fatty acid analyses within selected compartments are indicated (A1-A4 in the transect A and B1-B4 in the transect B). Smoothing lines (robust, locally weighted smoothing system based on the LOWESS algorithm with software $\mathrm{R}$ ) represent the fitted non-linear trends of values for SOM samples and for the bivalve $P$. maximus and the fish $C$. lyra that could be sampled along the two transects.

Figure 3: Calculations of "apparent Trophic Enrichment Factors (TEFs)" between two theoretical trophic levels (i.e., between $\mathrm{C} 1=$ Pecten maximus, bivalve mollusc, considered a theoretical primary consumer, and $\mathrm{C} 2=$ Callionymus lyra, fish, considered a theoretical secondary to tertiary consumer) as a function of depth, for $\delta^{15} \mathrm{~N}$ (top figures) and $\delta^{13} \mathrm{C}$ (bottom figures) and along the two transects. Values correspond to the mean difference calculated in isotope values for the selected organisms at each station. Smoothing lines (robust, locally weighted smoothing system based on the LOWESS algorithm with software $\mathrm{R})$ represent the fitted non-linear trends of TEF values along the transects.

Figure 4: Projection of variables (i.e., percentages of individual fatty acid (FA) relative to total FAs, in \%) and of samples analysed for FA compositions on the first two components resulting from the principal component analysis (PCA). (a) Correlation biplot showing the distribution of the variables. The length of the line for a variable shows how well it is represented by the two-dimensional approximation, and reflects its contribution to the two first principal components. Horizontal axis: principal component 1 (explaining $26.6 \%$ of the variability in the dataset); vertical axis: principal component 2 (explaining $15.2 \%$ of the variability in the dataset) (i.e., $41.8 \%$ of the variability in the dataset explained by axes 1 and 2). (b) Grouping of samples by type of compartment. POM = particulate organic matter; SOM = sedimentary organic matter; consumers: Pecten maximus, Callionymus lyra. (c) Grouping of samples by stations. The spatial correspondence for stations is indicated on Fig. 1 . $\mathrm{A} 1=9 \mathrm{~m}$ deep, $\mathrm{A} 2=79 \mathrm{~m}, \mathrm{~A} 3=127 \mathrm{~m}, \mathrm{~A} 4=184 \mathrm{~m} ; \mathrm{B} 1=7 \mathrm{~m}, \mathrm{~B} 2=44 \mathrm{~m}, \mathrm{~B} 3=120 \mathrm{~m}$, $\mathrm{B} 4=148 \mathrm{~m}$.

Figure 5: Percentages of total branched fatty acids (BFAs), saturated fatty acids (SFAs), monounsaturated fatty acids (MUFAs), polyunsaturated fatty acids (PUFAs) (relative to total FAs, in \%) and values of the calculated Unsaturation Index (UI; see text) as a function of organisms and stations. The spatial correspondence for stations is indicated on Fig. 1. Values are mean \pm standard deviation. Values with the same letter are not significantly different (multiple-comparison test with Holm's adjustment method following a Kruskal-Wallis test, $\alpha=0.05)$. When nothing is indicated, no statistical test could be performed $(n<2$ in at least one station). The number of samples within each station is indicated at the bottom. $\mathrm{POM}=$ particulate organic matter; $\mathrm{SOM}=$ sedimentary organic matter. $\mathrm{A} 1=9 \mathrm{~m}$ deep, $\mathrm{A} 2=79 \mathrm{~m}, \mathrm{~A} 3=127 \mathrm{~m}, \mathrm{~A} 4=184 \mathrm{~m} ; \mathrm{B} 1=7 \mathrm{~m}, \mathrm{~B} 2=44 \mathrm{~m}, \mathrm{~B} 3=120 \mathrm{~m}, \mathrm{~B} 4=148 \mathrm{~m}$. 
Figure 6: Percentages of selected fatty acids (those of trophic interpretation 1-2 in Table 2) as a function of organisms and stations. A listing of these fatty acids and their potential significance as biomarkers is given in Table 2 (with associated references). The spatial correspondence of stations is indicated in Fig. 1. Values are mean \pm standard deviation. Values with the same letter are not significantly different (multiple-comparison test with Holm's adjustment method following a Kruskal-Wallis test, $\alpha=0.05$ ). When no $p$-value or no letters are indicated, no statistical test could be performed ( $<2$ in at least one station). $\mathrm{POM}=$ particulate organic matter; $\mathrm{SOM}=$ sedimentary organic matter. $\mathrm{A} 1=9 \mathrm{~m}$ deep, $\mathrm{A} 2=79 \mathrm{~m}, \mathrm{~A} 3=127 \mathrm{~m}, \mathrm{~A} 4=184 \mathrm{~m} ; \mathrm{B} 1=7 \mathrm{~m}, \mathrm{~B} 2=44 \mathrm{~m}, \mathrm{~B} 3=120 \mathrm{~m}, \mathrm{~B} 4=148 \mathrm{~m}$.

Figure 7: Percentage of selected fatty acids (those of trophic interpretation 3-6 in Table 2) as a function of organisms and stations. A listing of these fatty acids and their potential significance as biomarkers is given in Table 2 (with associated references). The spatial correspondence of stations is indicated in Fig. 1. Values are mean \pm standard deviation. Values with the same letter are not significantly different (multiple-comparison test with Holm's adjustment method following a Kruskal-Wallis test, $\alpha=0.05$ ). When no $p$-value or no letters are indicated, no statistical test could be performed ( $\mathrm{n}<2$ in at least one station). $\mathrm{POM}=$ particulate organic matter; $\mathrm{SOM}=$ sedimentary organic matter. $\mathrm{A} 1=9 \mathrm{~m}$ deep, $\mathrm{A} 2=79 \mathrm{~m}, \mathrm{~A} 3=127 \mathrm{~m}, \mathrm{~A} 4=184 \mathrm{~m} ; \mathrm{B} 1=7 \mathrm{~m}, \mathrm{~B} 2=44 \mathrm{~m}, \mathrm{~B} 3=120 \mathrm{~m}, \mathrm{~B} 4=148 \mathrm{~m}$. 


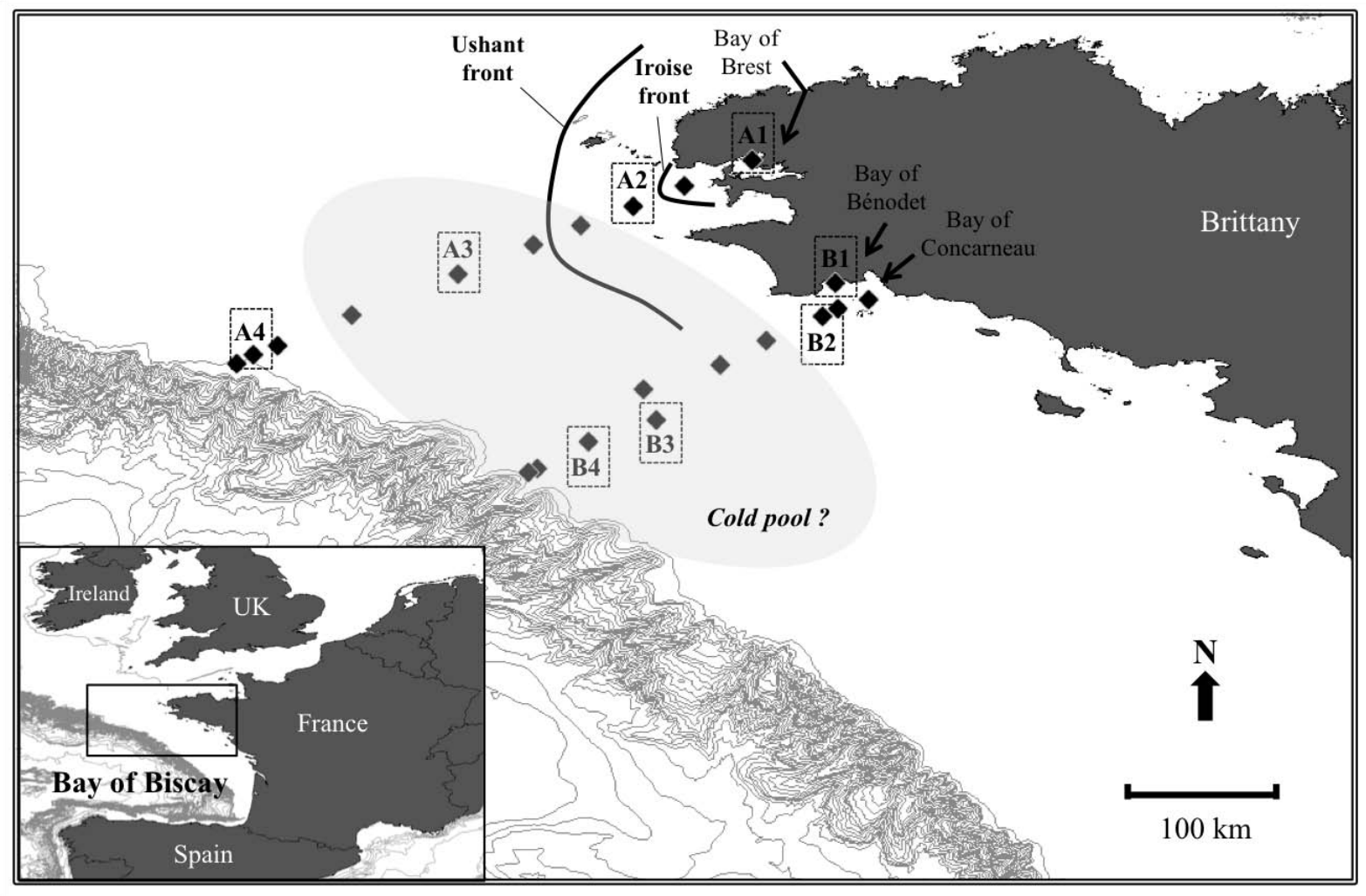

Figure 1 

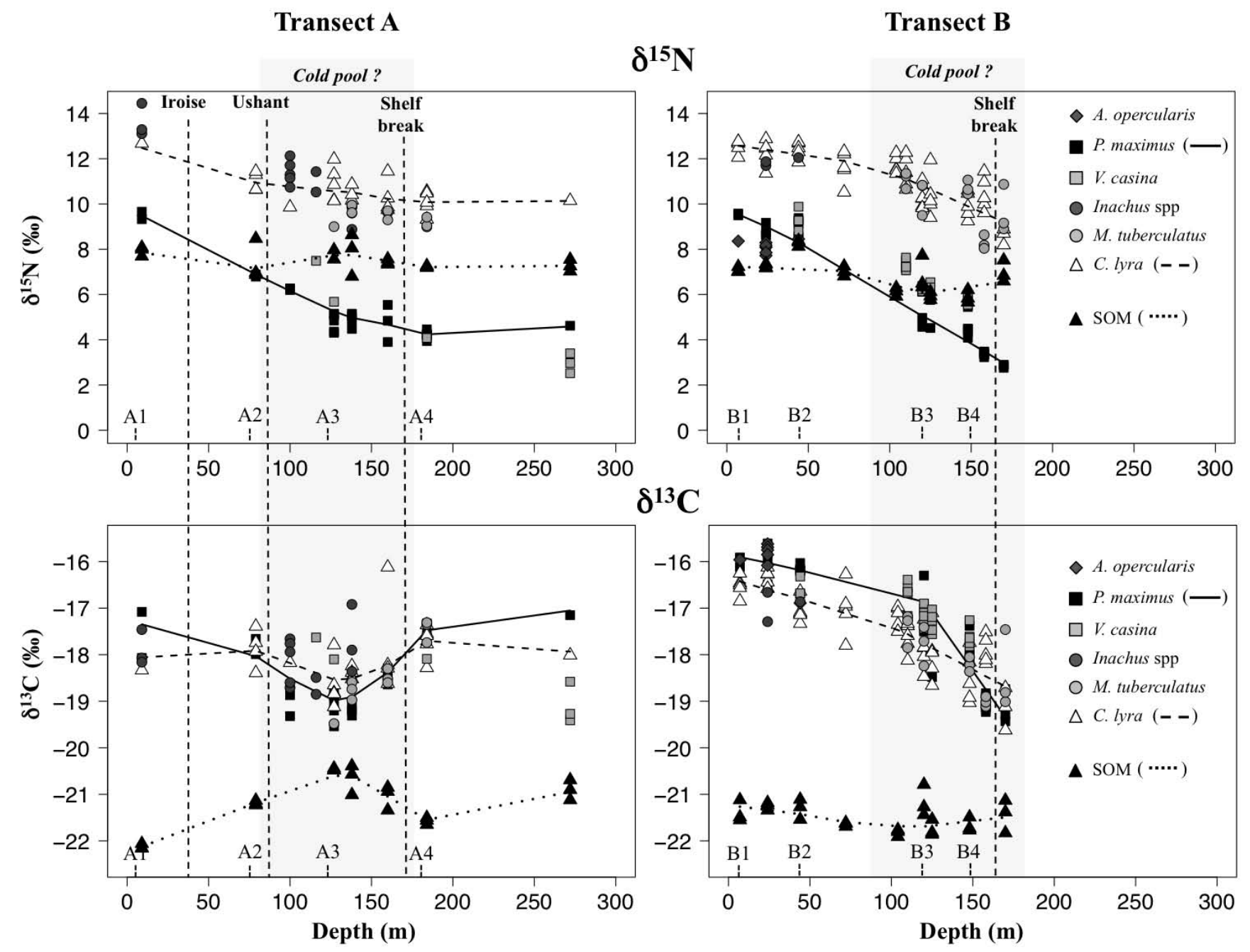

Figure 2 

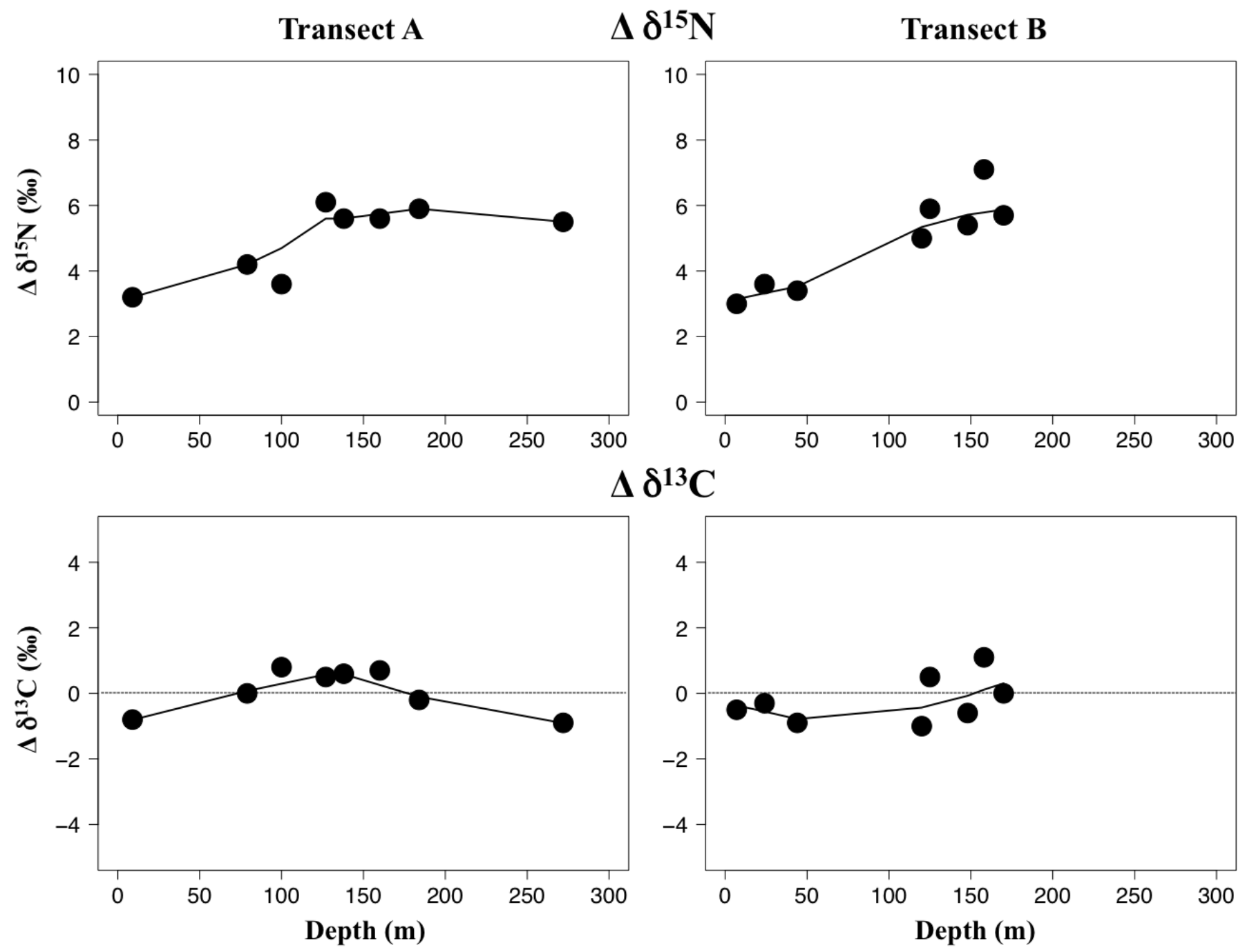

Figure 3 


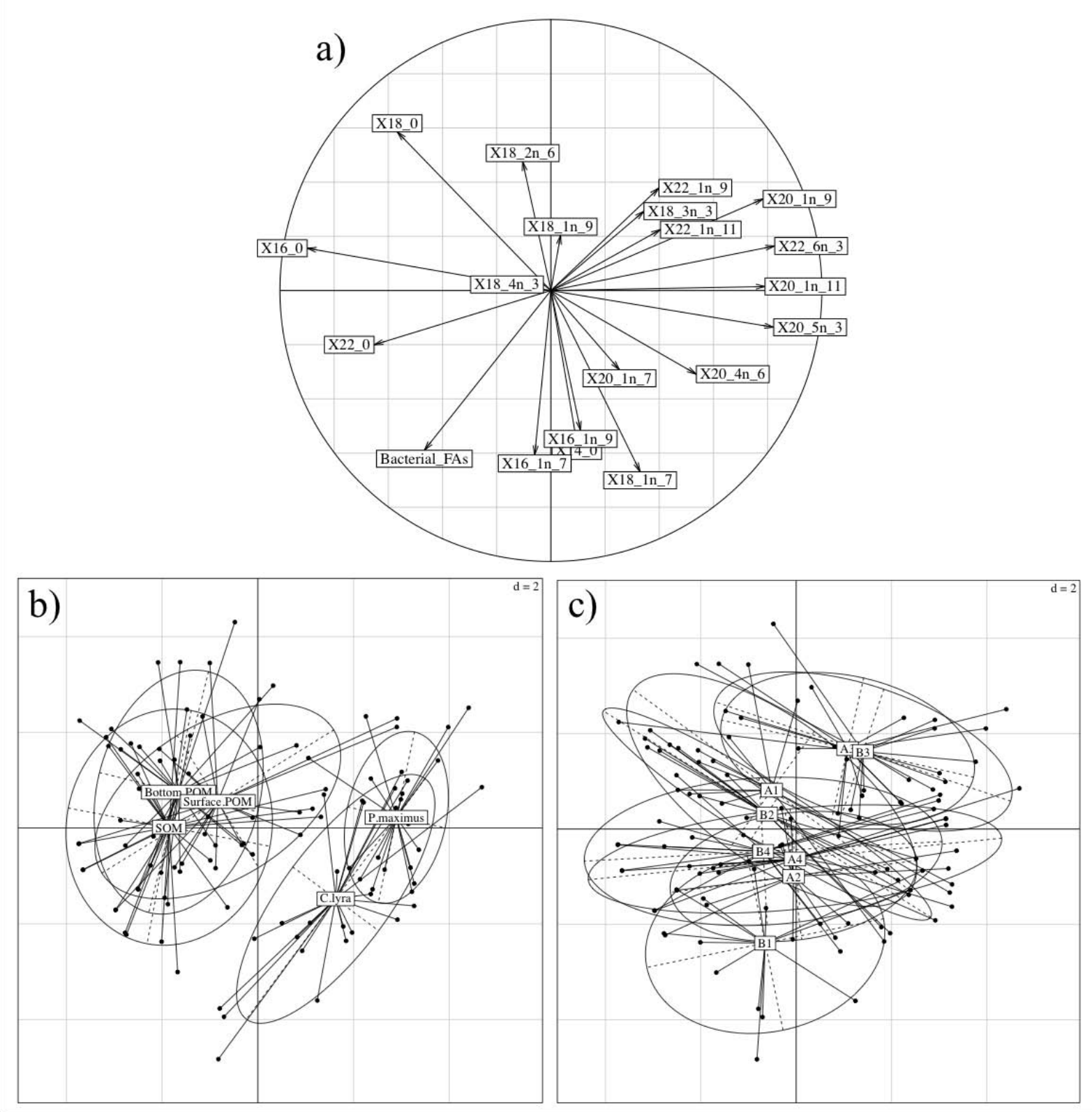

Figure 4 
Transect A
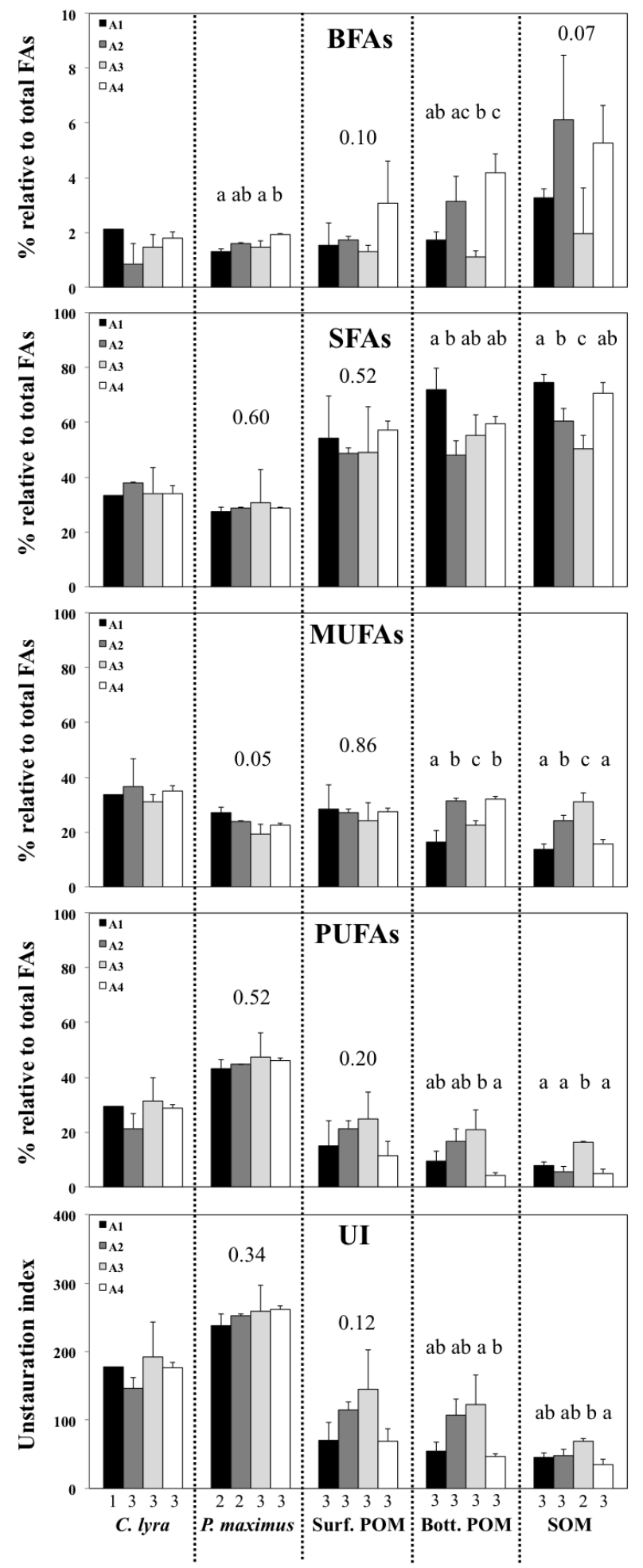

Transect B

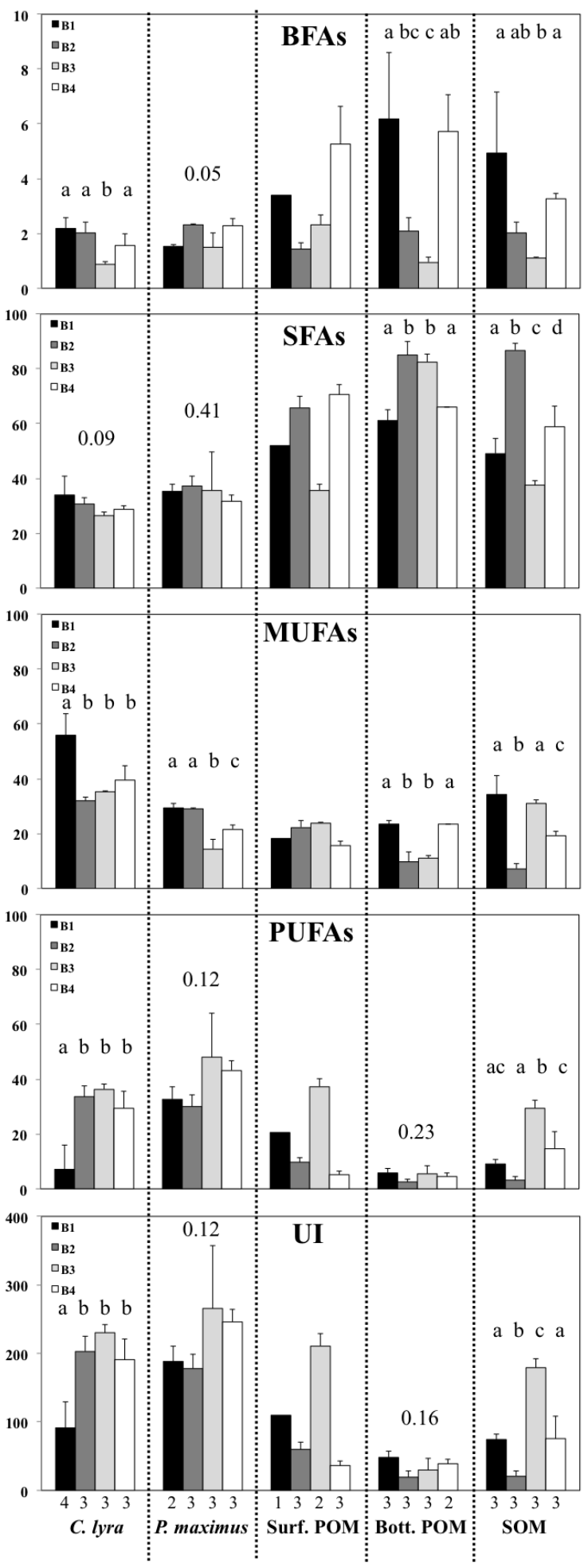

Figure 5 
Transect A

C. lyra

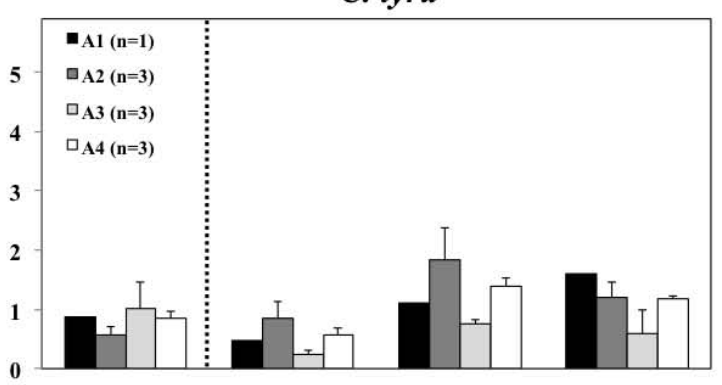

P. maximus

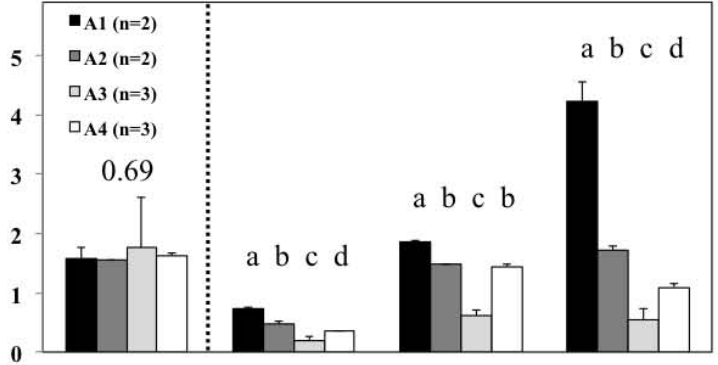

Surface POM

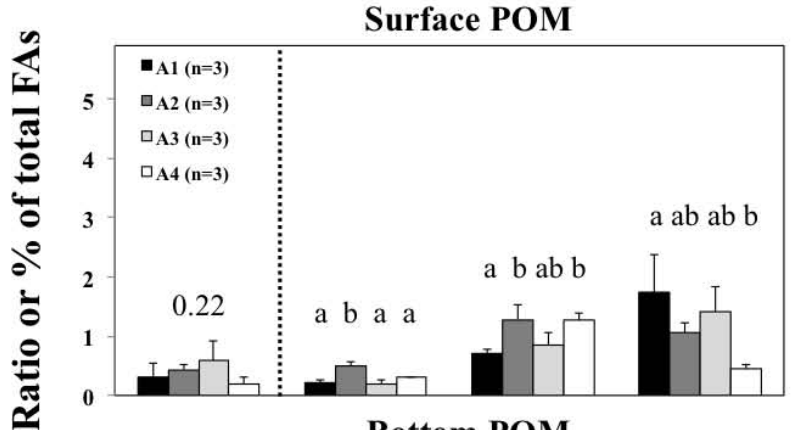

Bottom POM

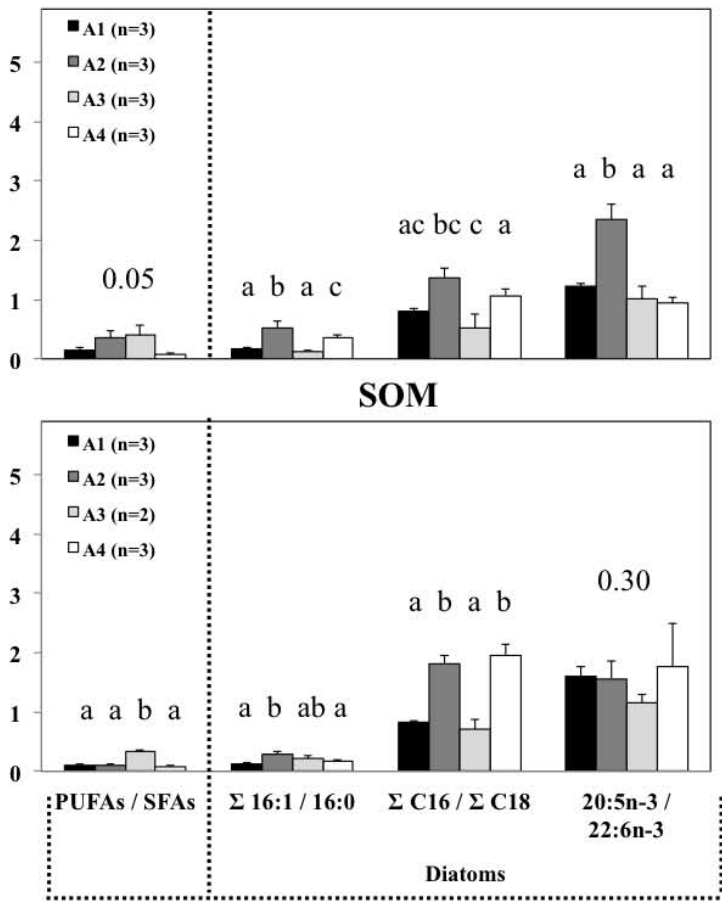

Transect B

C. lyra

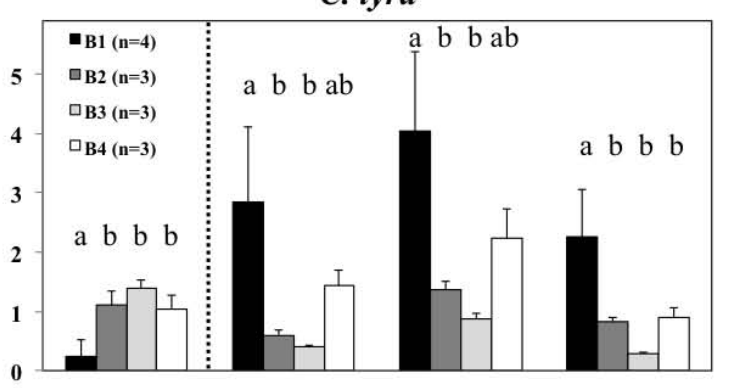

P. maximus

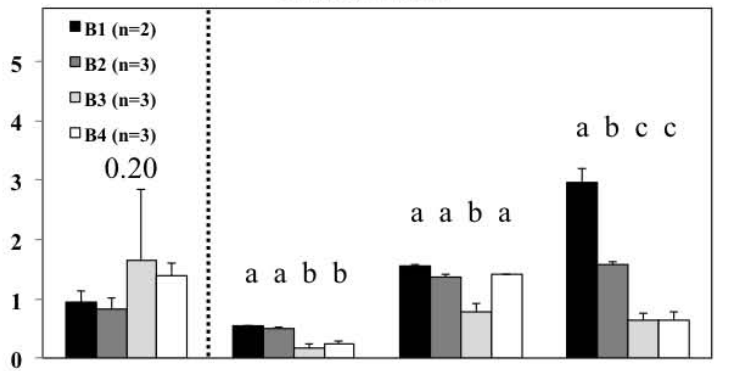

Surface POM

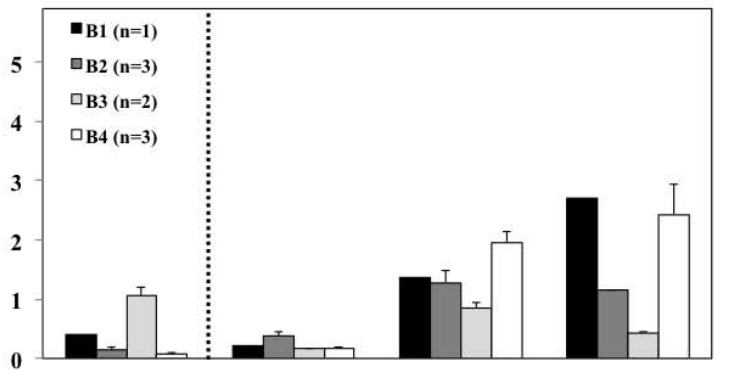

Bottom POM

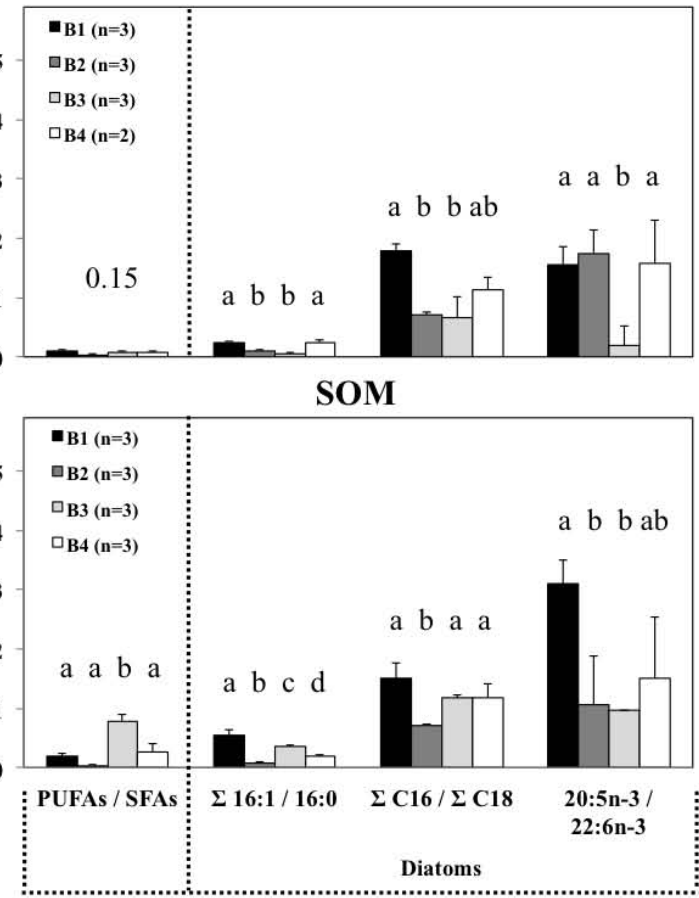

Figure 6 
Transect A

C. lyra
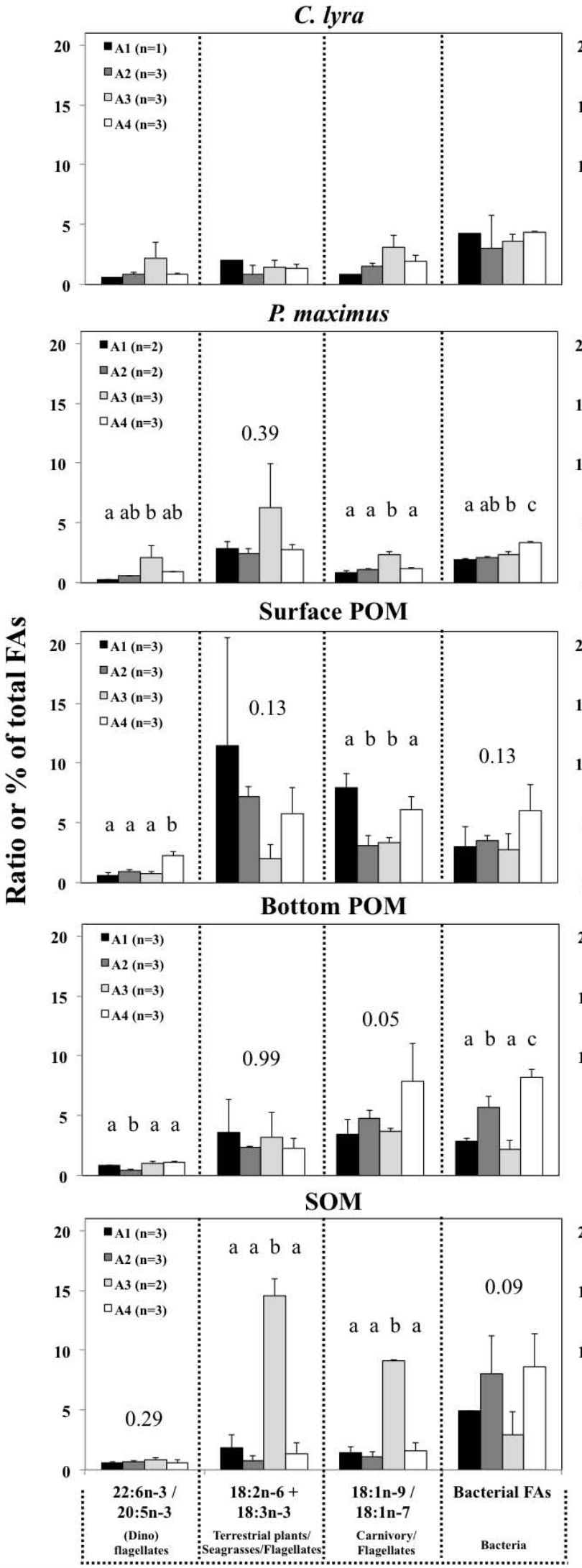

Transect B

C. lyra

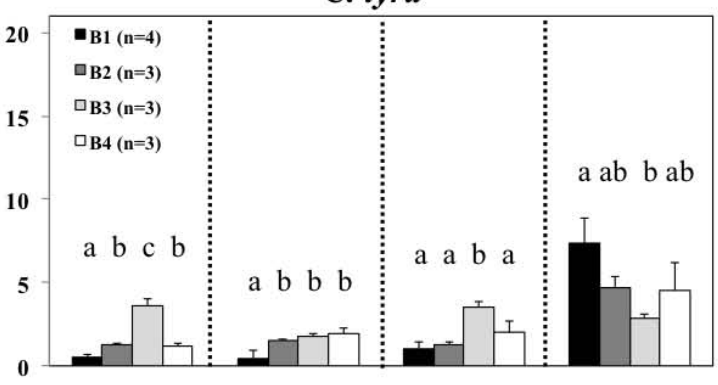

P. maximus

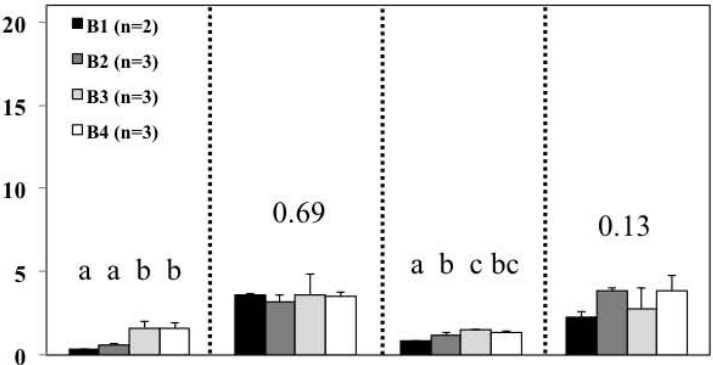

Surface POM
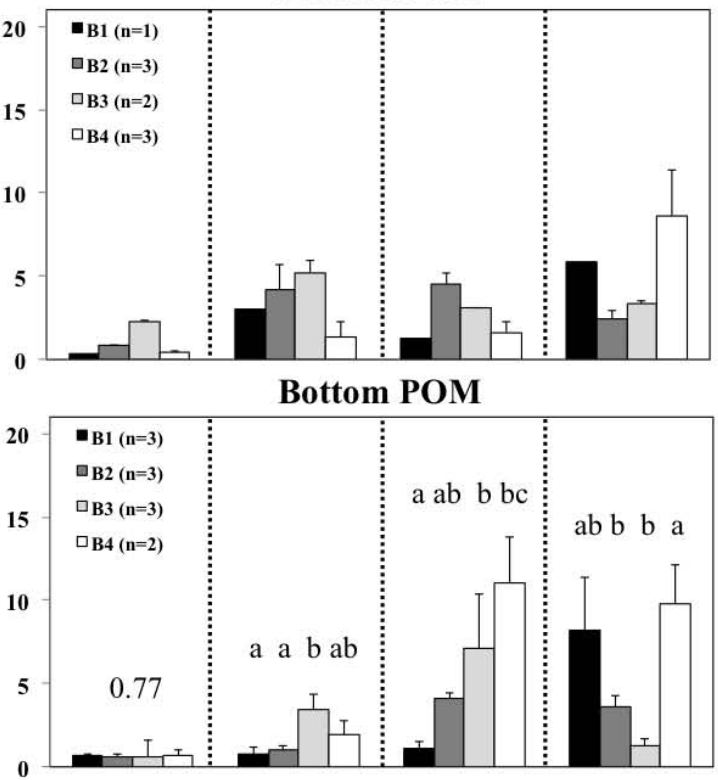

SOM

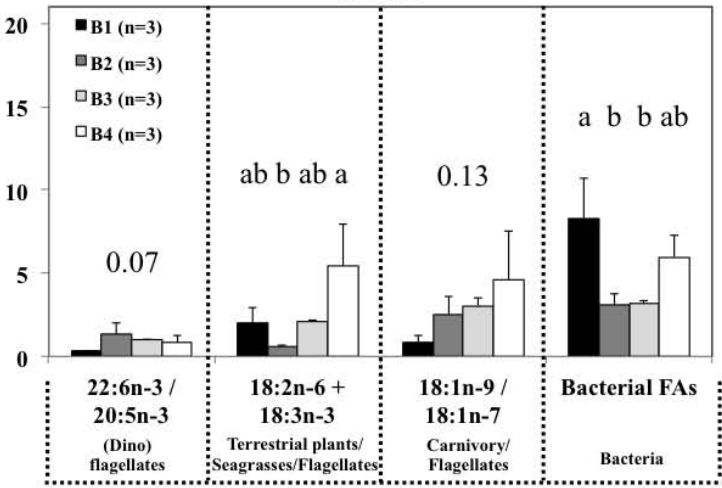

Figure 7 


\section{Supplemental material}

Table 1.a. Relative percentage (\%) of fatty acids (FAs) at concentration $\geq 1 \%$ relative to total $F A s$ in at least one sample over the whole dataset, and used for the calculation of total branched FAs (BFAs), saturated FAs (SFAs), monounsaturated FAs (MUFAs), polyunsaturated FAs (PUFAs) and unstauration index (UI) (Fig. 5) for the " source » compartments sampled in transect A. FA compositions reported and analysed in the present study only correspond to the neutral lipid fraction (see text). In bold = FAs used in the PCA (Fig. 4) and/or as trophic markers (Table 2 and Figs. 6 and 7). Values are mean \pm standard deviation. $n=$ number of samples.

\begin{tabular}{|c|c|c|c|c|c|c|c|c|c|c|c|c|}
\hline \multirow[b]{3}{*}{ Fatty acid(s) } & \multicolumn{12}{|c|}{ Transect A } \\
\hline & \multicolumn{4}{|c|}{ Surface POM } & \multicolumn{4}{|c|}{ Bottom POM } & \multicolumn{4}{|c|}{ SOM } \\
\hline & $\begin{array}{c}A 1 \\
(n=3)\end{array}$ & $\underset{(n=3)}{A 2}$ & $\begin{array}{c}\text { A3 } \\
(n=3)\end{array}$ & $\begin{array}{c}\mathrm{A} 4 \\
(n=3)\end{array}$ & $\begin{array}{c}A 1 \\
(n=3)\end{array}$ & $\underset{(n=3)}{A 2}$ & $\begin{array}{c}\text { A3 } \\
(n=3)\end{array}$ & $\begin{array}{c}\text { A4 } \\
(n=3)\end{array}$ & $\begin{array}{c}A 1 \\
(n=3)\end{array}$ & $\underset{(n=3)}{A 2}$ & $\begin{array}{c}\text { A3 } \\
(n=2)\end{array}$ & $\begin{array}{c}\text { A4 } \\
(n=3)\end{array}$ \\
\hline 15:0 iso & $0.1 \pm 0.1$ & $0.0 \pm 0.0$ & $0.0 \pm 0.0$ & $0.6 \pm 1.0$ & $0.1 \pm 0.1$ & $0.0 \pm 0.0$ & $0.0 \pm 0.0$ & $0.5 \pm 0.9$ & $0.0 \pm 0.1$ & $0.3 \pm 0.3$ & $0.2 \pm 0.3$ & $0.5 \pm 0.4$ \\
\hline 15:0 anteiso & $0.3 \pm 0.2$ & $0.7 \pm 0.0$ & $0.1 \pm 0.1$ & $0.8 \pm 0.2$ & $0.3 \pm 0.1$ & $1.5 \pm 1.3$ & $0.0 \pm 0.0$ & $1.0 \pm 0.2$ & $1.3 \pm 0.2$ & $3.2 \pm 2.0$ & $0.3 \pm 0.1$ & $1.8 \pm 0.5$ \\
\hline $16: 0$ iso & $0.2 \pm 0.2$ & $0.2 \pm 0.1$ & $0.1 \pm 0.2$ & $0.5 \pm 0.2$ & $0.2 \pm 0.2$ & $0.2 \pm 0.3$ & $0.0 \pm 0.0$ & $0.7 \pm 0.1$ & $0.6 \pm 0.1$ & $1.1 \pm 0.3$ & $0.5 \pm 0.7$ & $1.1 \pm 0.2$ \\
\hline $17: 0$ iso & $1.0 \pm 0.6$ & $0.8 \pm 0.0$ & $1.1 \pm 0.1$ & $1.1 \pm 0.3$ & $1.2 \pm 0.3$ & $1.5 \pm 0.4$ & $1.1 \pm 0.2$ & $1.9 \pm 0.1$ & $1.4 \pm 0.1$ & $1.6 \pm 0.1$ & $0.9 \pm 0.5$ & $1.9 \pm 0.3$ \\
\hline Total BFAs & $1.5 \pm 0.8$ & $1.7 \pm 0.1$ & $1.3 \pm 0.2$ & $3.1 \pm 1.6$ & $1.7 \pm 0.3$ & $3.1 \pm 0.9$ & $1.1 \pm 0.2$ & $4.2 \pm 0.7$ & $3.3 \pm 0.3$ & $6.1 \pm 2.4$ & $2.0 \pm 1.7$ & $5.3 \pm 1.4$ \\
\hline $12: 0$ & $0.0 \pm 0.0$ & $1.3 \pm 1.2$ & $0.0 \pm 0.0$ & $0.0 \pm 0.0$ & $0.0 \pm 0.0$ & $0.0 \pm 0.1$ & $0.0 \pm 0.0$ & $0.1 \pm 0.1$ & $0.0 \pm 0.0$ & $0.2 \pm 0.3$ & $0.0 \pm 0.0$ & $0.0 \pm 0.0$ \\
\hline $13: 0$ & $0.0 \pm 0.0$ & $0.4 \pm 0.5$ & $0.0 \pm 0.0$ & $0.0 \pm 0.0$ & $0.0 \pm 0.0$ & $0.1 \pm 0.1$ & $0.2 \pm 0.4$ & $0.0 \pm 0.0$ & $0.1 \pm 0.1$ & $0.2 \pm 0.2$ & $0.0 \pm 0.0$ & $0.2 \pm 0.2$ \\
\hline 14:0 & $3.6 \pm 0.3$ & $11.4 \pm 1.5$ & $3.3 \pm 2.4$ & $15.3 \pm 1.7$ & $4.3 \pm 0.3$ & $7.2 \pm 0.8$ & $0.5 \pm 0.4$ & $4.3 \pm 0.2$ & $2.5 \pm 0.3$ & $5.7 \pm 0.6$ & $0.8 \pm 0.2$ & $5.1 \pm 1.4$ \\
\hline $15: 0$ & $0.7 \pm 0.4$ & $1.4 \pm 0.3$ & $0.6 \pm 0.5$ & $2.1 \pm 0.4$ & $0.7 \pm 0.1$ & $1.5 \pm 1.4$ & $0.3 \pm 0.3$ & $3.0 \pm 0.4$ & $0.9 \pm 0.1$ & $1.0 \pm 1.7$ & $0.8 \pm 0.4$ & $3.0 \pm 0.8$ \\
\hline $16: 0$ & $29.4 \pm 2.0$ & $25.7 \pm 1.6$ & $25.3 \pm 4.1$ & $30.0 \pm 1.5$ & $31.8 \pm 1.8$ & $26.0 \pm 2.8$ & $21.0 \pm 5.5$ & $29.8 \pm 2.3$ & $\begin{array}{c}31.7 \pm \\
1.2\end{array}$ & $\begin{array}{c}34.2 \pm \\
2.8\end{array}$ & $\begin{array}{c}29.9 \pm \\
1.9\end{array}$ & $\begin{array}{c}39.8 \pm \\
2.3\end{array}$ \\
\hline $17: 0$ & $0.8 \pm 0.4$ & $0.4 \pm 0.1$ & $0.9 \pm 0.8$ & $0.9 \pm 0.3$ & $0.4 \pm 0.3$ & $1.0 \pm 0.5$ & $0.7 \pm 0.6$ & $1.0 \pm 0.7$ & $0.8 \pm 0.3$ & $1.0 \pm 0.3$ & $0.2 \pm 0.2$ & $0.3 \pm 0.6$ \\
\hline $18: 0$ & $19.1 \pm 12.3$ & $6.9 \pm 2.4$ & $18.2 \pm 16.8$ & $7.2 \pm 0.7$ & $33.9 \pm 6.4$ & $9.7 \pm 1.6$ & $31.4 \pm 13.2$ & $18.7 \pm 1.6$ & $\begin{array}{c}35.0 \pm \\
2.4\end{array}$ & $\begin{array}{c}12.5 \pm \\
1.9\end{array}$ & $\begin{array}{c}16.4 \pm \\
6.9\end{array}$ & $\begin{array}{c}15.1 \pm \\
2.3\end{array}$ \\
\hline $20: 0$ & $0.5 \pm 0.2$ & $0.3 \pm 0.0$ & $0.2 \pm 0.2$ & $0.5 \pm 0.1$ & $0.6 \pm 0.1$ & $0.6 \pm 0.1$ & $0.9 \pm 0.5$ & $0.9 \pm 0.0$ & $1.4 \pm 0.2$ & $1.3 \pm 0.1$ & $0.7 \pm 0.2$ & $1.6 \pm 0.2$ \\
\hline 22:0 & $0.2 \pm 0.1$ & $0.2 \pm 0.0$ & $0.1 \pm 0.1$ & $0.3 \pm 0.1$ & $0.2 \pm 0.0$ & $0.5 \pm 0.0$ & $0.1 \pm 0.1$ & $0.6 \pm 0.1$ & $1.4 \pm 0.3$ & $2.4 \pm 0.5$ & $0.9 \pm 0.1$ & $3.0 \pm 1.0$ \\
\hline $23: 0$ & $0.1 \pm 0.1$ & $0.3 \pm 0.2$ & $0.1 \pm 0.1$ & $0.3 \pm 0.1$ & $0.0 \pm 0.0$ & $0.6 \pm 0.5$ & $0.0 \pm 0.0$ & $0.2 \pm 0.3$ & $0.2 \pm 0.0$ & $0.8 \pm 0.1$ & $0.4 \pm 0.1$ & $1.0 \pm 0.2$ \\
\hline $24: 0$ & $0.0 \pm 0.1$ & $0.3 \pm 0.0$ & $0.1 \pm 0.1$ & $0.5 \pm 0.1$ & $0.1 \pm 0.1$ & $0.7 \pm 0.1$ & $0.0 \pm 0.0$ & $0.9 \pm 0.1$ & $0.5 \pm 0.0$ & $1.3 \pm 0.2$ & $0.3 \pm 0.0$ & $1.4 \pm 0.2$ \\
\hline Total SFAs & $54.4 \pm 15.2$ & $48.6 \pm 2.1$ & $48.9 \pm 16.8$ & $57.1 \pm 3.3$ & $71.9 \pm 7.8$ & $48.0 \pm 5.1$ & $55.1 \pm 7.7$ & $59.4 \pm 2.8$ & $\begin{array}{c}74.4 \pm \\
3.1\end{array}$ & $\begin{array}{c}60.6 \pm \\
4.4\end{array}$ & $\begin{array}{c}50.4 \pm \\
4.9\end{array}$ & $\begin{array}{c}70.7 \pm \\
3.8\end{array}$ \\
\hline $14: 1 n-9$ & $0.2 \pm 0.3$ & $0.3 \pm 0.6$ & $0.3 \pm 0.2$ & $1.2 \pm 1.0$ & $0.4 \pm 0.1$ & $1.3 \pm 0.2$ & $0.0 \pm 0.0$ & $1.1 \pm 1.0$ & $0.8 \pm 0.1$ & $1.9 \pm 0.3$ & $0.0 \pm 0.0$ & $1.3 \pm 0.2$ \\
\hline $16: 1 n-7$ & $4.9 \pm 2.3$ & $10.5 \pm 2.2$ & $4.1 \pm 1.8$ & $5.4 \pm 0.5$ & $4.1 \pm 0.7$ & $4.7 \pm 1.1$ & $2.0 \pm 0.9$ & $8.3 \pm 0.8$ & $3.6 \pm 0.3$ & $7.7 \pm 0.5$ & $3.1 \pm 0.7$ & $4.5 \pm 1.0$ \\
\hline $16: 1 n-9$ & $1.3 \pm 1.1$ & $2.6 \pm 0.1$ & $0.7 \pm 0.4$ & $3.6 \pm 1.1$ & $1.4 \pm 0.5$ & $9.0 \pm 0.7$ & $0.7 \pm 0.4$ & $2.0 \pm 1.9$ & $0.6 \pm 0.1$ & $2.1 \pm 0.9$ & $3.4 \pm 1.2$ & $2.0 \pm 0.2$ \\
\hline $18: 1 n-7$ & $2.2 \pm 1.0$ & $3.1 \pm 0.3$ & $3.4 \pm 1.1$ & $2.3 \pm 0.2$ & $1.7 \pm 0.4$ & $2.5 \pm 0.4$ & $3.0 \pm 0.1$ & $1.8 \pm 0.6$ & $2.7 \pm 0.2$ & $5.2 \pm 0.5$ & $2.2 \pm 0.1$ & $3.0 \pm 1.1$ \\
\hline $18: 1 n-9$ & $17.0 \pm 5.7$ & $9.3 \pm 1.4$ & $11.2 \pm 2.7$ & $14.2 \pm 1.4$ & $6.4 \pm 3.9$ & $11.5 \pm 0.3$ & $11.2 \pm 0.8$ & $13.1 \pm 0.7$ & $4.0 \pm 1.4$ & $5.6 \pm 1.5$ & $\begin{array}{c}20.2 \pm \\
0.8\end{array}$ & $4.5 \pm 0.5$ \\
\hline $18: 1 n-11$ & $0.4 \pm 0.2$ & $0.2 \pm 0.3$ & $1.4 \pm 0.2$ & $0.3 \pm 0.0$ & $0.6 \pm 0.1$ & $0.3 \pm 0.3$ & $1.2 \pm 0.2$ & $2.5 \pm 1.0$ & $0.8 \pm 0.2$ & $0.4 \pm 0.4$ & $0.3 \pm 0.1$ & $0.3 \pm 0.3$ \\
\hline
\end{tabular}




\begin{tabular}{|c|c|c|c|c|c|c|c|c|c|c|c|c|}
\hline $20: 1 n-7$ & $0.1 \pm 0.1$ & $0.0 \pm 0.0$ & $0.2 \pm 0.2$ & $0.0 \pm 0.0$ & $0.0 \pm 0.1$ & $0.2 \pm 0.3$ & $0.3 \pm 0.3$ & $2.9 \pm 1.0$ & $0.2 \pm 0.2$ & $0.3 \pm 0.3$ & $0.1 \pm 0.1$ & $0.1 \pm 0.1$ \\
\hline $20: 1 n-9$ & $1.2 \pm 0.9$ & $0.5 \pm 0.2$ & $0.8 \pm 0.2$ & $0.3 \pm 0.3$ & $0.4 \pm 0.3$ & $1.1 \pm 0.2$ & $1.1 \pm 0.5$ & $0.0 \pm 0.0$ & $0.3 \pm 0.1$ & $0.4 \pm 0.2$ & $0.9 \pm 0.2$ & $0.1 \pm 0.2$ \\
\hline $20: 1 n-11$ & $0.5 \pm 0.4$ & $0.0 \pm 0.0$ & $1.4 \pm 1.2$ & $0.0 \pm 0.0$ & $1.0 \pm 0.8$ & $0.0 \pm 0.0$ & $1.7 \pm 0.4$ & $0.2 \pm 0.3$ & $0.5 \pm 0.2$ & $0.6 \pm 0.5$ & $0.2 \pm 0.2$ & $0.0 \pm 0.0$ \\
\hline 22:1n-9 & $0.2 \pm 0.1$ & $0.1 \pm 0.0$ & $0.2 \pm 0.1$ & $0.0 \pm 0.0$ & $0.1 \pm 0.0$ & $0.1 \pm 0.1$ & $0.3 \pm 0.3$ & $0.0 \pm 0.0$ & $0.2 \pm 0.1$ & $0.0 \pm 0.0$ & $0.2 \pm 0.0$ & $0.0 \pm 0.0$ \\
\hline $22: 1 n-11$ & $0.4 \pm 0.4$ & $0.3 \pm 0.1$ & $0.5 \pm 0.5$ & $0.0 \pm 0.0$ & $0.1 \pm 0.2$ & $0.8 \pm 0.1$ & $0.8 \pm 0.8$ & $0.0 \pm 0.0$ & $0.0 \pm 0.1$ & $0.1 \pm 0.1$ & $0.6 \pm 0.1$ & $0.0 \pm 0.0$ \\
\hline Total MUFAs & $28.4 \pm 8.8$ & $27.0 \pm 1.3$ & $24.1 \pm 6.7$ & $27.3 \pm 1.6$ & $16.3 \pm 4.2$ & $31.4 \pm 1.1$ & $22.4 \pm 1.7$ & $31.9 \pm 1.2$ & $\begin{array}{c}13.7 \pm \\
1.9\end{array}$ & $\begin{array}{c}24.3 \pm \\
1.7\end{array}$ & $\begin{array}{c}31.0 \pm \\
3.1\end{array}$ & $\begin{array}{c}15.8 \pm \\
1.6\end{array}$ \\
\hline $18: 2 n-6$ & $9.7 \pm 8.1$ & $3.1 \pm 0.3$ & $1.7 \pm 1.4$ & $3.4 \pm 0.9$ & $2.7 \pm 2.5$ & $1.6 \pm 0.2$ & $2.3 \pm 1.5$ & $1.4 \pm 0.1$ & $1.5 \pm 0.9$ & $0.7 \pm 0.3$ & $\begin{array}{c}13.4 \pm \\
1.5\end{array}$ & $1.0 \pm 0.6$ \\
\hline $\begin{array}{l}18: 3 n-3 \\
18: 4 n-3\end{array}$ & $\begin{array}{l}1.8 \pm 1.0 \\
0.4 \pm 0.4\end{array}$ & $\begin{array}{l}4.1 \pm 0.8 \\
4.1 \pm 0.8\end{array}$ & $\begin{array}{l}0.3 \pm 0.2 \\
1.1 \pm 0.5\end{array}$ & $\begin{array}{l}2.4 \pm 1.2 \\
1.4 \pm 1.2\end{array}$ & $\begin{array}{l}0.9 \pm 0.3 \\
0.4 \pm 0.7\end{array}$ & $\begin{array}{l}0.7 \pm 0.2 \\
2.8 \pm 0.8\end{array}$ & $\begin{array}{l}0.9 \pm 0.6 \\
0.8 \pm 0.7\end{array}$ & $\begin{array}{l}1.0 \pm 0.8 \\
0.0 \pm 0.0\end{array}$ & $\begin{array}{l}0.3 \pm 0.3 \\
0.0 \pm 0.0\end{array}$ & $\begin{array}{l}0.1 \pm 0.1 \\
0.2 \pm 0.3\end{array}$ & $\begin{array}{l}1.2 \pm 0.1 \\
0.1 \pm 0.2\end{array}$ & $\begin{array}{l}0.3 \pm 0.3 \\
0.2 \pm 0.4\end{array}$ \\
\hline $20: 2 n-6$ & $0.2 \pm 0.2$ & $0.1 \pm 0.1$ & $0.3 \pm 0.3$ & $0.0 \pm 0.0$ & $0.0 \pm 0.1$ & $0.0 \pm 0.0$ & $0.0 \pm 0.0$ & $0.0 \pm 0.0$ & $0.4 \pm 0.0$ & $0.4 \pm 0.4$ & $0.2 \pm 0.3$ & $0.5 \pm 0.5$ \\
\hline $20: 3 n-3$ & $0.1 \pm 0.1$ & $0.1 \pm 0.0$ & $0.2 \pm 0.2$ & $0.3 \pm 0.2$ & $0.0 \pm 0.0$ & $0.1 \pm 0.1$ & $0.1 \pm 0.2$ & $0.5 \pm 0.5$ & $0.0 \pm 0.0$ & $0.0 \pm 0.0$ & $0.0 \pm 0.0$ & $0.0 \pm 0.0$ \\
\hline $20: 4 n-3$ & $0.2 \pm 0.2$ & $0.3 \pm 0.0$ & $0.8 \pm 0.7$ & $0.1 \pm 0.1$ & $0.1 \pm 0.0$ & $0.1 \pm 0.1$ & $0.4 \pm 0.4$ & $0.0 \pm 0.0$ & $0.1 \pm 0.1$ & $0.0 \pm 0.0$ & $0.0 \pm 0.1$ & $0.0 \pm 0.0$ \\
\hline $20: 4 n-6$ & $0.1 \pm 0.0$ & $0.4 \pm 0.0$ & $1.4 \pm 0.4$ & $0.2 \pm 0.1$ & $0.2 \pm 0.0$ & $0.6 \pm 0.1$ & $1.1 \pm 0.3$ & $0.0 \pm 0.0$ & $1.8 \pm 0.8$ & $1.1 \pm 0.2$ & $0.2 \pm 0.0$ & $0.8 \pm 0.1$ \\
\hline $20: 5 n-3$ & $1.3 \pm 0.4$ & $4.5 \pm 0.8$ & $9.4 \pm 4.7$ & $1.0 \pm 0.6$ & $2.6 \pm 0.3$ & $7.3 \pm 2.6$ & $6.6 \pm 3.5$ & $0.7 \pm 0.2$ & $2.0 \pm 0.3$ & $1.8 \pm 0.7$ & $0.5 \pm 0.1$ & $1.3 \pm 0.9$ \\
\hline $22: 5 n-3$ & $0.4 \pm 0.3$ & $0.3 \pm 0.1$ & $3.1 \pm 1.5$ & $0.2 \pm 0.1$ & $0.1 \pm 0.1$ & $0.1 \pm 0.1$ & $2.3 \pm 1.4$ & $0.1 \pm 0.1$ & $0.4 \pm 0.1$ & $0.2 \pm 0.1$ & $0.1 \pm 0.2$ & $0.1 \pm 0.1$ \\
\hline $22: 6 n-3$ & $0.8 \pm 0.3$ & $4.3 \pm 0.7$ & $6.6 \pm 3.0$ & $2.3 \pm 1.2$ & $2.2 \pm 0.1$ & $3.1 \pm 1.1$ & $6.5 \pm 3.2$ & $0.7 \pm 0.3$ & $1.2 \pm 0.3$ & $1.2 \pm 0.6$ & $0.5 \pm 0.2$ & $0.7 \pm 0.2$ \\
\hline Total PUFAs & $15.0 \pm 9.3$ & $21.2 \pm 2.8$ & $24.8 \pm 9.8$ & $11.3 \pm 5.1$ & $9.3 \pm 3.5$ & $16.5 \pm 4.8$ & $21.0 \pm 7.2$ & $4.3 \pm 0.9$ & $7.6 \pm 1.5$ & $5.6 \pm 1.7$ & $\begin{array}{c}16.2 \pm \\
0.4\end{array}$ & $4.9 \pm 1.4$ \\
\hline UI & $70.0 \pm 26.3$ & $114.6 \pm 12.6$ & $\begin{array}{c}144.5 \pm \\
58.6\end{array}$ & $\begin{array}{c}69.0 \pm \\
18.7\end{array}$ & $\begin{array}{c}54.4 \pm \\
13.0\end{array}$ & $106.8 \pm 23.2$ & $\begin{array}{c}122.7 \pm \\
43.3\end{array}$ & $47.0 \pm 3.3$ & $\begin{array}{c}44.8 \pm \\
7.6\end{array}$ & $\begin{array}{c}48.7 \pm \\
9.2\end{array}$ & $\begin{array}{c}69.1 \pm \\
4.5\end{array}$ & $\begin{array}{c}34.8 \pm \\
8.2\end{array}$ \\
\hline
\end{tabular}


Table 1.b. Relative percentage (\%) of fatty acids (FAs) at concentration $\geq 1 \%$ relative to total FAs in at least one sample over the whole dataset, and used for the calculation of total branched FAs (BFAs), saturated FAs (SFAs), monounsaturated FAs (MUFAs), polyunsaturated FAs (PUFAs) and unstauration index (UI) (Fig. 5) for consumers sampled in transect A. FA compositions reported and analysed in the present study only correspond to the neutral lipid fraction (see text). In bold = FAs used in the PCA (Fig. 4) and/or as trophic markers (Table 2 and Figs. 6 and 7 ). Values are mean \pm standard deviation. $n=$ number of samples.

\begin{tabular}{|c|c|c|c|c|c|c|c|c|}
\hline \multirow[b]{3}{*}{ Fatty acid(s) } & \multicolumn{8}{|c|}{ Transect A } \\
\hline & \multicolumn{4}{|c|}{ Pecten maximus } & \multicolumn{4}{|c|}{ Callionymus lyra } \\
\hline & $\underset{(n=2)}{A 1}$ & $\underset{(n=2)}{A 2}$ & $\begin{array}{c}\text { A3 } \\
(n=3)\end{array}$ & $\underset{(n=3)}{A 4}$ & $\underset{(n=1)}{A 1}$ & $\underset{(n=3)}{A 2}$ & $\begin{array}{c}A 3 \\
(n=3)\end{array}$ & $\underset{(n=3)}{A 4}$ \\
\hline $15: 0$ iso & $0.0 \pm 0.0$ & $0.0 \pm 0.0$ & $0.0 \pm 0.0$ & $0.0 \pm 0.0$ & 0.0 & $0.0 \pm 0.0$ & $0.0 \pm 0.0$ & $0.0 \pm 0.0$ \\
\hline $15: 0$ anteiso & $0.1 \pm 0.0$ & $0.2 \pm 0.0$ & $0.1 \pm 0.0$ & $0.3 \pm 0.0$ & 0.2 & $0.0 \pm 0.0$ & $0.1 \pm 0.0$ & $0.2 \pm 0.2$ \\
\hline $16: 0$ iso & $0.2 \pm 0.0$ & $0.2 \pm 0.0$ & $0.2 \pm 0.1$ & $0.3 \pm 0.0$ & 0.7 & $0.2 \pm 0.3$ & $0.3 \pm 0.1$ & $0.7 \pm 0.1$ \\
\hline $17: 0$ iso & $1.0 \pm 0.1$ & $1.2 \pm 0.1$ & $1.1 \pm 0.2$ & $1.4 \pm 0.0$ & 1.3 & $0.7 \pm 0.7$ & $1.1 \pm 0.4$ & $0.9 \pm 0.2$ \\
\hline Total BFAs & $1.3 \pm 0.1$ & $1.6 \pm 0.0$ & $1.5 \pm 0.2$ & $1.9 \pm 0.0$ & 2.1 & $0.9 \pm 0.8$ & $1.5 \pm 0.4$ & $1.8 \pm 0.2$ \\
\hline $12: 0$ & $0.0 \pm 0.1$ & $0.0 \pm 0.0$ & $0.0 \pm 0.0$ & $0.0 \pm 0.0$ & 0.1 & $0.0 \pm 0.0$ & $0.0 \pm 0.0$ & $0.0 \pm 0.0$ \\
\hline 13:0 & $0.0 \pm 0.0$ & $0.0 \pm 0.0$ & $0.0 \pm 0.0$ & $0.0 \pm 0.0$ & 0.0 & $0.0 \pm 0.0$ & $0.0 \pm 0.0$ & $0.0 \pm 0.1$ \\
\hline 14:0 & $8.6 \pm 0.7$ & $8.4 \pm 0.3$ & $0.7 \pm 0.3$ & $5.3 \pm 0.2$ & 5.4 & $9.4 \pm 1.3$ & $3.5 \pm 0.5$ & $9.0 \pm 2.9$ \\
\hline $15: 0$ & $0.4 \pm 0.0$ & $0.5 \pm 0.0$ & $0.3 \pm 0.3$ & $0.8 \pm 0.0$ & 1.0 & $1.2 \pm 1.0$ & $0.7 \pm 0.2$ & $1.3 \pm 0.2$ \\
\hline $16: 0$ & $14.8 \pm 0.9$ & $14.9 \pm 0.2$ & $14.5 \pm 4.1$ & $16.5 \pm 0.2$ & 19.6 & $20.0 \pm 4.7$ & $19.0 \pm 4.9$ & $18.0 \pm 0.2$ \\
\hline $17: 0$ & $0.2 \pm 0.0$ & $0.1 \pm 0.0$ & $0.6 \pm 0.1$ & $0.7 \pm 0.0$ & 1.1 & $1.0 \pm 0.9$ & $1.4 \pm 0.1$ & $1.3 \pm 0.2$ \\
\hline 18:0 & $3.0 \pm 0.1$ & $4.4 \pm 0.0$ & $13.7 \pm 8.3$ & $4.6 \pm 0.3$ & 5.5 & $4.4 \pm 0.9$ & $8.2 \pm 4.5$ & $3.7 \pm 0.1$ \\
\hline $20: 0$ & $0.2 \pm 0.0$ & $0.2 \pm 0.0$ & $0.3 \pm 0.1$ & $0.2 \pm 0.0$ & 0.2 & $0.1 \pm 0.1$ & $0.5 \pm 0.1$ & $0.1 \pm 0.1$ \\
\hline 22:0 & $0.1 \pm 0.0$ & $0.1 \pm 0.0$ & $0.0 \pm 0.0$ & $0.1 \pm 0.0$ & 0.1 & $0.2 \pm 0.3$ & $0.2 \pm 0.0$ & $0.0 \pm 0.0$ \\
\hline $23: 0$ & $0.0 \pm 0.0$ & $0.0 \pm 0.0$ & $0.1 \pm 0.2$ & $0.0 \pm 0.0$ & 0.0 & $0.2 \pm 0.3$ & $0.2 \pm 0.0$ & $0.0 \pm 0.0$ \\
\hline $24: 0$ & $0.2 \pm 0.0$ & $0.3 \pm 0.0$ & $0.5 \pm 0.0$ & $0.4 \pm 0.0$ & 0.3 & $1.5 \pm 2.5$ & $0.4 \pm 0.1$ & $0.6 \pm 0.3$ \\
\hline Total SFAs & $27.5 \pm 1.4$ & $28.9 \pm 0.0$ & $30.8 \pm 12.1$ & $28.6 \pm 0.6$ & 33.4 & $37.9 \pm 0.3$ & $34.1 \pm 9.4$ & $34.0 \pm 3.0$ \\
\hline $14: 1 n-9$ & $0.2 \pm 0.0$ & $0.2 \pm 0.0$ & $0.0 \pm 0.0$ & $0.4 \pm 0.0$ & 0.5 & $0.8 \pm 0.7$ & $0.3 \pm 0.0$ & $0.3 \pm 0.3$ \\
\hline $16: 1 n-7$ & $10.5 \pm 0.5$ & $6.6 \pm 0.4$ & $2.2 \pm 0.5$ & $5.5 \pm 0.0$ & 0.5 & $8.0 \pm 5.5$ & $0.2 \pm 0.2$ & $3.3 \pm 1.5$ \\
\hline $16: 1 n-9$ & $0.2 \pm 0.3$ & $0.4 \pm 0.0$ & $0.3 \pm 0.1$ & $0.3 \pm 0.0$ & 8.6 & $10.0 \pm 3.9$ & $4.2 \pm 0.5$ & $7.1 \pm 0.6$ \\
\hline $18: 1 n-7$ & $4.2 \pm 0.2$ & $3.7 \pm 0.4$ & $2.2 \pm 0.2$ & $3.7 \pm 0.3$ & 10.0 & $5.7 \pm 1.0$ & $4.7 \pm 0.6$ & $5.1 \pm 0.4$ \\
\hline $18: 1 n-9$ & $3.5 \pm 0.4$ & $4.1 \pm 0.0$ & $5.2 \pm 1.1$ & $4.4 \pm 0.1$ & 8.5 & $8.8 \pm 2.1$ & $14.0 \pm 2.9$ & $10.1 \pm 3.0$ \\
\hline $18: 1 n-11$ & $0.3 \pm 0.0$ & $0.2 \pm 0.0$ & $0.3 \pm 0.0$ & $0.3 \pm 0.0$ & 0.7 & $1.0 \pm 0.9$ & $1.1 \pm 1.0$ & $0.6 \pm 0.1$ \\
\hline $20: 1 n-7$ & $0.6 \pm 0.1$ & $0.7 \pm 0.2$ & $0.5 \pm 0.1$ & $0.6 \pm 0.1$ & 1.1 & $0.5 \pm 0.4$ & $0.4 \pm 0.0$ & $0.5 \pm 0.1$ \\
\hline $20: 1 n-9$ & $0.6 \pm 0.1$ & $0.9 \pm 0.2$ & $2.4 \pm 0.2$ & $1.6 \pm 0.1$ & 0.6 & $0.5 \pm 0.5$ & $1.3 \pm 0.2$ & $2.2 \pm 1.3$ \\
\hline $20: 1 n-11$ & $6.8 \pm 1.3$ & $6.9 \pm 0.6$ & $5.6 \pm 2.1$ & $4.9 \pm 0.4$ & 3.0 & $1.4 \pm 1.2$ & $3.1 \pm 0.1$ & $2.3 \pm 0.7$ \\
\hline 22:1n-9 & $0.1 \pm 0.0$ & $0.1 \pm 0.0$ & $0.2 \pm 0.1$ & $0.2 \pm 0.0$ & 0.2 & $0.0 \pm 0.0$ & $0.4 \pm 0.1$ & $0.4 \pm 0.5$ \\
\hline 22:1n-11 & $0.0 \pm 0.0$ & $0.0 \pm 0.0$ & $0.4 \pm 0.3$ & $0.4 \pm 0.1$ & 0.0 & $0.0 \pm 0.0$ & $1.1 \pm 0.3$ & $3.0 \pm 2.4$ \\
\hline Total MUFAs & $27.0 \pm 1.9$ & $24.0 \pm 0.1$ & $19.3 \pm 3.6$ & $22.3 \pm 0.8$ & 33.6 & $36.7 \pm 10.1$ & $30.9 \pm 2.8$ & $34.9 \pm 2.0$ \\
\hline
\end{tabular}




\begin{tabular}{|c|c|c|c|c|c|c|c|c|}
\hline $18: 2 n-6$ & $1.4 \pm 0.3$ & $1.2 \pm 0.0$ & $2.1 \pm 0.7$ & $1.3 \pm 0.1$ & 1.5 & $0.5 \pm 0.5$ & $1.2 \pm 0.5$ & $1.1 \pm 0.2$ \\
\hline $18: 3 n-3$ & $1.4 \pm 0.4$ & $1.3 \pm 0.4$ & $4.2 \pm 3.1$ & $1.5 \pm 0.3$ & 0.5 & $0.3 \pm 0.3$ & $0.2 \pm 0.1$ & $0.3 \pm 0.3$ \\
\hline $18: 4 n-3$ & $0.0 \pm 0.0$ & $0.0 \pm 0.0$ & $0.0 \pm 0.0$ & $0.0 \pm 0.0$ & 0.0 & $0.0 \pm 0.0$ & $1.9 \pm 0.3$ & $0.1 \pm 0.1$ \\
\hline $20: 2 n-6$ & $0.3 \pm 0.1$ & $0.2 \pm 0.3$ & $1.1 \pm 0.2$ & $0.0 \pm 0.0$ & 0.4 & $0.0 \pm 0.0$ & $0.7 \pm 0.1$ & $0.0 \pm 0.0$ \\
\hline $20: 3 n-3$ & $0.1 \pm 0.0$ & $0.1 \pm 0.0$ & $0.5 \pm 0.1$ & $0.2 \pm 0.0$ & 0.1 & $0.2 \pm 0.3$ & $0.3 \pm 0.0$ & $0.1 \pm 0.2$ \\
\hline $20: 4 n-3$ & $1.0 \pm 0.2$ & $0.9 \pm 0.3$ & $1.6 \pm 0.7$ & $1.1 \pm 0.2$ & 0.6 & $0.7 \pm 0.8$ & $1.0 \pm 0.1$ & $0.6 \pm 0.0$ \\
\hline $20: 4 n-6$ & $2.4 \pm 0.1$ & $1.8 \pm 0.3$ & $1.1 \pm 0.1$ & $1.2 \pm 0.2$ & 2.1 & $1.1 \pm 0.9$ & $1.6 \pm 0.1$ & $4.9 \pm 2.3$ \\
\hline $20: 5 n-3$ & $29.1 \pm 2.8$ & $24.3 \pm 1.0$ & $12.5 \pm 4.6$ & $20.7 \pm 0.4$ & 12.4 & $8.3 \pm 0.6$ & $6.7 \pm 0.7$ & $10.1 \pm 0.1$ \\
\hline $22: 5 n-3$ & $0.4 \pm 0.0$ & $0.6 \pm 0.1$ & $1.3 \pm 0.2$ & $1.2 \pm 0.1$ & 4.0 & $3.0 \pm 2.6$ & $3.1 \pm 0.8$ & $2.7 \pm 0.1$ \\
\hline $22: 6 n-3$ & $6.9 \pm 1.2$ & $14.2 \pm 0.0$ & $23.2 \pm 1.1$ & $18.9 \pm 0.9$ & 7.8 & $7.2 \pm 1.6$ & $14.7 \pm 8.0$ & $8.7 \pm 0.4$ \\
\hline Total PUFAs & $43.1 \pm 3.2$ & $44.7 \pm 0.2$ & $47.5 \pm 8.8$ & $46.1 \pm 0.8$ & 29.3 & $21.3 \pm 5.5$ & $31.5 \pm 8.4$ & $28.6 \pm 1.5$ \\
\hline UI & $237.9 \pm 17.0$ & $251.9 \pm 2.7$ & $\begin{array}{c}258.7 \pm \\
38.5\end{array}$ & $262.0 \pm 4.8$ & 178.4 & $\begin{array}{c}145.9 \pm \\
15.5\end{array}$ & $191.6 \pm 52.0$ & $176.9 \pm 8.0$ \\
\hline
\end{tabular}


Table 1.c. Relative percentage (\%) of fatty acids (FAs) at concentration $\geq 1 \%$ relative to total $F A s$ in at least one sample over the whole dataset, and used for the calculation of total branched FAs (BFAs), saturated FAs (SFAs), monounsaturated FAs (MUFAs), polyunsaturated FAs (PUFAs) and unstauration index (UI) (Fig. 5) for the " source » compartments sampled in transect B. FA compositions reported and analysed in the present study only correspond to the neutral lipid fraction (see text). In bold = FAs used in the PCA (Fig. 4) and/or as trophic markers (Table 2 and Figs. 6 and 7). Values are mean \pm standard deviation. $n=$ number of samples.

\begin{tabular}{|c|c|c|c|c|c|c|c|c|c|c|c|c|}
\hline \multirow[b]{3}{*}{ Fatty acid(s) } & \multicolumn{12}{|c|}{ Transect B } \\
\hline & \multicolumn{4}{|c|}{ Surface POM } & \multicolumn{4}{|c|}{ Bottom POM } & \multicolumn{4}{|c|}{ SOM } \\
\hline & $\begin{array}{c}B 1 \\
(n=1)\end{array}$ & $\begin{array}{c}B 2 \\
(n=3)\end{array}$ & $\begin{array}{c}\text { B3 } \\
(n=2)\end{array}$ & $\begin{array}{c}B 4 \\
(n=3)\end{array}$ & $\begin{array}{c}\text { B1 } \\
(n=3)\end{array}$ & $\begin{array}{c}B 2 \\
(n=3)\end{array}$ & $\begin{array}{c}\text { B3 } \\
(n=3)\end{array}$ & $\begin{array}{c}B 4 \\
(n=2)\end{array}$ & $\begin{array}{c}B 1 \\
(n=3)\end{array}$ & $\begin{array}{c}B 2 \\
(n=3)\end{array}$ & $\begin{array}{c}\text { B3 } \\
(n=3)\end{array}$ & $\begin{array}{c}B 4 \\
(n=3)\end{array}$ \\
\hline $\begin{array}{c}15: 0 \text { iso } \\
15: 0 \text { anteiso } \\
16: 0 \text { iso } \\
17: 0 \text { iso } \\
\text { Total BFAs }\end{array}$ & $\begin{array}{l}0.0 \\
1.1 \\
0.7 \\
1.6 \\
3.4\end{array}$ & $\begin{array}{l}0.1 \pm 0.1 \\
0.2 \pm 0.0 \\
0.2 \pm 0.1 \\
0.9 \pm 0.2 \\
1.4 \pm 0.2\end{array}$ & $\begin{array}{l}0.0 \pm 0.0 \\
0.4 \pm 0.4 \\
0.3 \pm 0.1 \\
1.6 \pm 0.1 \\
2.3 \pm 0.3\end{array}$ & $\begin{array}{l}0.5 \pm 0.4 \\
1.8 \pm 0.5 \\
1.1 \pm 0.2 \\
1.9 \pm 0.3 \\
5.2 \pm 1.4\end{array}$ & $\begin{array}{l}0.3 \pm 0.3 \\
3.2 \pm 2.0 \\
1.1 \pm 0.3 \\
1.6 \pm 0.1 \\
6.2 \pm 2.4\end{array}$ & $\begin{array}{l}0.2 \pm 0.1 \\
0.3 \pm 0.1 \\
0.2 \pm 0.2 \\
1.3 \pm 0.4 \\
2.1 \pm 0.5\end{array}$ & $\begin{array}{l}0.0 \pm 0.0 \\
0.1 \pm 0.1 \\
0.0 \pm 0.0 \\
0.9 \pm 0.1 \\
1.0 \pm 0.2\end{array}$ & $\begin{array}{l}2.0 \pm 0.4 \\
1.1 \pm 0.2 \\
0.7 \pm 0.5 \\
2.0 \pm 0.2 \\
5.7 \pm 1.3\end{array}$ & $\begin{array}{l}0.0 \pm 0.0 \\
2.3 \pm 2.0 \\
1.2 \pm 0.2 \\
1.4 \pm 0.1 \\
4.9 \pm 2.2\end{array}$ & $\begin{array}{l}0.3 \pm 0.2 \\
0.3 \pm 0.1 \\
0.3 \pm 0.0 \\
1.1 \pm 0.1 \\
2.0 \pm 0.4\end{array}$ & $\begin{array}{l}0.0 \pm 0.0 \\
0.1 \pm 0.1 \\
0.3 \pm 0.0 \\
0.7 \pm 0.1 \\
1.1 \pm 0.0\end{array}$ & $\begin{array}{l}0.0 \pm 0.0 \\
1.3 \pm 0.4 \\
0.4 \pm 0.4 \\
1.6 \pm 0.2 \\
3.3 \pm 0.2\end{array}$ \\
\hline $\begin{array}{l}12: 0 \\
13: 0 \\
14: 0 \\
15: 0\end{array}$ & $\begin{array}{l}0.5 \\
0.0 \\
5.4 \\
1.8\end{array}$ & $\begin{array}{l}0.1 \pm 0.1 \\
0.0 \pm 0.0 \\
8.8 \pm 1.2 \\
0.7 \pm 0.1\end{array}$ & $\begin{array}{l}0.0 \pm 0.0 \\
0.0 \pm 0.0 \\
1.5 \pm 0.1 \\
0.5 \pm 0.1\end{array}$ & $\begin{array}{l}0.0 \pm 0.0 \\
0.2 \pm 0.2 \\
5.1 \pm 1.4 \\
3.0 \pm 0.8\end{array}$ & $\begin{array}{l}0.2 \pm 0.3 \\
0.2 \pm 0.2 \\
5.7 \pm 0.7 \\
1.0 \pm 1.7\end{array}$ & $\begin{array}{l}0.0 \pm 0.0 \\
0.0 \pm 0.1 \\
2.4 \pm 0.2 \\
0.7 \pm 0.2\end{array}$ & $\begin{array}{l}0.0 \pm 0.0 \\
0.4 \pm 0.3 \\
0.3 \pm 0.3 \\
0.3 \pm 0.3\end{array}$ & $\begin{array}{l}1.1 \pm 0.1 \\
0.0 \pm 0.0 \\
6.2 \pm 0.0 \\
3.1 \pm 0.4\end{array}$ & $\begin{array}{l}0.3 \pm 0.5 \\
0.4 \pm 0.4 \\
5.3 \pm 0.5 \\
2.3 \pm 0.2\end{array}$ & $\begin{array}{l}0.0 \pm 0.0 \\
0.0 \pm 0.0 \\
1.4 \pm 0.1 \\
0.6 \pm 0.1\end{array}$ & $\begin{array}{l}0.1 \pm 0.0 \\
0.0 \pm 0.0 \\
4.1 \pm 0.3 \\
0.8 \pm 0.0\end{array}$ & $\begin{array}{l}2.6 \pm 4.0 \\
0.5 \pm 0.8 \\
4.3 \pm 1.5 \\
2.1 \pm 0.6\end{array}$ \\
\hline $16: 0$ & 29.3 & $32.3 \pm 4.5$ & $19.7 \pm 0.1$ & $39.7 \pm 2.2$ & $34.5 \pm 2.6$ & $34.1 \pm 1.5$ & $33.3 \pm 11.4$ & $31.5 \pm 1.5$ & $\begin{array}{c}25.6 \pm \\
2.8\end{array}$ & $\begin{array}{c}34.5 \pm \\
2.0\end{array}$ & $24.0 \pm 1.3$ & $30.6 \pm 0.9$ \\
\hline $17: 0$ & 0.7 & $0.4 \pm 0.3$ & $0.5 \pm 0.0$ & $0.3 \pm 0.6$ & $1.0 \pm 0.3$ & $0.8 \pm 0.4$ & $0.0 \pm 0.0$ & $1.0 \pm 0.6$ & $1.0 \pm 0.1$ & $0.5 \pm 0.2$ & $1.3 \pm 0.1$ & $0.6 \pm 0.6$ \\
\hline $18: 0$ & 10.5 & $22.7 \pm 1.4$ & $11.9 \pm 2.3$ & $15.1 \pm 2.2$ & $12.6 \pm 1.8$ & $46.1 \pm 4.5$ & $45.6 \pm 13.4$ & $19.9 \pm 2.0$ & $9.4 \pm 1.6$ & $\begin{array}{c}47.6 \pm \\
1.2\end{array}$ & $6.4 \pm 0.8$ & $12.2 \pm 1.3$ \\
\hline $\begin{array}{l}20: 0 \\
22: 0 \\
23: 0 \\
24: 0\end{array}$ & $\begin{array}{l}0.9 \\
1.4 \\
0.8 \\
0.8\end{array}$ & $\begin{array}{l}0.5 \pm 0.1 \\
0.2 \pm 0.1 \\
0.1 \pm 0.1 \\
0.1 \pm 0.1\end{array}$ & $\begin{array}{l}0.6 \pm 0.0 \\
0.1 \pm 0.0 \\
0.3 \pm 0.3 \\
0.6 \pm 0.1\end{array}$ & $\begin{array}{l}1.5 \pm 0.2 \\
3.0 \pm 1.0 \\
1.0 \pm 0.2 \\
1.4 \pm 0.2\end{array}$ & $\begin{array}{l}1.3 \pm 0.1 \\
2.5 \pm 0.5 \\
0.8 \pm 0.1 \\
1.3 \pm 0.2\end{array}$ & $\begin{array}{l}0.8 \pm 0.0 \\
0.2 \pm 0.0 \\
0.0 \pm 0.0 \\
0.0 \pm 0.0\end{array}$ & $\begin{array}{l}1.2 \pm 0.2 \\
0.6 \pm 1.0 \\
0.6 \pm 1.1 \\
0.2 \pm 0.3\end{array}$ & $\begin{array}{l}1.0 \pm 0.0 \\
0.7 \pm 0.0 \\
0.7 \pm 0.4 \\
0.8 \pm 0.1\end{array}$ & $\begin{array}{l}1.0 \pm 0.2 \\
1.8 \pm 0.4 \\
1.0 \pm 0.8 \\
1.0 \pm 0.1\end{array}$ & $\begin{array}{l}1.1 \pm 0.1 \\
0.9 \pm 0.1 \\
0.1 \pm 0.1 \\
0.2 \pm 0.0\end{array}$ & $\begin{array}{l}0.3 \pm 0.0 \\
0.2 \pm 0.0 \\
0.1 \pm 0.0 \\
0.2 \pm 0.0\end{array}$ & $\begin{array}{l}1.2 \pm 0.3 \\
2.3 \pm 0.7 \\
1.5 \pm 1.0 \\
1.0 \pm 0.1\end{array}$ \\
\hline Total SFAs & 52.1 & $65.8 \pm 4.2$ & $35.7 \pm 2.2$ & $70.5 \pm 3.7$ & $61.2 \pm 3.8$ & $85.1 \pm 4.8$ & $82.5 \pm 3.0$ & $65.9 \pm 0.1$ & $\begin{array}{l}49.1 \pm \\
5.3\end{array}$ & $\begin{array}{c}86.8 \pm \\
2.4\end{array}$ & $37.5 \pm 1.8$ & $58.7 \pm 7.6$ \\
\hline $14: 1 n-9$ & 0.0 & $0.3 \pm 0.1$ & $0.1 \pm 0.1$ & $1.3 \pm 0.2$ & $1.9 \pm 0.4$ & $0.2 \pm 0.2$ & $0.0 \pm 0.0$ & $0.0 \pm 0.0$ & $3.8 \pm 2.1$ & $0.2 \pm 0.1$ & $0.3 \pm 0.1$ & $0.0 \pm 0.0$ \\
\hline $16: 1 n-7$ & 0.4 & $11.0 \pm 2.0$ & $2.5 \pm 0.1$ & $4.5 \pm 1.0$ & $7.7 \pm 0.5$ & $1.8 \pm 0.5$ & $0.5 \pm 0.5$ & $5.6 \pm 1.3$ & $\begin{array}{c}12.7 \pm \\
0.7\end{array}$ & $1.2 \pm 0.4$ & $8.1 \pm 0.3$ & $4.9 \pm 2.3$ \\
\hline $\begin{array}{c}16: 1 n-9 \\
18: 1 n-7 \\
18: 1 n-9 \\
18: 1 n-11 \\
20: 1 n-7 \\
20: 1 n-9 \\
20: 1 n-11\end{array}$ & $\begin{array}{l}5.9 \\
4.6 \\
5.9 \\
0.0 \\
0.6 \\
0.7 \\
0.0\end{array}$ & $\begin{array}{l}0.9 \pm 0.8 \\
1.4 \pm 0.2 \\
6.1 \pm 1.1 \\
0.5 \pm 0.2 \\
0.2 \pm 0.2 \\
0.2 \pm 0.2 \\
1.4 \pm 0.3\end{array}$ & $\begin{array}{l}0.6 \pm 0.1 \\
2.4 \pm 0.1 \\
7.4 \pm 0.1 \\
0.3 \pm 0.1 \\
0.6 \pm 0.1 \\
2.7 \pm 0.4 \\
6.4 \pm 0.1\end{array}$ & $\begin{array}{l}2.0 \pm 0.2 \\
3.0 \pm 1.1 \\
4.5 \pm 0.5 \\
0.3 \pm 0.3 \\
0.1 \pm 0.1 \\
0.1 \pm 0.2 \\
0.0 \pm 0.0\end{array}$ & $\begin{array}{l}1.0 \pm 0.1 \\
5.3 \pm 0.4 \\
5.7 \pm 1.5 \\
0.4 \pm 0.4 \\
0.3 \pm 0.3 \\
0.4 \pm 0.2 \\
0.6 \pm 0.5\end{array}$ & $\begin{array}{l}1.3 \pm 0.4 \\
1.0 \pm 0.4 \\
4.0 \pm 1.5 \\
0.9 \pm 0.2 \\
0.0 \pm 0.0 \\
0.1 \pm 0.1 \\
0.3 \pm 0.1\end{array}$ & $\begin{array}{l}0.9 \pm 0.2 \\
1.0 \pm 0.1 \\
6.9 \pm 2.3 \\
0.3 \pm 0.2 \\
0.0 \pm 0.0 \\
0.5 \pm 0.4 \\
0.4 \pm 0.7\end{array}$ & $\begin{array}{c}2.2 \pm 0.2 \\
1.1 \pm 0.2 \\
12.2 \pm 0.5 \\
1.1 \pm 1.2 \\
0.7 \pm 1.0 \\
0.4 \pm 0.2 \\
0.0 \pm 0.0\end{array}$ & $\begin{array}{l}1.0 \pm 0.1 \\
8.4 \pm 0.9 \\
7.0 \pm 3.6 \\
0.3 \pm 0.3 \\
0.0 \pm 0.0 \\
0.2 \pm 0.2 \\
0.7 \pm 0.1\end{array}$ & $\begin{array}{l}1.0 \pm 1.1 \\
1.1 \pm 0.3 \\
2.6 \pm 0.8 \\
0.7 \pm 0.0 \\
0.0 \pm 0.1 \\
0.2 \pm 0.1 \\
0.1 \pm 0.2\end{array}$ & $\begin{array}{c}0.3 \pm 0.1 \\
4.6 \pm 0.4 \\
13.9 \pm 0.9 \\
0.3 \pm 0.0 \\
0.3 \pm 0.0 \\
1.3 \pm 0.3 \\
0.5 \pm 0.1\end{array}$ & $\begin{array}{c}0.9 \pm 1.2 \\
2.9 \pm 1.6 \\
10.3 \pm 4.1 \\
0.0 \pm 0.0 \\
0.2 \pm 0.3 \\
0.2 \pm 0.4 \\
0.0 \pm 0.0\end{array}$ \\
\hline
\end{tabular}




\begin{tabular}{|c|c|c|c|c|c|c|c|c|c|c|c|c|}
\hline $\begin{array}{c}22: 1 n-9 \\
22: 1 n-11\end{array}$ & $\begin{array}{l}0.1 \\
0.0\end{array}$ & $\begin{array}{l}0.1 \pm 0.0 \\
0.1 \pm 0.1\end{array}$ & $\begin{array}{l}0.3 \pm 0.1 \\
0.3 \pm 0.0\end{array}$ & $\begin{array}{l}0.0 \pm 0.0 \\
0.0 \pm 0.0\end{array}$ & $\begin{array}{l}0.0 \pm 0.0 \\
0.1 \pm 0.1\end{array}$ & $\begin{array}{l}0.1 \pm 0.1 \\
0.0 \pm 0.0\end{array}$ & $\begin{array}{l}0.5 \pm 0.9 \\
0.2 \pm 0.4\end{array}$ & $\begin{array}{l}0.0 \pm 0.0 \\
0.2 \pm 0.2\end{array}$ & $\begin{array}{l}0.1 \pm 0.1 \\
0.0 \pm 0.0\end{array}$ & $\begin{array}{l}0.0 \pm 0.1 \\
0.0 \pm 0.0\end{array}$ & $\begin{array}{l}0.4 \pm 0.1 \\
1.2 \pm 0.3\end{array}$ & $\begin{array}{l}0.0 \pm 0.0 \\
0.0 \pm 0.0\end{array}$ \\
\hline Total MUFAs & 18.2 & $22.3 \pm 2.4$ & $23.7 \pm 0.5$ & $15.7 \pm 1.7$ & $23.5 \pm 1.5$ & $9.7 \pm 3.5$ & $11.0 \pm 1.1$ & $23.5 \pm 0.0$ & $\begin{array}{c}34.3 \pm \\
7.0\end{array}$ & $7.2 \pm 1.8$ & $31.0 \pm 1.2$ & $19.4 \pm 1.4$ \\
\hline $18: 2 n-6$ & 1.7 & $3.0 \pm 1.4$ & $2.4 \pm 0.1$ & $1.0 \pm 0.6$ & $0.7 \pm 0.3$ & $0.8 \pm 0.3$ & $3.2 \pm 1.2$ & $1.2 \pm 0.1$ & $1.7 \pm 0.9$ & $0.6 \pm 0.1$ & $1.4 \pm 0.1$ & $3.4 \pm 1.5$ \\
\hline $18: 3 n-3$ & 1.3 & $1.2 \pm 0.2$ & $2.8 \pm 0.6$ & $0.3 \pm 0.3$ & $0.1 \pm 0.1$ & $0.2 \pm 0.0$ & $0.3 \pm 0.5$ & $0.7 \pm 1.0$ & $0.3 \pm 0.3$ & $0.0 \pm 0.0$ & $0.7 \pm 0.0$ & $2.1 \pm 1.1$ \\
\hline $18: 4 n-3$ & 2.8 & $0.0 \pm 0.0$ & $0.0 \pm 0.0$ & $0.2 \pm 0.4$ & $0.2 \pm 0.3$ & $0.0 \pm 0.0$ & $0.0 \pm 0.0$ & $0.0 \pm 0.0$ & $0.0 \pm 0.0$ & $0.0 \pm 0.0$ & $0.7 \pm 0.1$ & $0.9 \pm 1.6$ \\
\hline $20: 2 n-6$ & 0.6 & $0.1 \pm 0.0$ & $1.0 \pm 0.0$ & $0.5 \pm 0.5$ & $0.4 \pm 0.4$ & $0.0 \pm 0.0$ & $0.0 \pm 0.0$ & $0.2 \pm 0.2$ & $0.2 \pm 0.2$ & $0.2 \pm 0.0$ & $0.5 \pm 0.0$ & $0.2 \pm 0.4$ \\
\hline $20: 3 n-3$ & 0.1 & $0.1 \pm 0.0$ & $0.4 \pm 0.1$ & $0.0 \pm 0.0$ & $0.0 \pm 0.0$ & $0.0 \pm 0.0$ & $0.0 \pm 0.0$ & $0.4 \pm 0.6$ & $0.0 \pm 0.0$ & $0.0 \pm 0.0$ & $0.2 \pm 0.0$ & $0.9 \pm 1.0$ \\
\hline $20: 4 n-3$ & 0.6 & $0.3 \pm 0.0$ & $1.5 \pm 0.2$ & $0.0 \pm 0.0$ & $0.0 \pm 0.0$ & $0.0 \pm 0.0$ & $0.0 \pm 0.0$ & $0.0 \pm 0.0$ & $0.1 \pm 0.1$ & $0.0 \pm 0.0$ & $0.5 \pm 0.0$ & $0.2 \pm 0.4$ \\
\hline $20: 4 n-6$ & 1.1 & $0.2 \pm 0.1$ & $0.6 \pm 0.1$ & $0.8 \pm 0.1$ & $1.1 \pm 0.2$ & $0.1 \pm 0.1$ & $0.0 \pm 0.0$ & $0.1 \pm 0.1$ & $1.1 \pm 0.1$ & $0.4 \pm 0.1$ & $1.7 \pm 0.1$ & $0.6 \pm 0.5$ \\
\hline $20: 5 n-3$ & 8.6 & $2.4 \pm 0.7$ & $8.4 \pm 1.4$ & $1.3 \pm 0.9$ & $1.8 \pm 0.7$ & $0.8 \pm 0.5$ & $0.6 \pm 1.1$ & $0.6 \pm 0.2$ & $4.0 \pm 0.3$ & $0.7 \pm 0.4$ & $10.2 \pm 1.1$ & $3.6 \pm 4.4$ \\
\hline $22: 5 n-3$ & 0.4 & $0.2 \pm 0.1$ & $0.8 \pm 0.0$ & $0.4 \pm 0.2$ & $0.2 \pm 0.1$ & $0.1 \pm 0.2$ & $0.0 \pm 0.0$ & $0.7 \pm 0.3$ & $0.5 \pm 0.4$ & $0.3 \pm 0.3$ & $2.9 \pm 0.4$ & $0.7 \pm 0.2$ \\
\hline $22: 6 n-3$ & 3.2 & $2.1 \pm 0.6$ & $19.3 \pm 2.4$ & $0.5 \pm 0.3$ & $1.2 \pm 0.7$ & $0.4 \pm 0.2$ & $1.4 \pm 1.8$ & $0.4 \pm 0.1$ & $1.3 \pm 0.1$ & $1.0 \pm 0.8$ & $10.6 \pm 1.2$ & $1.8 \pm 1.3$ \\
\hline Total PUFAs & 20.5 & $9.7 \pm 1.7$ & $37.4 \pm 3.0$ & $5.2 \pm 1.3$ & $5.6 \pm 1.8$ & $2.4 \pm 1.2$ & $5.5 \pm 2.8$ & $4.3 \pm 1.6$ & $9.2 \pm 1.4$ & $3.1 \pm 1.3$ & $29.4 \pm 2.9$ & $14.5 \pm 6.3$ \\
\hline UI & 109.4 & $60.4 \pm 9.7$ & $210.9 \pm 18.5$ & $35.7 \pm 7.6$ & $48.2 \pm 8.8$ & $19.3 \pm 8.6$ & $30.1 \pm 16.8$ & $39.0 \pm 5.9$ & $\begin{array}{c}73.9 \pm \\
8.8\end{array}$ & $\begin{array}{c}21.1 \pm \\
7.8\end{array}$ & $178.5 \pm 14.1$ & $75.2 \pm 33.4$ \\
\hline
\end{tabular}


Table 1.d. Relative percentage (\%) of fatty acids (FAs) at concentration $\geq 1 \%$ relative to total FAs in at least one sample over the whole dataset, and used for the calculation of total branched FAs (BFAs), saturated FAs (SFAs), monounsaturated FAs (MUFAs), polyunsaturated FAs (PUFAs) and unstauration index (UI) (Fig. 5) for consumers sampled in transect B. FA compositions reported and analysed in the present study only correspond to the neutral lipid fraction (see text). In bold = FAs used in the PCA (Fig. 4) and/or as trophic markers (Table 2 and Figs. 6 and 7 ). Values are mean \pm standard deviation. $n=$ number of samples.

\begin{tabular}{|c|c|c|c|c|c|c|c|c|}
\hline \multirow[b]{3}{*}{ Fatty acid(s) } & \multicolumn{8}{|c|}{ Transect B } \\
\hline & \multicolumn{4}{|c|}{ Pecten maximus } & \multicolumn{4}{|c|}{ Callionymus lyra } \\
\hline & $\begin{array}{c}\text { B1 } \\
(n=2)\end{array}$ & $\begin{array}{c}\text { B2 } \\
(n=3)\end{array}$ & $\begin{array}{c}\text { B3 } \\
(n=3)\end{array}$ & $\begin{array}{c}\text { B4 } \\
(n=3)\end{array}$ & $\begin{array}{c}\text { B1 } \\
(n=4)\end{array}$ & $\begin{array}{c}\text { B2 } \\
(n=3)\end{array}$ & $\begin{array}{c}\text { B3 } \\
(n=3)\end{array}$ & $\begin{array}{c}\text { B4 } \\
(n=3)\end{array}$ \\
\hline $15: 0$ iso & $0.0 \pm 0.0$ & $0.0 \pm 0.0$ & $0.0 \pm 0.0$ & $0.0 \pm 0.0$ & $0.1 \pm 0.3$ & $0.0 \pm 0.0$ & $0.0 \pm 0.0$ & $0.0 \pm 0.0$ \\
\hline 15:0 anteiso & $0.2 \pm 0.0$ & $0.3 \pm 0.0$ & $0.3 \pm 0.1$ & $0.2 \pm 0.0$ & $0.4 \pm 0.4$ & $0.1 \pm 0.2$ & $0.0 \pm 0.0$ & $0.0 \pm 0.0$ \\
\hline $16: 0$ iso & $0.3 \pm 0.0$ & $0.5 \pm 0.1$ & $0.3 \pm 0.1$ & $0.4 \pm 0.1$ & $0.8 \pm 0.2$ & $0.9 \pm 0.2$ & $0.3 \pm 0.0$ & $0.3 \pm 0.3$ \\
\hline $17: 0$ iso & $1.0 \pm 0.1$ & $1.5 \pm 0.1$ & $0.9 \pm 0.3$ & $1.7 \pm 0.2$ & $0.9 \pm 0.3$ & $1.0 \pm 0.1$ & $0.6 \pm 0.1$ & $1.2 \pm 0.6$ \\
\hline Total BFAs & $1.5 \pm 0.1$ & $2.3 \pm 0.0$ & $1.5 \pm 0.5$ & $2.3 \pm 0.2$ & $2.2 \pm 0.4$ & $2.0 \pm 0.4$ & $0.9 \pm 0.1$ & $1.6 \pm 0.4$ \\
\hline 12:0 & $0.1 \pm 0.0$ & $0.0 \pm 0.0$ & $0.0 \pm 0.0$ & $0.0 \pm 0.0$ & $0.2 \pm 0.2$ & $0.1 \pm 0.0$ & $0.1 \pm 0.0$ & $0.4 \pm 0.4$ \\
\hline 13:0 & $0.0 \pm 0.0$ & $0.0 \pm 0.0$ & $0.1 \pm 0.1$ & $0.0 \pm 0.0$ & $0.1 \pm 0.2$ & $0.0 \pm 0.0$ & $0.0 \pm 0.0$ & $0.0 \pm 0.1$ \\
\hline $14: 0$ & $9.4 \pm 0.7$ & $9.3 \pm 0.9$ & $1.3 \pm 0.9$ & $5.0 \pm 0.7$ & $7.8 \pm 2.6$ & $5.9 \pm 0.9$ & $3.3 \pm 0.4$ & $4.0 \pm 3.4$ \\
\hline 15:0 & $0.5 \pm 0.1$ & $0.8 \pm 0.1$ & $0.7 \pm 0.4$ & $1.1 \pm 0.1$ & $4.3 \pm 1.1$ & $1.1 \pm 0.1$ & $0.5 \pm 0.0$ & $1.7 \pm 1.6$ \\
\hline $16: 0$ & $19.0 \pm 1.0$ & $19.2 \pm 1.9$ & $16.8 \pm 7.3$ & $18.2 \pm 1.4$ & $15.7 \pm 4.3$ & $17.2 \pm 1.2$ & $16.5 \pm 1.2$ & $16.9 \pm 2.7$ \\
\hline $17: 0$ & $0.2 \pm 0.2$ & $0.7 \pm 0.1$ & $0.5 \pm 0.4$ & $0.5 \pm 0.6$ & $1.0 \pm 0.4$ & $1.5 \pm 0.1$ & $1.5 \pm 0.1$ & $1.2 \pm 0.3$ \\
\hline 18:0 & $5.2 \pm 0.9$ & $6.4 \pm 0.9$ & $15.1 \pm 6.5$ & $5.8 \pm 0.9$ & $4.3 \pm 1.7$ & $3.5 \pm 0.3$ & $3.1 \pm 0.4$ & $4.3 \pm 1.9$ \\
\hline $20: 0$ & $0.5 \pm 0.2$ & $0.3 \pm 0.0$ & $0.3 \pm 0.1$ & $0.4 \pm 0.0$ & $0.1 \pm 0.1$ & $0.3 \pm 0.0$ & $0.4 \pm 0.0$ & $0.0 \pm 0.0$ \\
\hline 22:0 & $0.1 \pm 0.0$ & $0.0 \pm 0.0$ & $0.0 \pm 0.0$ & $0.1 \pm 0.0$ & $0.2 \pm 0.2$ & $0.1 \pm 0.0$ & $0.2 \pm 0.1$ & $0.0 \pm 0.0$ \\
\hline $23: 0$ & $0.0 \pm 0.0$ & $0.0 \pm 0.0$ & $0.0 \pm 0.0$ & $0.1 \pm 0.0$ & $0.0 \pm 0.0$ & $0.1 \pm 0.0$ & $0.2 \pm 0.0$ & $0.0 \pm 0.0$ \\
\hline $24: 0$ & $0.2 \pm 0.0$ & $0.4 \pm 0.1$ & $0.7 \pm 0.4$ & $0.5 \pm 0.1$ & $0.1 \pm 0.1$ & $0.6 \pm 0.0$ & $0.5 \pm 0.1$ & $0.1 \pm 0.1$ \\
\hline Total SFAs & $35.3 \pm 2.7$ & $37.1 \pm 3.8$ & $35.5 \pm 14.3$ & $31.5 \pm 2.3$ & $33.9 \pm 7.0$ & $30.6 \pm 2.5$ & $26.4 \pm 1.5$ & $28.7 \pm 1.3$ \\
\hline $14: 1 n-9$ & $0.2 \pm 0.0$ & $0.4 \pm 0.0$ & $0.1 \pm 0.2$ & $0.4 \pm 0.0$ & $0.9 \pm 0.6$ & $1.0 \pm 0.2$ & $0.3 \pm 0.1$ & $0.6 \pm 0.5$ \\
\hline $16: 1 n-7$ & $10.1 \pm 0.7$ & $9.0 \pm 0.1$ & $2.5 \pm 1.2$ & $4.2 \pm 0.8$ & $30.6 \pm 16.3$ & $0.7 \pm 0.2$ & $0.2 \pm 0.0$ & $16.9 \pm 3.0$ \\
\hline $16: 1 n-9$ & $0.3 \pm 0.0$ & $0.3 \pm 0.3$ & $0.2 \pm 0.2$ & $0.3 \pm 0.0$ & $11.2 \pm 5.0$ & $9.7 \pm 1.4$ & $6.6 \pm 0.6$ & $7.1 \pm 2.4$ \\
\hline $18: 1 n-7$ & $5.6 \pm 0.6$ & $5.1 \pm 0.5$ & $2.2 \pm 0.6$ & $2.9 \pm 0.4$ & $5.0 \pm 1.0$ & $6.6 \pm 0.5$ & $4.7 \pm 0.4$ & $4.6 \pm 2.2$ \\
\hline $18: 1 n-9$ & $4.5 \pm 0.1$ & $6.1 \pm 0.2$ & $3.4 \pm 0.9$ & $3.9 \pm 0.3$ & $4.9 \pm 2.1$ & $8.3 \pm 0.6$ & $16.7 \pm 0.4$ & $8.3 \pm 2.3$ \\
\hline $18: 1 n-11$ & $0.4 \pm 0.1$ & $0.4 \pm 0.1$ & $0.3 \pm 0.1$ & $0.3 \pm 0.0$ & $0.5 \pm 0.1$ & $0.7 \pm 0.2$ & $0.4 \pm 0.1$ & $0.2 \pm 0.2$ \\
\hline $20: 1 n-7$ & $1.3 \pm 0.3$ & $0.7 \pm 0.1$ & $0.4 \pm 0.1$ & $0.7 \pm 0.1$ & $0.9 \pm 0.4$ & $1.1 \pm 0.3$ & $0.4 \pm 0.1$ & $0.1 \pm 0.2$ \\
\hline $20: 1 n-9$ & $1.2 \pm 0.2$ & $1.5 \pm 0.2$ & $1.4 \pm 0.0$ & $1.7 \pm 0.1$ & $0.3 \pm 0.1$ & $0.8 \pm 0.1$ & $2.0 \pm 0.3$ & $0.4 \pm 0.4$ \\
\hline $20: 1 n-11$ & $5.7 \pm 0.2$ & $5.5 \pm 0.8$ & $3.7 \pm 0.4$ & $6.7 \pm 1.3$ & $1.5 \pm 1.2$ & $2.7 \pm 0.4$ & $1.3 \pm 0.3$ & $1.3 \pm 1.3$ \\
\hline $22: 1 n-9$ & $0.2 \pm 0.0$ & $0.1 \pm 0.1$ & $0.0 \pm 0.0$ & $0.1 \pm 0.0$ & $0.0 \pm 0.1$ & $0.2 \pm 0.1$ & $0.6 \pm 0.1$ & $0.0 \pm 0.1$ \\
\hline 22:1n-11 & $0.0 \pm 0.0$ & $0.0 \pm 0.0$ & $0.2 \pm 0.1$ & $0.3 \pm 0.1$ & $0.0 \pm 0.0$ & $0.1 \pm 0.1$ & $2.0 \pm 0.4$ & $0.1 \pm 0.1$ \\
\hline Total MUFAs & $29.4 \pm 1.7$ & $29.0 \pm 0.5$ & $14.4 \pm 3.4$ & $21.6 \pm 1.6$ & $55.9 \pm 7.8$ & $31.9 \pm 1.4$ & $35.2 \pm 0.4$ & $39.6 \pm 5.1$ \\
\hline
\end{tabular}




\begin{tabular}{|c|c|c|c|c|c|c|c|c|}
\hline $18: 2 n-6$ & $1.8 \pm 0.1$ & $1.3 \pm 0.1$ & $1.7 \pm 0.6$ & $1.5 \pm 0.1$ & $0.3 \pm 0.3$ & $1.1 \pm 0.0$ & $1.4 \pm 0.1$ & $1.4 \pm 0.3$ \\
\hline $18: 3 n-3$ & $1.8 \pm 0.0$ & $1.9 \pm 0.3$ & $1.9 \pm 0.7$ & $2.0 \pm 0.2$ & $0.1 \pm 0.2$ & $0.4 \pm 0.1$ & $0.4 \pm 0.0$ & $0.5 \pm 0.5$ \\
\hline $18: 4 n-3$ & $0.0 \pm 0.0$ & $0.0 \pm 0.0$ & $0.0 \pm 0.0$ & $0.0 \pm 0.0$ & $0.0 \pm 0.0$ & $0.0 \pm 0.0$ & $0.1 \pm 0.3$ & $0.0 \pm 0.0$ \\
\hline $20: 2 n-6$ & $0.0 \pm 0.0$ & $0.4 \pm 0.0$ & $0.5 \pm 0.4$ & $0.6 \pm 0.5$ & $0.0 \pm 0.0$ & $0.5 \pm 0.1$ & $0.7 \pm 0.1$ & $0.0 \pm 0.0$ \\
\hline $20: 3 n-3$ & $0.2 \pm 0.0$ & $0.2 \pm 0.0$ & $0.3 \pm 0.1$ & $0.4 \pm 0.0$ & $0.0 \pm 0.1$ & $0.2 \pm 0.0$ & $0.2 \pm 0.0$ & $0.1 \pm 0.1$ \\
\hline $20: 4 n-3$ & $1.1 \pm 0.0$ & $0.7 \pm 0.1$ & $0.9 \pm 0.1$ & $1.3 \pm 0.1$ & $0.1 \pm 0.2$ & $0.7 \pm 0.1$ & $0.4 \pm 0.0$ & $0.3 \pm 0.3$ \\
\hline $20: 4 n-6$ & $1.0 \pm 0.0$ & $1.0 \pm 0.1$ & $1.6 \pm 0.7$ & $1.0 \pm 0.0$ & $0.7 \pm 0.7$ & $2.4 \pm 0.4$ & $1.7 \pm 0.2$ & $2.4 \pm 0.6$ \\
\hline $20: 5 n-3$ & $19.6 \pm 2.9$ & $14.8 \pm 2.3$ & $14.7 \pm 3.7$ & $13.7 \pm 1.0$ & $3.7 \pm 4.9$ & $10.5 \pm 1.7$ & $6.3 \pm 0.1$ & $10.3 \pm 2.3$ \\
\hline $22: 5 n-3$ & $0.6 \pm 0.0$ & $0.5 \pm 0.1$ & $1.4 \pm 0.5$ & $0.9 \pm 0.2$ & $0.8 \pm 1.1$ & $4.7 \pm 0.8$ & $2.6 \pm 0.2$ & $2.3 \pm 0.5$ \\
\hline $22: 6 n-3$ & $6.7 \pm 1.5$ & $9.4 \pm 1.3$ & $25.0 \pm 12.0$ & $21.8 \pm 3.6$ & $1.5 \pm 1.5$ & $12.9 \pm 2.6$ & $22.6 \pm 2.2$ & $12.1 \pm 4.5$ \\
\hline Total PUFAs & $32.8 \pm 4.5$ & $30.0 \pm 4.2$ & $47.9 \pm 16.3$ & $43.2 \pm 3.4$ & $7.2 \pm 8.7$ & $33.5 \pm 4.2$ & $36.4 \pm 2.0$ & $29.4 \pm 6.3$ \\
\hline UI & $188.4 \pm 22.0$ & $177.8 \pm 20.7$ & $\begin{array}{c}265.5 \pm \\
92.2\end{array}$ & $246.2 \pm 18.1$ & $91.3 \pm 38.5$ & $203.1 \pm 22.5$ & $230.1 \pm 11.7$ & $190.4 \pm 30.8$ \\
\hline
\end{tabular}

